

\section{JOURNAL OF COLLEGE ACADEMIC SUPPORT PROGRAMS}

EDITORIAL BOARD

\section{EDITOR}

Michael C. McConnell

Doctoral Student

Graduate Program in DE

Texas State University

\section{ASSISTANT EDITOR}

Cassandra Gonzales

Doctoral Student

Graduate Program in DE

Texas State University

\section{EDITORIAL ADVISORS}

\section{Russ Hodges}

Associate Professor

Graduate Program in DE

Texas State University

Emily Miller Payne Associate Professor Graduate Program in DE Texas State University

\section{LAYOUT EDITOR}

Cortney Akers

Pre-Press Technician II

Texas State University

\section{EDITORIAL ASSISTANTS}

Ann Marie Cotman

Doctoral Student

Graduate Program

School Improvement

Texas State University

\section{Denise Guckert}

Doctoral Student

Graduate Program in DE

Texas State University

Christie Hill-Troglin Cox Doctoral Student

Graduate Program in DE

Texas State University

Meagan A. Hoff

Doctoral Student

Graduate Program in DE

Texas State University

Jonathan Lollar

Doctoral Student

Graduate Program in DE

Texas State University

\section{Barrie McGee}

Doctoral Student

Graduate Program in DE

Texas State University

Shiniece Owens

Doctoral Student

Graduate Program in DE

Texas State University

\section{EDITORIAL REVIEW BOARD}

Sonya L. Armstrong

Director of the Doctoral Program

in Developmental Education,

Texas State University

Marc Azard

Professor of English,

Collin College

Tammy J. Bishop

Department Chair

Academic Foundation,

Wayne Community College

Marsha Cardenas

Coordinator of Developmental

Math Program,

The University of Texas at El Paso

Ruth Dalrymple

Associate Vice Chancellor of

Academic Partnerships \&

Initiatives, Alamo College District

Cristella Rivera Diaz

Professor of Mathematics,

Northeast Lakeview College

Carol W. Dochen

Program Director,

Student Learning Assistance,

Texas State University

Tammy C. Francis

Assistant Professor of Reading,

Faculty Coordinator of

Developmental Education,

Del Mar College

\section{Cynthia Ferrell}

Vice President of the Texas Success

Center at the Texas Association

of Community Colleges

Rochelle Gregory

ESFL Division Chair,

North Central Texas College

Juanita J. Hall

Academic Counselor \& Student

Success Advocate,

University of Houston

Elizabeth Howell

Chair of Mathematics Division,

North Central Texas College

Forrest Lane

Associate Professor,

Sam Houston State University

Denise Lujan

Director of Developmental Math,

The University of Texas at El Paso

\section{Rebecca Jackson}

Professor of English, Director of the

MA in Rhetoric \& Composition,

Texas State University

Nara Martirosyan

Associate Professor, Department

of Educational Leadership,

Sam Houston State University

Rebekah McCloud

Executive Director, Student

Development and Enrollment

Services, University of Central Florida
Trey Miller

Principal Researcher,

American Institutes for Research

Eric J. Paulson

Professor, Curriculum \& Instruction

Associate Dean, The Graduate

College, Texas State University

Jennifer Phillips-Denny

Coordinator of Tutoring, The Write

Site at Texas Woman's University

Hillary Procknow

Director for the Core Curriculum and

Texas Success Initiative,

The University of Texas at Austin

Pamela Sawyer

Professor

Collin College

Monica Stansberry

Senior Program Specialist, Dallas

County Community College District

Tasha Vice

Assistant Professor of Literacy,

Texas A\&M University-San Antonio

Erika Warnick

Associate Professor of Reading,

South Plains College

Quentin Wright

College President,

Lone Star College-Houston North

C2020 Journal of College Academic Support Programs (J-CASP) is funded, supported, and endorsed through the Texas Association for Developmental Education (TADE), the Texas chapter of the College Reading and Learning Association (TxCRLA), and the Graduate Program in Developmental Education at Texas State University (education.txstate.edu/ci/deved). The J-CASP is managed, administered, and published through The Education Institute at Texas State University (tei. education.txstate.edu). Design by Russell Gibson Content (erinmarissarussell.wordpress.com/russell-gibson-content). Layout by Cortney Akers, Print \& Mail Services - Texas State University (auxiliaryservices.txstate.edu/printmail). Logo by On A Roll Designs (etsy.com/shop/ onarolldesigns).

Authors retain copyright and grant the journal right of first publication with the work simultaneously licensed under a Creative Commons Attribution License that allows others to share the work with an acknowledgement of the work's authorship and initial publication in this journal.

The J-CASP is an academic journal for developmental education, learning assistance, and student success. The editorial staff will give preference to authors, institutions, and/or topics relevant to the context of developmental education and learning assistance in Texas. Please review our submission guidelines at journals.tdl.org/ jcasp/index.php/jcasp/about/ submissions. Please address any questions, comments, concerns, and suggestions to JCASP_Editor@txstate.edu. 
$\mathrm{J}$
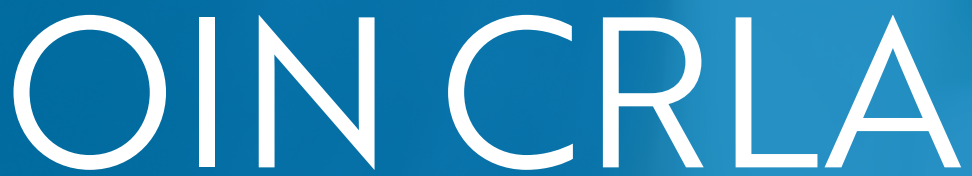

College Reading \& Learning Association (CRLA) strives

to be the professional development resource of choice

for college professionals dedicated to enhancing

student academic success. Its mission is to provide

college reading and learning professionals with an

open forum to discover and exchange the leading tools

and techniques to enhance student academic success.

Find out more about CRLA, its guiding principles, and

membership benefits at www.crla.net

\section{benefits}

CERTIFICATION PROGRAMS: Create,

improve, and expand tutor and peer

educator training for a campus' unique programs.

SPECIAL INTEREST GROUPS (SIG): Share

and promote professional interests.

STATES, REGIONS, \& CHAPTERS (SRCs):

Connect with colleagues in the same

geographic area

AWARDS AND SCHOLARSHIPS: Recognize those who contribute significantly to the

field and the organization.
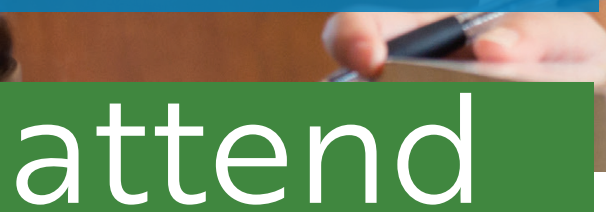

ANNUAL CONFERENCE: A schedule packed with pre-conference institutes, roundtables, concurrent sessions, as well as a variety of social and cultural events. Our 53rd Conference will be in Cincinnati, November 11-14, 2020. Save the Date!

SUMMER INSTITUTE: Train the trainers in mentor and tutor training programs. Attendance is limited to provide opportunity to work in small groups and benefit from in-depth, personalized interaction with the instructors.

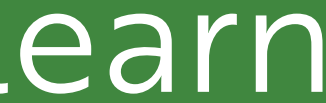

JOURNAL OF COLLEGE READING AND LEARNING (JCRL): An international, peer-reviewed forum for theory, research, and policy related to learning assistance and developmental education at the postsecondary level.

WHITE PAPERS: Authoritative, evidencebased reports written by experts.

Sharing the Best for Student Success!

JOIN TODAY! www.crla.net
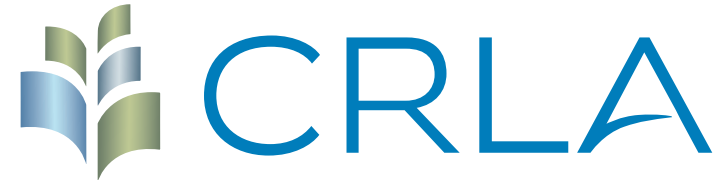

College Reading \& Learning Association
Proud Members of

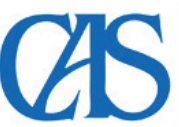

Council for the

Advancement of

Standards in Higher Education 
CONTENT

6 WELCOME

Foreword

By Michael C. McConnell, Editor

9 FEATURED ARTICLE

Everyone is Responsible for Everything: Corequisites and the First-Year Seminar

By Nadya Pittendrigh

Eric Camarillo

Sara Thurmond

21 FEATURED ARTICLE

A Collective Impact Model Towards Increasing STEM Major Student Retention

By Araceli Martinez Ortiz

Clara M. Novoa

Vedaraman Sriraman

32 FEATURED ARTICLE

Recipe for Successful Collaborative Corequisites

By Mary Orlando

Karen Hattaway

42 PROMISING PRACTICE

Student-to-Student Support in

Developmental Mathematics Courses

By Randy L. Collins

Rosemary M. Karr

49 PROMISING PRACTICE

Merging Personal and Academic Identities

By Tamara Harper Setron

Kristie O’Donnell Lussier
53 PROMISING PRACTICE

State University's Approach to the Corequisite Model

By Codi Jaynes

Mario Barrientos

Wayne Humphrey

59 EXPLORATORY PIECE

Discussing the Place of Corequisites in Juvenile Correctional Education and GED Success

By Jonathan Lollar

Cesar Bernal
COVER PHOTO

Sam Houston State University Clock

SECTION BREAK

8

Wonder World Cave

By Russ Hodges

SECTION BREAK

41

Texas State Capitol Building

By Russ Hodges

SECTION BREAK

58

Port Mansfield

By Cassandra Gonzales 


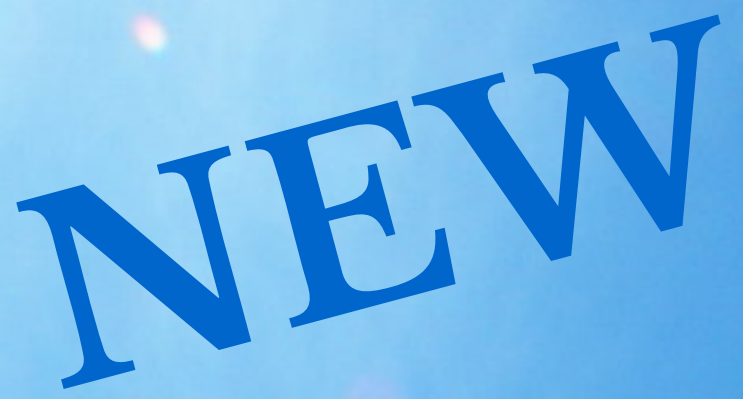

\section{$\mathrm{H} \& \mathrm{H}$ \\ Publishing}

Becoming A Strategic Learner

LASSI INSTRUCTIONAL MODULES

NEW EDITION!

NEW LOWER PRICE!

\section{NOW Includes}

Pre and Post LASSIs

Diagnose Instruct Evaluate

\$25 Direct Student Pricing

$$
\text { or }
$$

\$2,500 Annual Site License

for up to 300 students,

just $\mathbf{\$ 8 . 3 3}$ per student !

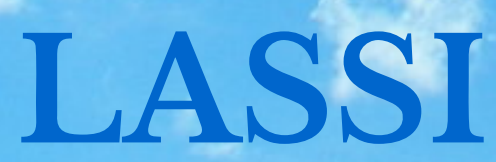

$30+$ years of improving

learning outcomes

There is also a High-School version of LASSI

WWw.hlopublishing.com
Designed to empower students by emphasizing research-based learning strategies they can use to increase their chances of college success.

First-Year Experience, Learning Frameworks, and College Success course instructors will find these modules use concise examples and

language that encourage students to adopt mindsets for strategic, life-long learning!

Please call us if you'd like a sample account $727-442-7760$ 


\section{FOREWORD}

As editor of the Journal of College Academic Support Programs (J-CASP), I welcome you to our fourth issue (volume 2 , issue 2 ), marking two years of successful and beneficial publishing trajectory in service of Texas developmental education and student success.

The majority of the articles in this issue pertain to corequisite models of developmental education (DE) as public institutions of higher education continue to accommodate the mandate specifics of HB 2223, requiring an increasing implementation of students placed into the DE sequence to take a paired-course combination. While the second issue of the J-CASP (volume 1, issue 2) was based on a call-for-submissions specific to corequisite models, a year later, the corequisite theme has emerged as a dominant and salient category in terms of manuscripts submitted to and articles published by the J-CASP, which has published such articles in all four issues.

Furthermore, two feature articles pertain specifically to corequisite models of DE implementation, as do two promising practices and this issue's only exploratory piece. More importantly, the exploratory piece highlights the role of corequisites in terms of juvenile detention and GED matriculation. Such emphasis on these special populations underscores the importance of this new genre for the J-CASP and hopefully, as is the goal for all of the exploratory pieces that we publish, will open the conversation on this topic and possibly lead to new or fledgling avenues of research.

On behalf of the editorial staff here at the J-CASP, I am so, so very proud that this forum has turned into not only a medium for legislative application, but also a sounding board for further research in avenues where research and publication might positively benefit scholarship aligned with student success and practitioner growth in the state of Texas and beyond.

We appreciate your readership, service, participation, and feedback pertinent to all that we do, which is for you and ostensibly, by you. Thank you all so much.

Michael C. McConnell, Editor

Journal of College Academic Support Programs 

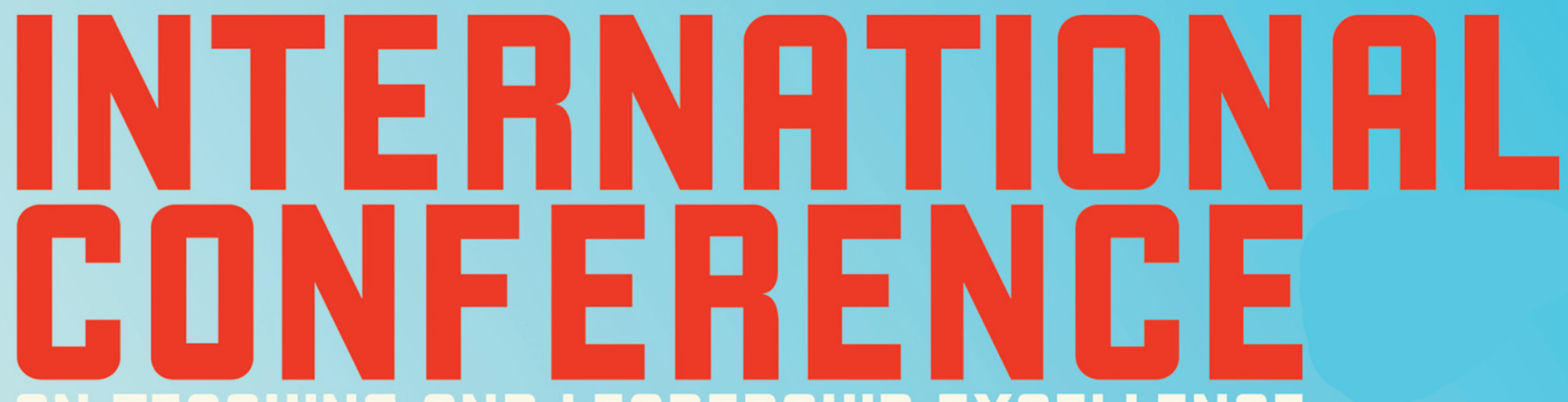

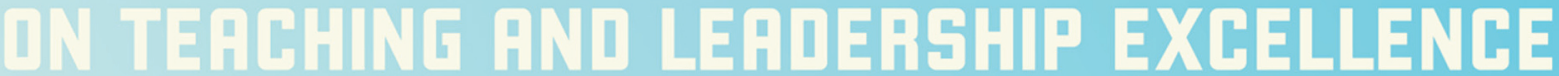
MAЧ ᄅ3-25, 2020 | AUSTIN, TEX月5

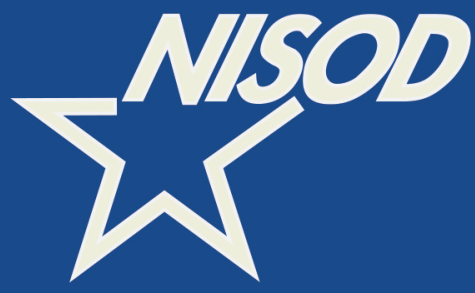

announces its

\section{Call for Presentations}

\section{for the}

2020 International Conference on Teaching and Leadership Excellence.

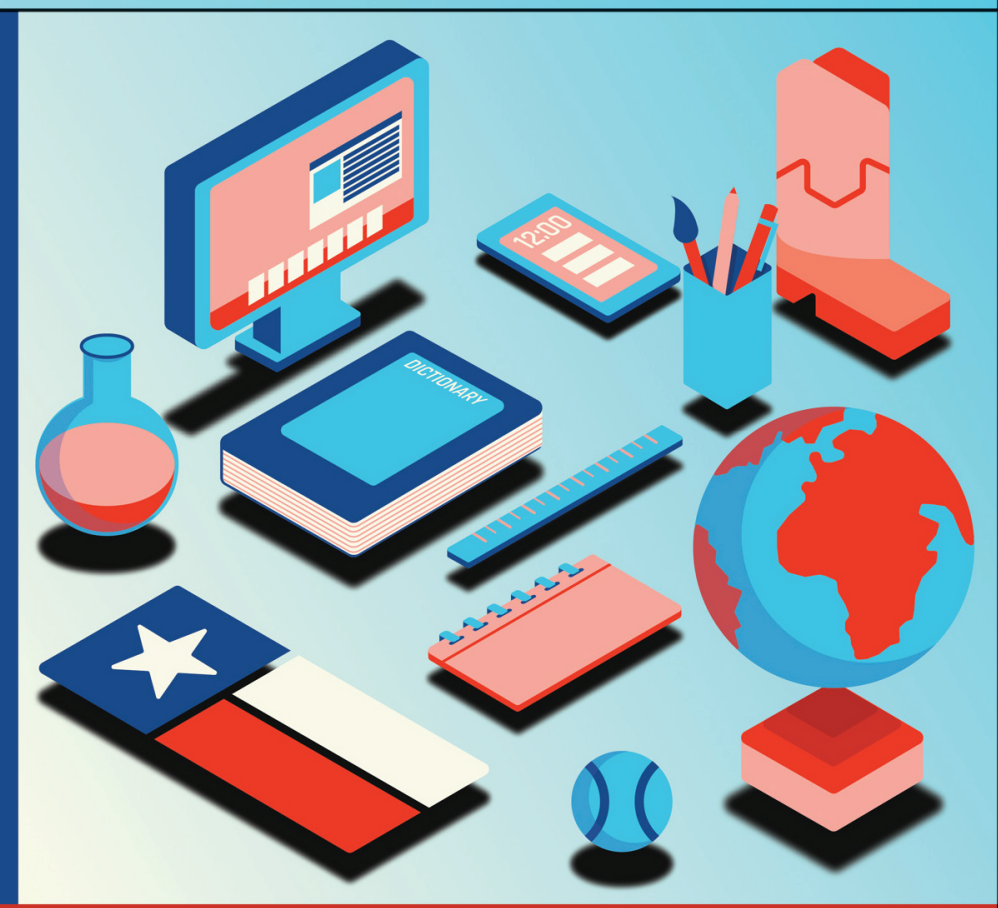

Do you have an innovative practice or cutting-edge research you want to share with your colleagues from across the world? Don't hesitate! Submit your presentation proposal today!

\section{www.nisod.org/cfp}

Submission Deadline: January 31, 2020

For more than 40 years, NISOD's annual conference has provided faculty, administrators, and staff with the resources, ideas, and solutions that drive excellence in all areas of community and technical college campuses. 


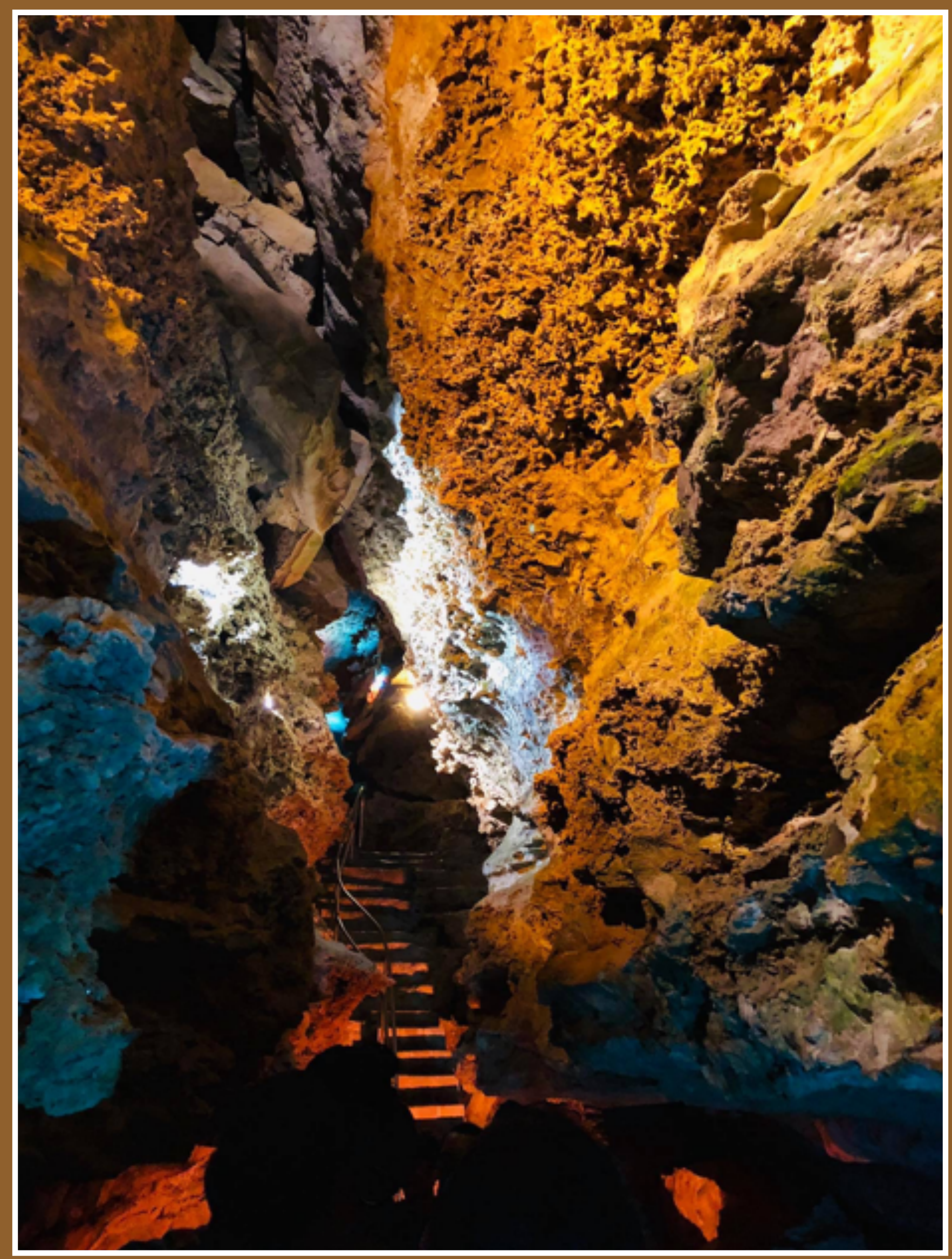




\title{
Everyone is Responsible for Everything: Corequisites and the First-Year Seminar
}

\author{
Nadya Pittendrigh, University of Houston-Victoria \\ Eric Camarillo, University of Houston-Victoria \\ Sara Thurmond, University of Houston-Victoria
}

\section{ABSTRACT}

Following state legislation mandating corequisite support in lieu of remedial prerequisites for underprepared students, this article tells the story of a specific corequisite program piloted in South Texas. Our model transformed certain sections of our institution's first-year seminar into corequisite courses, which were paired with required gateway classes. We argue, this model helped to extend existing networks of student support beyond classrooms and beyond advising.

in he University of Houston-Victoria (U of $\mathrm{H}-\mathrm{V}$ ) is a small, public Hispanic Serving Institution in southeast Texas. Originally established as a teaching center for upper division and graduate students in 1974, U of H-V achieved "downward expansion" in 2010, a term used to refer to the expansion of the university's offerings to include freshmen and sophomores at the university. This expansion also reconfigured the student body, making it more urban, young, and diverse. As an example, in the fall of 2018, $\mathrm{U}$ of $\mathrm{H}-\mathrm{V}$ enrolled 3,237 undergraduate students, $42 \%$ of whom identified as Hispanic, with $32 \%$ representing the first generation in their family to attend college. This student population increasingly reflects the demographics of the local area, where the population is over $50 \%$ minority, and approximately $50 \%$ Hispanic.

In addition to diversifying the student body, downward expansion also resulted in enrolling more students who need extra support in order to succeed in a college environment, particularly in first-year math and English courses. Our institution's most recent efforts to provide this support forms the basis of this article, namely the unique version of corequisite support that emerged at our institution, as an organic outgrowth of our specific history, combined with a statewide mandate to create corequisites. Certainly, as we explain, the passage of state legislation helped provide the impetus for our move toward corequisites. Yet we were also motivated to re-assess our developmental curriculum, even without the new legislation, based on our own frustrations with the previous iteration of developmental classes. We knew (and know) our students need help with getting through their gateway courses but also finding an effective form for that assistance has been a challenge. We will briefly describe our previous efforts at providing that support before explicating our rationale for the current program.

As we discuss in more detail in the course of this article, our response to the recent mandate to create a corequisite combined the purpose of the corequisite with our institution's first-year seminar; we created a few special sections of the first-year seminar designed especially for students designated as TSI-incomplete in one or more subject areas, each section of which supports a specific gateway course. Our idea was that the mission of the first-year seminar, to orient students to life at the university, could itself be advanced by making it more academic for these students, or more clearly contextualized with explicit links to academic work. In order to achieve this, we believed that corequisite remediation could be meaningfully accomplished in the first-year seminar.

To achieve this mashup of the first-year seminar and corequisite, we initiated an otherwise unlooked-for collaboration between academic faculty and student support services staff, and we found that this cross-pollination between divisions of our institution also offered another payoff: it had the potential to extend and strengthen institutional safety-nets meant to support students underprepared for college. We find that remediation for underprepared students happens not only in academic content classes, but as part of a larger pedagogical ecology, or as one researcher describes it, "a constellation of people, programs, initiatives, opportunities, constraints, and cultures that emerge and interact within a specific university context" (Schoen, 2019, p. 38). Based on preliminary findings 
from our 2018-2019 pilot, we believe that our mashup of the first-year seminar and corequisite effectively extends the university's existing ecologies of support and responsibility for underprepared students to more corners of the university, providing a promising framework for addressing the non-cognitive issues that impede the progress of so many students. We argue not only that the missions of the first-year seminar and corequisite curriculum symbiotically support one another, but that our structural choices in creating the corequisite helped to extend existing networks of student support beyond classrooms and beyond advising.

Institutional Context, or the Local Learning Ecology Shortly after $U$ of $\mathrm{H}-\mathrm{V}$ 's move to serve freshmen and sophomores through downward expansion, it became evident that our students were underprepared for their college coursework, especially in college algebra, and in reading and writing, as faculty raised serious concerns about their students' performance and their ability to succeed at the college level. In response to this need, the Division of Student Affairs created a series of Non-Credit Bearing Options, or NCBO classes. These classes were taught by staff members with backgrounds in the appropriate subjects (either a $\mathrm{BA} / \mathrm{BS}$ or $\mathrm{MA} / \mathrm{MS}$ in math or English), lasted for 8 weeks, and were optional for students to attend. Additionally, instructors for the NCBOs were told not to link their instructional efforts to the very credit-bearing English and math courses that they were supporting, nor even communicate with the main course instructors about course content (based on misunderstandings or poor communication between student affairs and faculty). In addition to the problem of poor communication, we eventually concluded that an eight-week, optional, non-credit bearing course was never going to accomplish its goal of improving student performance at our institution.

Given these shortcomings of the NCBO, we eventually moved to a truly remedial course sequence with "basic" math and English courses that served as prerequisites for College Algebra and English Composition. These courses were mandatory, lasted a whole semester, bore credit, and were taught by faculty in the School of Arts and Sciences (which houses the math and English departments). Additionally, while these courses were prerequisites for the primary gateway classes of College Algebra and English Composition, the basic courses could be linked through theme and content to $\mathrm{U}$ of $\mathrm{H}-\mathrm{V}$ 's first-year seminar courses, which aimed to prepare students for how to succeed in college. However, while these "remedial" courses seemed more academically rigorous than the NCBO, they suffered from two key problems: (a) the courses stigmatized students, and (b) the courses functioned as a potential obstacle to the main gateway class, providing another roadblock to student success, increasing the risk that students would drop or stop out before ever taking the main class (Adams, Gearhart, Miller, \& Roberts, 2009; Cho, Kopko, Jenkins, \& Smith Jaggars, 2012; Sullivan, 2013; see also Trammell, 2018). Our observations of students at $\mathrm{U}$ of $\mathrm{H}-\mathrm{V}$ support these claims. Instructors and staff who interact with first-year students report that students sometimes made fun of each other saying, "Oh you're in English for dummies," or "That's the dumb people's math." One student reflected that both the developmental courses and first-year seminar were "holding me back," a sentiment echoed by other students as well.

While faculty, staff, and students were already questioning this remedial course sequence, the passage of Texas HB 2223 provided the university with a mandate to replace these classes with something else. The bill requires institutions of higher education to implement "a corequisite model" for developmental coursework, "under which a student concurrently enrolls in a developmental education course and a freshman-level course in the same subject area" in any subject area where the student seems to need remediation (Sec. $51.336 \mathrm{C}$ ). In addition to providing a corequisite option to students, institutions of higher education within Texas were also required to ensure that a certain percentage of their students eligible for developmental education were enrolled in a corequisite course: $25 \%$ in fall $2018,50 \%$ by 2019, and $75 \%$ by 2020.

In the past, $\mathrm{U}$ of $\mathrm{H}-\mathrm{V}$ used scores from the ACT, SAT, as well as from the Texas Success Initiative test (TSI) to determine students' college readiness and ability to register for courses. Students admitted to $\mathrm{U}$ of $\mathrm{H}-\mathrm{V}$ who were TSI incomplete in reading, writing, or mathematics worked with their Student Success Coach (academic advisor and support service for students with less than 45 earned credit hours) or Academic Advisor to become TSI compliant. Historically, students enrolled in one or more support classes to help them become TSI compliant needed 
to become TSI complete in reading and/or writing, students concurrently enrolled in ENGL 1301 and NCBO 1001. They needed to pass ENGL 1301 with a "C" or better and earn an "S" in NCBO 1001 to satisfy the TSI requirements. To become TSI complete in mathematics, students concurrently enrolled in MATH 1314 and NCBO 1002. They needed to pass MATH 1314 with a " $C$ " or better and earn an " $S$ " in NCBO 1002 to satisfy the TSI requirements. After the NCBOs were determined ineffective and phased out, students enrolled in either ENGL 1300 or MATH 1300 to satisfy their TSI requirements. They needed to earn a " $C$ " or better in the courses to satisfy the TSI requirements and move on to the college- and entry-level English and math courses. Our 2018 pilot of the corequisite mashup with the first-year seminar emerged from this history, and we attempted to improve upon it.

\section{Literature Review}

Educators have been discussing how to fix remedial education since its inception. HB 2223 challenges educators to take a more dramatic approach-to get rid of them altogether because they are not working, they do not count for credit, they waste students' time and money, and they make it more likely that students will not complete their degrees. In support of this approach, Watkins (2017) reported some of the major issues faced by community colleges in regards to remedial students: $60 \%$ of students are not college ready; $85 \%$ of students that enroll in remedial math do not pass a single college-level math course; community colleges have open enrollment so anyone with a high school diploma or GED can enroll in classes. How then do we make it possible for students who are not college ready to attend college? HB 2223 offers a few suggestions but leaves the major details up to community colleges and universities.

Atkins and Beggs (2017) conducted a study at a mid-west, 4-year university that compared traditional remedial education in mathematics education to a corequisite program. Their primary purpose was to determine if the corequisite model was comparable to the traditional remedial education model. Secondly, they wanted to find out if the corequisite model could reduce risk factors associated with underprepared students. The study yielded promising results, with $78.75 \%$ to $90.13 \%$ earning a 70 or better in their gateway math course (Atkins \& Beggs, 2017, p. 22). Their research documents a corequisite model offering learner-centered, "just-intime" support for underprepared students enrolled in gateway courses with concurrent enrollment in those courses, which suggests that academic advisors and cross-departmental faculty communication was crucial to building this support network.
Our response to this research and to $\mathrm{HB}$ 2223 follows the example set by the Accelerated Learning Program (ALP, n.d.). Pioneered by Adams at the Community College of Baltimore County, ALP emphasizes small classes, destigmatizing remedial coursework, and the emphasis on community building. The discrete features of ALP include the following:

1. ALP students are mainstreamed into ENGL 101 for which they can receive college credit.

2. ALP students are part of a cohort of eight students and one instructor who spend six hours a week together.

3. ENGL 101 serves as a meaningful context for what they are learning in the developmental course.

4. Class size is just eight, changing the instructional environment.

5. The pipeline through which they must travel is shortened from two semesters to one.

6. In the ENGL 101 class, ALP students work with students who are stronger writers and can serve as role models.

7. ALP instructors consciously pay attention to helping ALP students develop successful student behaviors.

8. ALP instructors consciously pay attention to issues from outside the college that may have a negative impact on ALP students (http://alp-deved.org/ features-of-alp-success/).

Perhaps most importantly, especially as it pertains to HB 2223, Adams' work was predicated on the question of mainstreaming students in stimulating college-level work from the get-go. Inquiry itself or engaging with genuinely challenging questions represents the most potentially motivating force in any classroom, and underprepared students can not only do it (provided a little extra support) but they most stand in need of the potential motivation in seeing the application of "skills" in a context that matters (Adams et al., 2009; Cho, Kopko, Jenkins, \& Jaggars, 2012).

\section{Program Concept}

Our solution to the statewide push towards corequisites emerged organically from our institution's needs and history. In order to meet the demands of HB 2223, we decided, in conjunction with key administrators at $\mathrm{U}$ of $\mathrm{H}-\mathrm{V}$ to turn particular sections of the University Seminar (first-year seminar) into the corequisite courses. Though the seminar course at $\mathrm{U}$ of $\mathrm{H}-\mathrm{V}$ has itself evolved through many iterations, its consistent central purpose has been to help to acculturate students to a college environment and connect them to the $\mathrm{U}$ of $\mathrm{H}-\mathrm{V}$ community. Traditionally, the course has included strategies for time management, organization, studying, taking notes, and reading college-level texts. Because of 
the academically supportive nature of the course, it made sense to us to convert sections of the seminar course into a corequisite course.

Crucially, this conversion also necessitates a high amount of collaboration between university units - units that would have remained more separate had it not been for the corequisite collaboration. While the main/gateway courses, College Algebra and English Composition, are taught in Arts and Sciences, the seminar courses are taught through the new University College, which houses the student success coaches and the manager of academic support, all of whom teach either a standard university seminar course or a corequisite seminar course. The corequisite courses, as a result, were developed and taught by a team of faculty from Arts and Sciences and staff in the University College (though these staff also have faculty status). Because of the way we structured the corequisite, these groups wound up collaborating closely as we planned our pilot and as we sought to provide "just-in-time" support for the gateway classes. We believe that this structure enabled instructors to fulfill one of the principles of effective corequisite support, as articulated by Adams et al. (2009), namely that instructors "consciously pay attention to issues from outside the college that may have a negative impact" on students. We believe that our model helped instructors become cognizant of their own involvement in the larger university ecology as a result of teaching the corequisite course, in part because it retains some elements of its original seminar function. That is, the corequisite course is not just a support class for the main math or English class. It is also an introduction to the college environment and requires the instructor to work with departments across campus as a result. In this sense, we believe that this structure makes instructors more attuned to the overall ecology of learning while also facilitating more direct teaching of metacognition and success strategies contextualized with academic content.

Part of what we take from this collaboration between academic and student success oriented divisions of the university is that first-year seminars, corequisite support classes, and possibly all academic classes are best when they incorporate attention to both academic and non-cognitive challenges and dimensions of learning, as well as metacognitive strategies for addressing those challenges. Part of why support for at-risk or underprepared students often falls under the purview of University College is precisely because academic faculty understand what they have to offer students as primarily academic and not significantly enmeshed with students' personal and affective experiences. Given this reality, faculty themselves sometimes express feeling underprepared to effectively help underprepared students. In addition, we find that people with advanced academic degrees either never struggled as students have with academic work, or they have forgotten the experience of not already knowing. For these reasons, in the eyes of our students, there is a gigantic distance between where they are sitting and the instructor standing at the front of the class. In this context, we see the combination of Arts \& Sciences faculty and University College staff in our corequisite as one of the advantages of the model. Ideally, we believe, every class would directly address non-cognitive challenges and learning strategies for coping with those challenges, along with academic content. By putting staff who are focused on student success into collaborative conversation with faculty who tend to be more focused on academic content together, the program more effectively works with students to overcome daily obstacles, both academic and personal.

Based on extensive discussion among stakeholders, $\mathrm{U}$ of $\mathrm{H}-\mathrm{V}$ determined that requiring 6 hours of English and/or 6 hours of math, along with a first-year seminar during students' first semester, would be difficult at our institution; a fully realized three-credit corequisite class would take up too much real estate in students' schedules during their first semester. Those who made this argument pushed for a return to the

1-hour NCBO (already attempted at our institution which struck the rest of us as too little support for many of our students). Faced with a choice between a 1-hour support session with no academic credit, versus something more closely approximating the ALP model, we resolved to continue to push for something closer to ALP. We knew that the previous iteration of the non-credit bearing option at $U$ of $\mathrm{H}-\mathrm{V}$ was poorly attended; in part, because it bore no credit, students viewed it as optional. We also observed its ineffectiveness compared to the required developmental prerequisite classes that replaced it. We wanted to create something that would actually improve on that improvement.

Though $\mathrm{U}$ of $\mathrm{H}-\mathrm{V}$ was not able to offer all aspects of the ALP model, we were able to create a 
corequisite inspired by some of ALP's key tenets, each of which, we believe, offers potential for improvement on the previously existing developmental courses that our corequisite replaced. We created a fully realized, credit-bearing, content-rich, academic corequisite course. We also combined the function of corequisite support with that of our freshman seminar. Finally, students deemed underprepared would now receive just-in-time support in the new corequisite seminar for the college-level work assigned in their gateway core courses.

If the focus of the old University Seminar was to provide a road map for navigating life on campus, with an emphasis on study skills, or "life hacks," linking such a class with an academic gateway course effectively provided a meaningful context for those life hacks. Adams et al. (2009) argued a similar point when they explain the power of linking corequisite remediation to a gateway course; students can more readily and more actively engage with corequisite coursework when those can immediately and obviously be applied in a college-level course, as opposed to teaching such skills in a "basic skills" vacuum. If demonstrating the immediate connection between one set of skills and another arena of a student's life helps with motivation, according to the same principle, we believe that the "life hacks" for navigating college, which provide the focus of the freshman seminar, and the content of English or math gateway courses provide an immediate context for one another. In other words, the freshman seminar's "life hacks" for college life can be more effectively taught when contextualized with meaningful academic work.

Above all, the program elucidated for us the various non-cognitive challenges our students face and how these "life" factors affect their performance in the classroom. Our previous attempts at remedial coursework were founded on the assumption that our students struggled with content and that they needed more time to learn basic skills. That supposition may be true to an extent, but our pilot and our limited assessments so far support the growing consensus that non-cognitive factors play at least as decisive a role in student success as academic knowledge (Adams et al., 2009). As we move forward, changes to the corequisite curriculum will include an even greater emphasis on non-cognitive aspects of learning, or what some people in the university call success strategy acquisition.

\section{Pilot}

Our corequisite pilot designated a few sections of our first-year seminar courses as English satellite seminars and a few as math satellite seminars, replacing one hundred percent of our developmental math and English courses in the fall of 2018. We also still offer our standard first-year seminar to students who are not identified as needing corequisite support. Incoming freshmen whose scores indicated that they were not TSI-complete in reading or writing were strongly encouraged to enroll in an English satellite seminar and to enroll in the math satellite if their math scores were below the cut off. Those students would get credit for their first-year seminar requirement and, if they passed the gateway course, would become TSI-complete in that area. If a student was incomplete in both math and English, students were encouraged to take the English satellite seminar in the fall, based on the idea that reading and writing are more mission-critical to overall college success, and would take a math-focused corequisite seminar in the spring, which would differ entirely in its content, insofar as it would be focused on math.

In our fall 2018 pilot, 73 incoming freshmen were placed into English corequisite seminars in the fall, 60 were placed in math corequisite seminars, and 118 were placed in traditional, non-corequisite seminars. There were five English corequisite seminars and four math corequisite seminars in the fall. In some cases, the same instructor taught both the corequisite and the gateway course, and in some cases one instructor taught the gateway course and another taught the corequisite. Most of the corequisite sections were taught by tenuretrack faculty in the fall, while two were taught by credentialed staff housed in the Student Success Center; we suspect that this mixture of collaborating stakeholders laid the groundwork for building a stronger program.

\section{Math Engagement and Self-Efficacy}

If the premise of the original first-year seminar at $\mathrm{U}$ of $\mathrm{H}-\mathrm{V}$ was that academic learning has a concrete, real-world application, that concrete application was made vivid in the math corequisite seminar taught by one of the authors. Her corequisite seminar supports the gateway algebra class, providing justin-time support for that class, as well as "life hacks" for student success at the college level. She also prioritizes student motivation and has observed high levels of student engagement with one assignment in particular. The assignment unfolded in three steps. First, students attended two library visits to learn how to research and produce an annotated bibliography. Students also researched their major and their careers. Next, students created an office building model based on their research on careers/major. Students spent no more than $\$ 10$ on materials. The space could not be more than 2000 square feet, and it could not be either a rectangle or a square. The space had to include one gender-neutral bathroom, or two gender-specific bathrooms. The model had to include a reception area, and it had to be built to scale. Finally, a math report was required with a rationale for the design choices and an explanation 
of the math involved accompanied with a blueprint. This assignment demonstrates math's real-world application and incorporates some of the specific math skills that one of the authors is already reviewing early in the semester, including fractions and the concept of scale, multiplication and division, and calculating the area of triangles, circles, or composite shapes.

One of the authors also engages a variety of methods in the math corequisite for the specific purpose of building students' self-efficacy in math. Self-efficacy broadly refers to both metacognitive awareness, enabling a student to repeat a success or transfer their learning in another context, and self-confidence (Roick \& Ringeisen, 2016). Using write-to-learn strategies for building self-efficacy, the instructor asks students to reflect on and explain the math involved in their projects as well as their design choices. She hopes that through writing, students will consolidate their learning, take ownership of their own choices within the learning process, and become more aware of their own efficacy. She recalls one particularly successful project in which two highly engaged business students building code restrictions and required permit restrictions and their write up of the project included those as part of their calculations. Students working on these projects are also generally partnered with students in other sections of the math corequisite, which means that they cannot do the collaborative work that is required to complete the project in class, which forces them to engage strategically with time management, make connections across the university, and take professional/planning initiative with someone they did not already know.

In response to her observations of student needs, the most recent iteration of the course turned one of the author's previous emphasis on metacognition and self-efficacy (and not just mathematical content) into a tool for increasing student motivation. This version of the course included the same essential three-step assignment described above, but students researched playgrounds and playground safety, and she required students to write their reports for the benefit of local school officials. In future semesters, that instructor plans to use the same structure, but will focus the initial step on the question, "Why is math important?" As she puts it, "We've all sat in math class and wondered, 'When am I going to use this?'
In this assignment, the student will answer that question themselves." We believe this assignment represents the promise of combining the corequisite with the freshman-seminar: when various areas of learning are engaged, or when various spaces at the university or outside it are meaningfully connected, learning becomes three-dimensional, or feels more relevant and real. By the same logic, we also contend that student success strategies, which provide the focus of the standard first-year seminar at our school, are more effectively engaged by being contextualized with academic content.

As part of emphasizing metacognition, selfefficacy and student success strategies as integral to math instruction, one of the authors also weighs "process work" very heavily into her grading. In her math corequisite, if the students simply do all of the assignments and attend class, they will certainly pass. In explaining her curriculum choices, she emphasizes metacognitive reflection, or reflection on one's own thinking and learning. Upwards of $25 \%$ of the assigned points in the course involve reflection on thinking and study practices. Clearly, thinking about thinking in order to heighten metacognitive self-efficacy fits the mission of the traditional freshman seminar, whose focus is supposed to be study skills-the reflection assignments in the math corequisite invite students to examine and potentially adjust their own thinking processes, their choices in terms of time management, their learning process, and their emotions. Yet these written reflection assignments also incorporate mathematical content, making metacognition, or awareness of what one is doing in order to better learn from one's own trial-anderror, central to a student's success in a math class. Given the serious emotional, financial and personal challenges faced by so many of our students, we believe that incorporating written reflection on students' own learning processes also enables instructors to connect with the non-cognitive and affective dimensions of students' lives; reflective metacognition not only provides students with a therapeutic habit of directly addressing disruptive emotion, but also helps make the personal dimensions of students' lives visible to instructors. We believe these non-cognitive dimensions of students' lives represent the make-or-break issue for students who are underprepared, and therefore need to be addressed in the math corequisite class. 
The instructor's dual role at the university as both a success coach and as a corequisite instructor makes this point particularly vivid to us. As one of the designers and instructors of the corequisite, her role as success coach has influenced her approach to conceptualizing the corequisite. The success coaches at $\mathrm{U}$ of $\mathrm{H}-\mathrm{V}$ use an invasive advising approach, which means that they actively seek out students who are struggling, sometimes knocking on dorm room doors, and generally providing proactive, and relatively intimate intervention in students' choices and lives. The role of the success coach is primarily to get students registered and on track to get their degrees, from the moment they walk in the door, but the role also blurs the line between counseling and advising. To us, this point goes back to the concept outlined by Adams et al. (2009) in their description of ALP's key tenets, that instructors pay attention to issues from outside the parameters of academic content. This same concept was also echoed in a remarkable written suggestion made by one of our students. He wrote:

I been thinking [sic] and I wonder how students would perform if they had a mandatory class that teaches them mental health. I would like a required elective that helps all students with negativity. Negativity spreads doubt and it's contagious.

This student's comment goes further than the language used by Adams et al. (2009) or most educators when we talk about corequisites. Even though we have not gone so far as to frame our corequisite as a required course in mental health, the thrust of this student's concept speaks to an intangible element of what Adams has formalized in his articulation of corequisite support. We have combined the ethic of care inherent in the role of success coach with academic course work. This approach is widely supported by an emerging body of research which places students' non-cognitive challenges at the center of their chances for success in the academy (Dweck, Walton, \& Cohen, 2014).

\section{English Engagement and Self-Efficacy}

If the math corequisite seminar takes advantage of synergy between academic learning and the non-cognitive coping skills essential to learning those skills, the English corequisite also embraces potential synergy between reading and writing instruction and the mission of the first-year seminar. Like the traditional first-year seminar at $\mathrm{U}$ of $\mathrm{H}-\mathrm{V}$ the English corequisite seminar focuses on orienting students to university life, but with a reading and writing focus. The course teaches both college-readiness and reading and writing through a rhetorical lens, an approach described in composition and basic writing literature as "rhetorical adaptability" (Negretti, 2012). Similarly, in the pages of this journal, Threadgill and Paulson (2018) explored the teaching of "rhetorical situation" as a powerful tool for "disciplinary literacy," or for helping students to understand the need to adapt their mindsets or approaches to reading and writing in various contexts or disciplines. According to the authors, teaching a context-sensitive approach to reading and writing at the university not only advances students' abilities to navigate the university and its many conventions, but also helps to build the metacognitive, strategic, self-monitoring, self-aware habits required for student success at the college level. In other words, heightened awareness of a text's author, audience and the overall context not only advances students' reading and writing, but functions as a metacognitive survival kit for college. Thus, if we are teaching reading and writing as processes, we are not only teaching academic content, but also metacognitive strategies for effective learning and thinking. In that sense, we are also potentially teaching students to transfer their learning between contexts and to adapt their approaches to learning for a variety of learning spaces, on and off campus (Carillo, 2016; Hassel \& Giordano, 2009; Threadgill \& Paulson, 2018; Wilson \& Conyers, 2016). Thus, we contend that rhetorical reading and writing represent a particularly appropriate element of first-year seminar coursework.

\section{The Use of Grading Contracts}

As part of directly engaging the non-cognitive dimensions of learning, including self-efficacy and metacognition, the instructor's emphasis on process work in her math corequisite also played a defining role in the English corequisite: the faculty and staff who taught our 2018 corequisite pilot were chosen because they tended to embrace an ethic of care and, as part of that care, four out of five of the English corequisite instructors used a grading system similar to Thurmond's, in which brainstorming and reflection, along with other low-stakes writing, played a decisive role in determining whether or not students passed the corequisite section.

This emphasis on process work led the manager of academic support to use grading contracts in his sections of the English corequisite courses. In essence, grading contracts are agreements between instructors and students that outline the required activities for a particular grade. As Elbow (1996) stated, "A contract says, 'If you do $x, y$, and $z$, you can count on such and such grade" (p. 2). This "default grade" can be a B or C, depending on a course's requirements or an instructor's preference, but what's most important is the emphasis of labor and behavior. Elbow posited that using grading contracts allows him to "specify activities and behaviors that will lead to learning" ( $p$. 2) rather than relying on grades to assess learning. 
Inoue (2019) asserts something similar: "Learning contracts are designed to help learners achieve particular learning outcomes, not grades" (p. 63). Given that we were working with students who need extra support for their main English class, we found it prudent to shift away from grading every single assignment students were asked to do. Instead, by focusing on labor, students were encouraged to take risks without worrying about their final grade in the class. Additionally, "learning contracts promote student responsibility, agency, and control in mostly self-governed, learning processes, with an attention to what that process is meant to achieve or produce" (Inoue, 2019, p. 65). This also helps to de-emphasize what Dweck et al. (2014) has called a fixed mindset and helps to foster a growth mindset among students.

That is, with a grading contract that focuses on activities related to learning rather than measuring the quality of the work, students understand that developing facility with writing often requires multiple attempts, rather than being perfect from the beginning.

There are also other reasons for using a grading contract specifically at an HSI. Inoue (2019) indicated the importance of giving students, particularly students of color, full access to the entire range of grades in the class, something that is not possible in a traditionally graded classroom. He asserted,

Because the teacher's judgments of quality are what determines whether any draft is acceptable or not in the system, some students may still not be able to achieve a high grade, even if they desire to and are willing to work extra hard. (p. 68)

He contended that traditionally graded classrooms lock students from non-dominant discourses out of the highest grades available in the class ipso facto, regardless of a student's motivation and willingness to do well. While we do not argue that grading contracts can be effective in all classes and in all subjects, their use in the English corequisite classes seems necessary to create the fairest assessment possible, to emphasize success strategies, and to help students develop confidence to succeed in a college environment.

\section{An Ecosystem of Learning}

Combining the first-year seminar with the corequisite proves particularly promising for addressing non-cognitive issues as part of a larger $U$ of $\mathrm{H}-\mathrm{V}$ ecosystem. For instance, the Success Coaches use academic success referrals (ASR) as a form of early alert for students falling behind in their coursework. Faculty in the corequisite and main courses may submit an ASR to alert a success coach that a student has missed several classes or has not completed homework, or seems to be falling asleep in class, among a myriad of other things. While the ASR is geared around academic success, faculty may cite non-academic reasons for alerting the success coach. From there, the coach will reach out to the student through phone calls, e-mails, and text messages. However, if these modes of communication do not elicit a response, the success coaches will go as far as to visit the student's residence hall room (although this tactic is rarely used at $\mathrm{U}$ of H-V Most students respond to the text messages). After getting the student to schedule a meeting with them, the success coach will discuss the topics in the ASR, ask the students about any underlying causes, and present strategies to resolve the issue.

Besides the ASR process, the implementation of the corequisite courses has necessitated stronger collaborations administratively between the University College and the School of Arts and Sciences. This has especially been the case with the pairing of certain main courses and their satellite corequisite courses. In the ALP model, the main class and the support class are taught by the same person, and the main class contains roughly half or fewer students who are underprepared for college. At $\mathrm{U}$ of $\mathrm{H}-\mathrm{V}$, a perfect linking like this proved challenging to achieve due to scheduling issues, resource shortages, and the fact that the two courses are housed in different departments. Instead, our corequisite and main courses were taught by different faculty, and the corequisite instructors may have students from multiple English 1301 courses (although, some paired instructors had the same 25 students in both courses). The math corequisite courses were organized in a similar way, though both College Algebra and the corequisite courses are much larger than those in English. While this type of structuring made scaling the program to $100 \%$ of underprepared students possible in the first year, it also resulted in less communication between paired instructors than would be ideal.

\section{Success}

We were gratified to hear students describing corequisite as a place where they feel like they belong. One student remarked of the instructor's class in particular, "You created a family." Another pair commented in an end-of-semester reflection, 
"This class was our home away from home." But beyond that crucial affective dimension, there were also signals from some students that they did in fact transfer some of the learning that took place in the corequisite seminar to other courses. In this unprompted account, one student describes how his corequisite class was helping him in his English gateway course:

In my freshmen seminar class with an instructor, she talked about the different ways where you can put an argument and have backup towards your argument. What she talked about helped me on this writing project by putting an idea I was against about immigrants and having backup towards those ideas.... The words will make the backup more interesting and it will help people understand why they should not be against something or someone without knowing the reason why someone looks, acts, dresses, moves or does something. That instructor's information helped me a lot with this writing process with the information she talked about.

We contend that when instructors and students are able to see relevant connections between classes, and when otherwise separate divisions of the university are able to collaborate in the name of student success, students benefit.

\section{Challenges}

Though we believe in the pedagogical tenets of our model, which contextualizes metacognition and success strategy acquisition with academic content by combining the first-year seminar with the corequisite, some aspects of implementation proved to be a challenge. The first challenge that we experienced in implementing this model has had to do with the logistics of linking the corequisite seminars to the gateway courses. Teaching load issues prevented Arts \& Sciences faculty from teaching both the gateway courses and the corequisite seminar. That limitation drove us to forge collaborations between University College staff and Arts and Sciences faculty. But then the challenge became keeping the size of the corequisites low while still integrating underprepared students (without stigmatizing them). During our first semester pilot, our efforts to accomplish these goals required the registrar to create confusing, unsustainable fixes for registration purposes. Since then we have reverted to larger class sizes, with as many as 25 students in each section. In math, we have gateway courses consisting entirely of students who have also been placed in the corequisite seminar, which creates a one-to-one cohort: the same group of students in gateway math also meets in the corequisite seminar for just-in-time support for that class. The English corequisite seminar, by contrast, contains a mixed group of students coming from multiple core English sections. The advantage is that those students are not stigmatized in their English core classes, but the instructor of the English corequisite seminar cannot provide "just-in-time" support for the English gateway course.

The second clear challenge that we have faced in implementing this model has had to do with the fact that many of our incoming freshmen were TSI incomplete in math and in at least one English area. Our solution in this scenario was to require students to take the English corequisite seminar in their first semester and to take the math corequisite seminar in the spring. Our rationale is that the freshman seminar content (focused on metacognition or student success strategies) could bear repeating and would not be identical to what they experienced in the fall semester English corequisite anyway since it would have been contextualized with English content.

\section{Discussion}

Particularly in light of the fact that our program does not actually de-stigmatize students for having been placed in obviously marked developmental courses, we are resolved in the future to de-emphasize TSI test scores in placing students and potentially to move closer to directed self-placement. Additionally, in light of preliminary assessment findings, we hope to strengthen instruction in both math and English with a renewed focus on addressing two pivotal issues impacting our students' success. First, we hope to assess and come to a more fine-grained understanding of what impacts student motivation. If our courses feature process work prominently in students' course grades (such that attending class and turning in work means they will pass) what, then accounts for the students who still do not pass our corequisite classes? Second, based on a survey (described below) completed by students in English corequisite sections, we hope to assess/track the influence of something we are calling metacognitive initiative as well as the corequisite's potential for developing it. Though our survey was based on an admittedly small sample size, we are intrigued by its results. It asked, "Do you use any 'life hacks' [sic] for tackling a challenging reading assignments?" And it asked the same question related to writing. The students who described strategies of some kind did better during their first year of college, even if the strategies they described were eccentric or seemed like they might be counter-productive. All of these refer to students in the spring of 2019, following the first fall semester of our pilot, as indicated in Figure 1. 


\section{StRATEgIES}

Average cumulative GPA when...

NON-Strategies

Average cumulative GPA when...

\begin{tabular}{l|l|}
$\begin{array}{l}\text { Enrolled in composition } \\
\text { II: } 2.78\end{array}$ & $\begin{array}{l}\text { Enrolled in composition } \\
\text { II: } 2.10\end{array}$ \\
\hline Enrolled in algebra: 2.53 & Enrolled in algebra: 1.85 \\
\hline $\begin{array}{l}\text { Overall cumulative GPA of } \\
\text { strategies: } 2.44\end{array}$ & $\begin{array}{l}\text { Overall cumulative GPA of } \\
\text { non-strategies: } 1.85\end{array}$
\end{tabular}

Figure 1. Strategies and non-strategies.

On one hand, we cannot draw a causal connection between the strategies and the success. For instance, we were fascinated to see that those who reported using reading and writing strategies were higher grade earners in both English and math. This could mean that the more self-consciously strategic students were simply disposed to be better at school across the board, and the same thing that made them better at school also made them the kind of person who would be able to recite elements of strategies or teacher talk from high school. At the same time, we are intrigued by the association between having some strategies and higher GPA, and we think it is worth exploring further. We were particularly interested to see that even students whose reading/writing strategies did not seem like strong strategies did better. Just to name one example, one student informed us that she routinely uses the HELP strategy to write a paper, which she explained means incorporating "History, Economy, Language and Process" into her papers. When I asked for further clarification, this student said that the acronym helps her come up with ideas for papers and sometimes she structures her papers with sections to match. Certainly, to a writing teacher, this student's strategy appears idiosyncratic, yet we find it remarkable that along with the other strategic students, this student's GPA was significantly higher than the average GPA for students who declined to identify themselves as using any reading or writing strategies. To us, this suggests that taking the initiative to implement strategies at all matters a great deal-maybe even more than the wisdom of the strategy itself.

\section{Conclusion}

On the one hand, we have described our response to the Texas mandate to institute corequisites as rooted in a particular place with its own institutional history. For instance, for us, the high percentage of minority students at our HSI school demanded that we carefully consider the emerging literature on grading contracts and antiracist writing assessment as part of our considerations in developing the English portion of the first-year seminar/corequisite. Other structuring elements of our local context drove us to use specialized sections of the first-year seminar as the corequisite and that choice effectively placed math, English and success coaches into close collaboration with one another. That cross-pollination fruitfully encouraged all of us to place a primary emphasis upon process work and metacognitive reflection as a part of scaffolding learning for gateway courses. It also meant that we found more blurred lines between counseling and teaching than are expected in our non-corequisite classes. Yet at the same time, perhaps our story of developing a unique corequisite model, whose uniqueness derives precisely from responding to local needs and institutional histories while also fulfilling the state mandate, itself suggests methods for other contexts. Fundamentally, the lesson of the corequisite or our implementation of it is one of radical sharing or sharing of responsibility for underprepared students across all divisions.

Developing and teaching the corequisite demanded high involvement of faculty and staff with students, and with each other, through an ethic of care. As we see it, this process effectively extended already existing ecosystems of support unique to our institutional context. The fact that staff who are responsible for providing student success services were involved in teaching and developing the courses along with the academic faculty and vice versa-combined with the smallness of our schoolmeant that a close knit team of people, people who affectively engage with student success, shaped the program. This ethic of care boils down not only to affectation but also a willingness to engage students' non-cognitive needs. Given our online mission, many faculty actually live elsewhere, so they cannot participate in meeting-intensive collaborations or are not available to students outside of their office hours. The people who developed and shaped the corequisite by contrast, tend to be the faculty and staff who live locally and make themselves available to students. Because part of an ecosystem is place and space, the students feel more connected to the faculty who live here. We also found that the learning ecologies of the writing and reading program extended to students' performances and practices in the math classes, and vice versa. Additionally, the math and English instructors influence each other and have become increasingly interconnected. The same is true of the corequisite seminar courses and their paired core/gateway courses. The effect has been to create a support network that goes beyond classrooms, beyond advising, and extends all across campus. Because of extensive collaborative links between us, we forget 
that we are distinct departments, which seems to create a tighter safety-net for struggling students. For instance, as a success coach and collaborator on the math corequisite seminar, the instructor finds herself reaching out to the math faculty member who teaches algebra, sometimes going back and forth via text message at midnight, in order to figure out why a student is struggling. In this sense, the learning ecosystem involves us in a way that would not occur in traditional courses.

When Adams et al. (2009) called for mainstreaming of students normally placed in remedial courses, he critiqued "isolating" those students. That isolation sometimes takes the form of outsourcing support for those students, from the perspective of faculty who feel underprepared to help underprepared students. In our experience, outsourcing support for underprepared students conduces to institutional "silo-ing," where certain divisions are designated as responsible for student success initiatives and certain divisions are less so. Our model resists those divisions. Thus, in the same sense in which there is Writing Across the Curriculum, perhaps our model can be understood as metacognition across the curriculum, or Success Strategies Across the Curriculum. In our model, everyone is responsible for everything.

\section{References}

Accelerated learning program. (n.d.). Retrieved from http://alp-deved.org/features-of-alp-success/

Adams, P., Gearhart, S., Miller, R., \& Roberts, A. (2009). The accelerated learning program: Throwing open the gates. Journal of Basic Writing, 28(2), 50-69.

Atkins, C., \& Beggs, C. T. (2017). Commuting the math sentence: Accelerating developmental mathematics using the corequisite model. NADE Digest, 9(1), 20-24. Retrieved from https://login.ruby.uhv.edu/login?url=http:// search.ebscohost.com/login.aspx?direct=tru e\&AuthType=ip, uid\&db=eric\&AN=EJ1178226 \&site=eds-live

Carillo, E. (2016). Creating mindful readers in firstyear composition courses: A strategy to facilitate transfer. Pedagogy, 16(1), 9-22.

Cho, S. W., Kopko E., Jenkins, D., \& Smith Jaggars S. (2012). New evidence of success for community college remedial English students: Tracking the outcomes of students in the accelerated learning program (ALP). CCRC Working Paper No. 53, 1-26.

Dweck, C. S., Walton, G. M., \& Cohen, G. L. (2014). Academic tenacity: Mindsets and skills that promote long-term learning. Retrieved from https://ed.stanford.edu/sites/default/files/ manual/dweck-walton-cohen-2014.pdf
Elbow, P. (1996). Getting along without grades-and getting along with them too. Conference on College Composition and Communication. Milwaukee, WI.

Hassel, H., \& Giordano J. B. (2009). Transfer institutions, transfer of knowledge: The development of rhetorical adaptability and underprepared writers. TETYC, 24-40.

Inoue, A. (2019). Labor-based grading contracts: Building equity and inclusion in the compassionate classroom. Fort Collins, CO: UP of Colorado.

Negretti, R. (2012). Metacognition in student academic writing: A longitudinal study of metacognitive awareness and its relation to task perception, self-regulation, and evaluation of performance. Written Communication, 29(2), 142-179.

Roick, J. \& Ringeisen, T. (2018). Students' math performance in higher education: Examining the role of self-regulated learning and self-efficacy. Learning and Individual Differences 65, 148-158.

Schoen, M. (2019). Your mission, should you choose to accept it: A survey on writing programs and institutional mission. WPA, 42(2), 37-57.

Sullivan, P. (2013). "Just in time" curriculum for the basic writing class. TETYC. 118-134.

Threadgill, E. J., \& Paulson, E. J. (2018). Teaching the rhetorical situation to improve disciplinary literacy. Journal of Academic Support Programs, 1(1), 49-50.

Trammell, J. (2018). Goffman and spoiled identity: Helping developmental students shed the label. Journal of Academic Support Programs, 1(1), 51-2.

Watkins, M. (2017, September 29). Major Texas overhaul aims to improve the odds for students who begin college unprepared. The Texas Tribune. Retrieved from https://www. texastribune.org/

Wilson, D., \& Conyers, M. (2016). Teaching students to drive their brains: Metacognitive strategies, activities, and lesson ideas. Alexandria, VA: ASCD. 


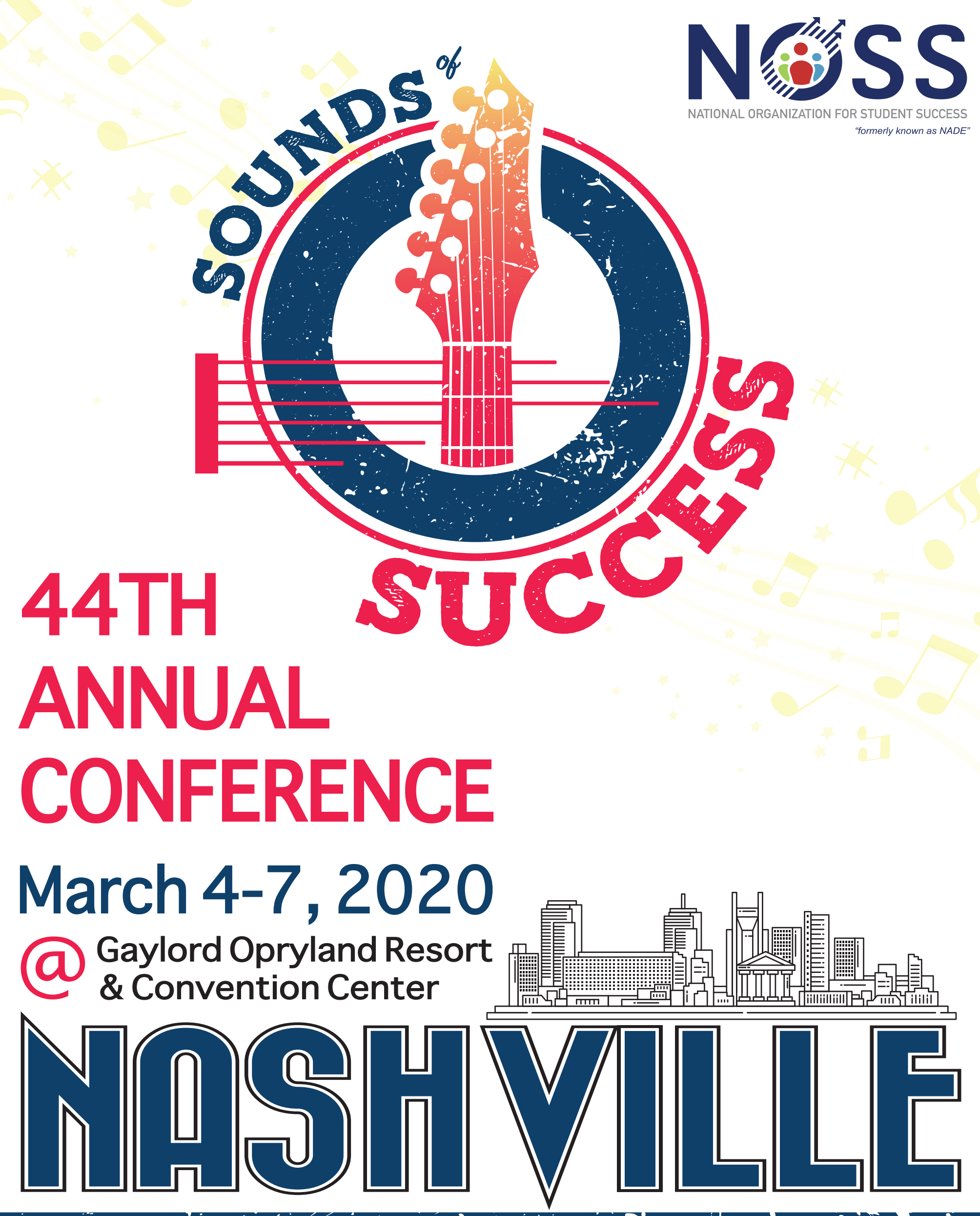

\# WWW THENADE

NAME, CO-CHAIR@EMAIL.COM
NAME, CO-CHAIR@EMAIL.COM

$\because \quad \because$ 


\title{
A Collective Impact Model Towards
}

\section{Increasing STEM Major Student Retention}

\author{
Araceli Martinez Ortiz, Texas State University \\ Clara M. Novoa, Texas State University \\ Vedaraman Sriraman, Texas State University
}

\section{ABSTRACT}

This article presents the research findings of a multidisciplinary team's collective research effort at one university over a five-year period as funded by the National Science Foundation's Improving Undergraduate STEM Education (IUSE) program. A collaborative learning and retention action research effort at a large Hispanic Serving Institution is analyzed using mixed methods to document the power of collective impact as the foundation for a learning support model for students historically underrepresented majoring in science, technology, engineering and mathematics (STEM) academic programs. The actions of the team of researchers are presented to describe the Rising Stars Collective Impact model and the impacts achieved. This is a model that aligns objectives, intervention efforts, and reports collective results. The long-term goals of the Rising Stars Collective Impact multiple programs managed by the funded program team included the following: (a) to improve the campus sense of community for students historically under-represented in STEM, (b) to establish innovative and robust STEM education research-based practices to support critical skill attainment for students, and (c) to support faculty understanding of the funds of knowledge of diverse students. The positive student retention and success impacts of this research effort are measured through quantitative statistical analysis of the changes in second-year STEM undergraduate student retention rates and representation rates of women, Hispanics, and African American STEM majors.

T

he continued call to provide greater support for college and university student learning to encourage their completion of an increased number of degrees in science, technology, engineering, and math (STEM) is now coming from coordinated policy efforts that claim it is time to scale the adoption of evidence-based instructional practices and key strategies that may support students in their STEM courses (Committee on STEM Education of the National Science \& Technology Council, 2018). While many important research efforts focus on isolated approaches by single or small groups of researchers, it may be time to consider the potential value of system-wide research approaches that encourages multi-disciplinary collaboration and conduct action research as a collective. At our university in 2014, a group of faculty with research interests in engineering education, chemistry education, physics education, mathematics education, and computer science education came together to design a series of interventions. These faculty were guided by university goals to support strategic STEM goals (Texas State University, 2013) and of assisting students to persist and succeed in their STEM courses and academic preparation for STEM careers. The intervention ideas proposed by this team included strategies to redesign courses; to provide mentoring and academic advising; to support supplemental instruction innovations; to establish learning communities; and to create academic and key skill development workshops for learners historically underrepresented in STEM and learners encountering new technologies. Educating a diverse, technologically capable workforce from all sectors of the population is of utmost importance (Page, 2007) and identifying best practices to support undergraduate students in particularly challenging fields such as in STEM was approached by this team as a collective effort.

This paper presents the final report research findings of this research team's collective research effort at one university over a 5-year period as funded by the National Science Foundation'sImproving Undergraduate STEM Education (IUSE) initiative. Specifically, this NSF initiative supports research proposals that include potentially effective approaches towards improving student learning in STEM while also offering high potential for broader societal impacts. The goal of this STEM education and research initiative was to create a professional learning community of faculty at a large university that would find ways to positively impact student learning, while attending to motivation and persistence of historically 
underrepresented students in STEM academic fields of study. A collective impact framework (Kania \& Kramer, 2011) served to guide the team to carry out various programmatic interventions for a large cohort of undergraduate students. The professional learning community's approach to organizing and managing this effort relied on a complementary vision of establishing and managing an infrastructure that would promote synergy among stakeholders to achieve a more comprehensive understanding of the most challenging diversity and inclusion issues while developing and disseminating evidence-based strategies that support increased student success in STEM.

\section{Literature Review}

The vision for the fundamental approach to this work is grounded in an understanding of the interrelated set of complex issues that contribute to the systemicchallenge of diversifying the STEM workforce (Committee on Equal Opportunities in Science and Engineering, 2014) and the need to support students who may be underprepared to carry out collegelevel work in foundational mathematics and science courses (Jackson \& Kurlaender, 2014). For example, many students benefit from early exposure to captivating STEM experiences to ignite their imaginations and propel them toward future STEM pursuits. Studies based on nationally representative longitudinal data suggest that to attract students into the sciences and engineering fields, educators should pay close attention to children's early exposure to science at the middle and elementary grades (National Academies of Sciences, Engineering, and Medicine, 2011; Tinto, 1993). Further, the quality of STEM instruction students receive often determines whether they have the foundational skills and academic backgrounds to be successful in STEM. The need for more and better-prepared science and mathematics teachers is prevalent nationwide, but is especially important for regions of the U.S. that have rapid growth rates and large concentrations of minority populations who can benefit from professional preparation in these careers. Inequality in STEM Career Representation

Once on the STEM pathway, students need continuing opportunities to learn about new applications for their learning and mentoring from role models with whom they can identify. This is especially important for women as the National Research Council (Heldenfels IV et al., 2013; Swail, Redd \& Perna, 2003) and the Committee on Equal
Opportunities in Science and Engineering (2013) have reported gaps in unequal participation of women and minorities in STEM occupations. Gender equality in STEM is a challenging issue in that women often report feelings of isolation and lack of credibility in the workplace and in their academic pursuits (Waitzer \& Paul, 2011); the complex issues surrounding equity, access, and inclusion in STEM comprise the what that is the focus of the research project. The question of how presents another set of equally complex issues in creating the conditions in which members can learn from and support one another's work and can coalesce around issues that can be advanced collaboratively by combining the talents and efforts of the whole network (Turner, Merchant, Kania, \& Martin, 2012).

\section{Collective Impact}

Despite a multitude of past interventions, the cumulative impact of research investments on the overall participation of minorities and persons with disabilities in STEM has been minimal (National Science Foundation \& National Center for Science and Engineering Statistics, 2013). The answer to this intractable social issue may lie in recent developments along three fronts of social research including the areas of collective impact, social network management, and systems theory. Large scale social problems such as poverty, health, education and the environment compound these problems, and even if a solution were known, no one individual organization is able to compel all players involved to adopt it. Important variables that influence the outcome are not often known and/or cannot be readily predicted in advance. Under these conditions of complexity, predetermined solutions rarely succeed (Kania \& Kramer, 2013), and in many ways, this phenomenon explains the limited, isolated impact of past efforts in reducing the national gap in STEM education career participation by women and students from historically underrepresented groups. We consider other transformational practices from the field of community development, community building, and civic engagement such as Guajardo, Guajardo, Janson, and Militello's (2015) approach to creating a "Community Learning Exchange" through the use of participatory practices and a collective leadership to complement the collective impact primary model.

Gaps in Target University STEM Student Participation and Retention

In 2012, STEM majors constituted about $7.7 \%$ 
of the overall undergraduate student population at the target university $(2,264$ of 29,458$)$. About $33 \%$ of those STEM undergraduates were Hispanics and African Americans, and $22.6 \%$ were females. Through analysis of retention rates by ethnicity and gender, several gaps were detected; Figure 1 identifies those that were addressed as part of this research effort.

\begin{tabular}{|c|c|c|c|}
\hline \multicolumn{3}{|c|}{ Identified Gaps at Target University } & \multirow{2}{*}{$\begin{array}{c}\text { Goals } \\
\text { 4-year Goal (\%) } \\
\text { Target Goal }\end{array}$} \\
\hline & $\begin{array}{l}\text { All Undergrad } \\
\text { Students } \\
2012 \text { Data }\end{array}$ & $\begin{array}{l}\text { All STEM } \\
\text { Students } \\
2012 \text { Data }\end{array}$ & \\
\hline $\begin{array}{l}\text { Gap 1: } \\
\text { Hispanic } \\
\text { and African } \\
\text { American } \\
\text { students } \\
\text { not propor- } \\
\text { tionately } \\
\text { represented } \\
\text { in STEM } \\
\text { majors }\end{array}$ & $\begin{array}{l}36 \% \text { of un- } \\
\text { dergraduate } \\
\text { students are } \\
\text { Hispanic or Afri- } \\
\text { can American. }\end{array}$ & $\begin{array}{l}\mathbf{2 7 . 7 \%} \text { of STEM } \\
\text { majors are His- } \\
\text { panic or African } \\
\text { American. }\end{array}$ & $\begin{array}{l}\text { Increase the } \\
\text { percentage of } \\
\text { Hispanic and } \\
\text { African American } \\
\text { students choos- } \\
\text { ing STEM majors } \\
\text { to reach a target } \\
\text { of } \mathbf{3 4 \%} \text { represen- } \\
\text { tation. }\end{array}$ \\
\hline $\begin{array}{l}\text { Gap 2: STEM } \\
\text { majors not } \\
\text { propor- } \\
\text { tionately } \\
\text { retained in } \\
\text { their chosen } \\
\text { field of study }\end{array}$ & $\begin{array}{l}67 \% \text { of } 2 \text { nd- } \\
\text { year students } \\
\text { are retained in } \\
\text { their chosen } \\
\text { field of study. }\end{array}$ & $\begin{array}{l}62.7 \% \text { of } 2 \mathrm{nd}- \\
\text { year STEM ma- } \\
\text { jors are retained } \\
\text { in their chosen } \\
\text { field of study. }\end{array}$ & $\begin{array}{l}\text { Increase the } \\
2 \text { nd-year re- } \\
\text { tention rate of } \\
\text { STEM majors to } \\
\text { reach a target of } \\
67 \% \text { retention. }\end{array}$ \\
\hline $\begin{array}{l}\text { Gap 3: } \\
\text { Hispanic } \\
\text { and African } \\
\text { American } \\
\text { students do } \\
\text { not grad- } \\
\text { uate at the } \\
\text { same levels } \\
\text { as majority } \\
\text { students in } \\
\text { STEM }\end{array}$ & $\begin{array}{l}\mathbf{2 9 . 7 \%} \text { of all } \\
\text { bachelor degree } \\
\text { graduates are } \\
\text { Hispanic or Afri- } \\
\text { can American. }\end{array}$ & $\begin{array}{l}\mathbf{2 8 \%} \text { of STEM } \\
\text { bachelor degree } \\
\text { graduates are } \\
\text { Hispanic or Afri- } \\
\text { can American. }\end{array}$ & $\begin{array}{l}\text { Increase the \% } \\
\text { of Hispanic and } \\
\text { African American } \\
\text { graduates in } \\
\text { STEM to } \mathbf{3 4 \% .}\end{array}$ \\
\hline $\begin{array}{l}\text { Gap 4: } \\
\text { Female } \\
\text { students } \\
\text { not propor- } \\
\text { tionately } \\
\text { represented } \\
\text { in STEM } \\
\text { majors }\end{array}$ & $\begin{array}{l}\mathbf{5 7 \%} \text { of un- } \\
\text { dergraduate } \\
\text { students are } \\
\text { female. }\end{array}$ & $\begin{array}{l}\mathbf{2 2 . 6 \%} \text { of STEM } \\
\text { majors are } \\
\text { female. }\end{array}$ & $\begin{array}{l}\text { Increase the } \\
\text { percentage of } \\
\text { female students } \\
\text { graduating in } \\
\text { STEM to reach } \\
\text { a target of } \mathbf{2 5 \%} \\
\text { representation. }\end{array}$ \\
\hline
\end{tabular}

Figure 1. Identified gaps and goals based on 2012 student data. This figure illustrates the identified gaps in student representation, success, or retention at the target university.

The above gaps are intertwined. For example, increasing the retention rate of Hispanics and African Americans (Gap 3) would also impact Gaps 1 and 2 . In this research effort, activities were designed to address student needs that would contribute to reducing some of the gaps.

Over the past decade scaling what works has captured the attention of the social sector. The consensus amongst social entrepreneurs is that those who wish to scale must learn to transition from an "enterprise to an ecosystem" (Waitzer \& Paul, 2011; Meadows \& Wright, 2008). It is with a deep understanding of and appreciation for the multitude of complex issues surrounding both the what and the how that the collective impact approach provides a networked community in which members can explore issues and test solutions. This approach has provided opportunities and avenues for members to showcase and disseminate evidence-based practices and has empowered members to be path-lighters for practitioners and policymakers who have a vested interest in achieving a more diverse and equitable STEM workforce.

\section{Research Design}

\section{Methodology}

While each of the various embedded research studies pertinent to our overall study utilized varying mixed methods, the overall impact study is presented as a case study in order to facilitate a deeper investigation of this real-world contemporary collective impact phenomenon (Yin, 2012).

Collective impact as the theoretical organizing framework. Collective impact initiatives most often prove to be long-term commitments by groups of important actors from different sectors guided by a common agenda for solving a specific social problem as studied by Kania and Kramer (2011); Malcom and Feder (2016). Achieving large-scale change through collective impact involves five key conditions for shared success. These include: (a) having a common agenda, (b) establishing shared measurement modes, (c) enacting mutually reinforcing activities, (d) assuring continuous communication, and e) counting on backbone support (Waitzer \& Paul, 2011).

Defining a common agenda. The Rising Stars Collective Impact team developed a common agenda consisting of three major long-term goals and five supporting objectives identified as a result of a College of Science and Engineering student success data self-study (Ortiz \& Sriraman, 2015). The shared long-term goals of the Rising Stars Collective Impact were the following: (a) to improve the campus sense of community for students historically underrepresented in STEM, (b) to establish innovative and robust STEM education research-based practices to support critical skill attainment for students, and (c) to support faculty understanding of the funds of knowledge of diverse students. We then developed the five program objectives based on careful consideration of specific STEM fields with greatest equity gaps and measurable outcomes that might be realistically realized in the 5-year life-cycle of the project. From here forward, when STEM is noted, we refer to the five academic STEM units at Texas State University that highlight the greatest participation or success student equity gaps: mathematics, chemistry, physics, engineering, engineering technology and computer science. The following five objectives were developed and served as the common agenda for the project/research team: 
1. Increase the percentage of Hispanic and African American students choosing STEM majors to achieve a 34\% representation by 2018 .

2. Increase the retention rate of all STEM majors to achieve a target of $67 \%$ retention rate in 2018 .

3. Increase the percentage of Hispanic and African American graduates in STEM majors to achieve a target of 34\% representation by 2018 .

4. Increase the percentage of female students participating in undergraduate STEM degrees programs to achieve a target of $25 \%$ representation by 2018 .

Establishing shared measurement modes. The common agenda gaps and goals identified above are what drove the various sub-project research efforts. Progress towards these goals was gauged using shared measurement modes such as data sources and common survey instruments. A university wide system of databases is available with a dashboard interface that provides consistent data about graduation rates, grades, retention from year to year, and demographic data regarding representation in any particular college, major, and time period.

\section{Enacting mutually reinforcing} activities strategies. The Rising Stars Collective Impact project identified four strategies to support the objectives and goals of the group. Each of the faculty co-investigators led a set of activities designed to achieve the project goals and objectives. One key activity from each of these strategies will be featured. The evaluation of the strategies and activities is described in the following sections:

Strategy 1: Redesign critical computer science (CS) classes and improve instruction. As shown by the retention statistics in critical courses analyzed during the College of Science and Engineering's self-study, the majority of declared undergraduate computer science majors who leave the field do so in their first two years. Contributing to this problem is that students are typically introduced to computer science in introductory courses that focus on programming and syntax without a broader understanding of how computer science is relevant to their lives. To address this need, the introductory course was revised by developing course modules containing contexts focused on familiarizing students with computational thinking, data-driven analysis, and multidisciplinary approaches early in their careers in contrast to the traditional expository instructional methodology currently prevalent in these courses.
The new high context computer science modules were designed to enable students to see the big picture of how computer science affects our lives. For example, one of the first modules was designed to help students understand how information and communication technologies (ICTs) are rapidly connecting people and things together and to think about what could go wrong in the increasingly connected infrastructure. The researchers conducted a pilot study of the introductory course entitled Computer Science 1428 (CS1428), a freshman level required course, to determine the differences in the survey responses between student groups who experienced instruction embedded with and without these newly designed modules. Data were collected related to student attitudes, awareness, and understanding of the field of computer science post-instruction. The study results showed differences favoring the student groups who participated in the course embedded with the new modules (Rodríguez Amaya, Guirguis, \& Marquez, 2019).

Strategy 2: Provide career exploration and visual spatial skill development. This strategy was intended to provide opportunities for engineering and engineering technology students to more clearly understand STEM fields of study, related career options, and to develop important visual spatial skills. Students were provided specific opportunities to connect with fieldspecific learning communities through early and frequent interaction with faculty, peers, and representatives from industry while developing these skills. A special course to refine spatial visualization skills and create community among students was developed and delivered twice per semester over the span of three years. All freshman in STEM fields, as well as students registered for physics-mechanics and fundamental of architectural problem and design courses, were invited to take the Purdue Spatial Visualization Test - Rotations (PSVT-R) online, prior to taking an intervention workshop. The students who scored below $70 \%$ were invited to register for a spatial visual thinking skills (SVS) training workshop designed to help them refine these skills. The workshop program consisted of six 2-hour training sessions that included a talk by a speaker related to the practical applications of spatial visualization, faculty lectures, the use of a SVS computer-based training program, and practice with specialized materials. 
Strategy 3: Foster meaningful student engagement experiences. This strategy was focused on increasing STEM student-reported feeling of community by building connections with peers and mentors and creating opportunities for students to interact with professionals in their chosen fields. A special engineering section of an existing freshman required university seminar was created. The new section University Seminar (US) 1100-Engineering and was offered once a year exclusively to incoming freshmen who indicated an intention to study engineering or engineering technology. The course covered the required seminar content while additionally using introductory engineering content elements. An engineering design project was integrated into the US 1100-Engineering introductory course and students were introduced to a university maker space-a creative student-run lab with equipment, simple tools, and materials.

Another meaningful way to engage students is to provide early career internship experiences. An industrial internship program was created to enable second year students to participate in a guided professional experience that combines academic and professional components. The program represented a fundamental change in a long-standing internship program that previously was only available to students the summer before senior year. This change was supported by the department's three advisory boards with input from internship supervisors in industry. The administrators, faculty, and industrial representatives worked together to reach consensus on the desired changes for the new internship program. In the previous internship program, students were required to complete at least 75 hours of coursework, including completion of all math and science courses, before engaging in the internship experience. In the new approach, the students now complete 45 hours of coursework and two math and/or science courses before their internship experience. This change enabled students to complete sufficient coursework to prepare them for the internship while allowing them to participate in the internship early enough in the experience academic program to gain a positive career engagement experience.

Strategy 4: Support student learning through evidence-based instruction. Two related models of peer-assisted learning, the Supplemental Instruction program and the Learning Assistant (LA) program, have been used in some STEM courses at our university. A goal of the Rising Stars Collective Impact project was to expand these programs to serve more students in the first and second year gateway STEM courses such as introductory calculus, chemistry, and physics. The following describes the activities within this strategy, and we present some data on their impact.
Expansion of the supplemental instruction (SI) program. The university had already implemented a Supplemental Instruction (SI) program in select chemistry and mathematics courses since 1995. SI is a nontraditional form of tutoring that focuses on collaboration, group study, and interaction led by a student peer, referred to as a Student Supplemental Instruction Leader (SI Leader). A study by Hodges and White (2001) investigated the effect of high-risk students' participation in an SI program at a very large university and concluded that a positive impact upon high-risk students' academic achievement could be achieved. Based on this and other related efforts in developmental education research, the Rising Stars Collective Impact project expanded the SI program to include additional courses in Chemistry, Calculus and Physics. In the SI program, the SI Leader attends class sessions and models good study skills and habits to those who are taking the course. The SI Leader also meets with students outside of class and helps them to work collaboratively in discussing readings, comparing notes and sharing ideas for improving study skills and class material. In our implementation, one SI Leader was assigned to each faculty member teaching two sections of the target course. The SI Leader attended one section of the course and made appearances, when possible, to the other section. Student participation data was collected for the supplementary instruction activities hosted and demonstrated that the participation rate was higher for students in which the SI Leader primarily attended.

Use of peer mentors. Another major support component of the Rising Stars Collective Impact program was the Peer Mentor program for women in STEM. This program was implemented to help support women and increase their retention in STEM. The peer mentors set office hours in order to enable students to meet with them to discuss their progress. The mentors met with the women students at least twice during the semester to monitor their progress. The enrollment in the chemistry and mathematics departments increased- potentially as a result of several factors including the Rising Stars Collective Impact program's recruitment and support initiatives, the overall increase in university enrollment, and potentially due to specific academic programs in nursing and engineering which require chemistry and mathematics courses. The enrollment in the Calculus I and Calculus II courses continues to trend upwards with an increase in the number of students served in the Spring 2017 compared to the Spring 2015. For example, the enrollment in MATH 2471 increased to 453 in 2017 from 325 in 2015. Similarly, MATH 2472 enrollment increased to 327 from 280 which had been the attendance during the previous 2 years. Analysis of the data showed that the variation in participation rates depended upon the faculty member teaching 
and whether the course had or did not have an SI Leader assigned to the course. The average grades of the calculus courses also increased during the study period's five semesters. MATH 2471 had an average grade difference over five semesters of 0.49 . For MATH 2472, the average grade difference over this same period was 0.44 .

Expansion of the Learning Assistant (LA) program. The LA program is another peer-tutor model program designed to benefit both the students that are assisted by the LAs as well as the LAs themselves. Through the Rising Stars Collective Impact program, we were able to expand the university's LA program to be included in all sections of introductory calculus-based physics: five sections of mechanics, four sections of electricity and magnetism, and one section of waves and heat per semester. In the LA program, the LA attends the assigned class to assist the instructor by mentoring students, facilitating collaboration among learning teams, and by assisting in facilitating student understanding, and in grading. In addition, they work in the Physics Help Center, a walk-in tutoring center that is open 35 hours a week. They also serve as laboratory instructors for the calculus-based mechanics course. Applicants for the LA position must have successfully completed the first course in the introductory sequence and be recommended by faculty or current LAs regarding their communication skills and facility with productive small group interactions. Students of all STEM majors are encouraged to apply, and special efforts are made to recruit women and students from underrepresented minorities.

\section{Data Analysis}

We used a comprehensive evaluation process and included varied strategies for data collection and examination of each activity within the four major initiatives supporting the student, faculty, and institutional objectives of the program. The effectiveness and impact of the various new support systems were evaluated by answering the key questions shown in Figure 2. The program evaluation approach involved a mixed-methods approach for formative and summative assessment. Formative assessment tracked program implementation and facilitated timely feedback to the project team to assure continuous project improvement. This evaluation component assessed student participants' learning by measuring changes in their STEM learning based on pre/post assessments, course grades, and the degree to which students reported a continuing interest in STEM fields of study. Questionnaires and collected artifacts were used to determine if targeted STEM faculty demonstrated use of best practices relevant to program components. The impact of the project upon the university was a long-term goal that is assessed by the impact upon current faculty and in the future, by enacting policies that reward and encourage faculty to continue using learningcentered instructional practices. This is a distinct component of the impact on increased learning and success for Hispanic, African American, and female students in STEM courses. Given the project's

core goals of supporting student persistence and completion rates, we have used a longitudinal database for tracking participating students and a survival analysis statistical method to analyze rates of student persistence/ attrition among project participants. Survival analysis is a powerful statistical tool for tracking timedependent variables; therefore, this analysis was used to determine hazard functions to evaluate the relationship of explanatory variables to survival time.

\section{Participant Population}

The student population who are considered as participants in our team's various strategic interventions varied in number from 2014-2018. We agreed to define STEM majors as students in five specific majors: chemistry, computer science, engineering, engineering technology, mathematics and physics. Students in these majors were targeted as participants in specific intervention programs, and data for these groups as a whole were examined year-to-year. The Strategy 2 efforts involved 251 students beginning Fall 2015 to Fall 2018. Analysis of students' surveys administered during the entire period for some of the interventions permitted us to conclude that Viz Stars training, spatial visual thinking skills (SVS) embedded training in special sections of the freshman introductory course (US 1100) and summer orientations, not only increased career awareness but also grew students' confidence and expectations of success. This is particularly noteworthy since for some student populations, confidence and expectations of success are not at the highest level when coming in to the student freshman orientations. 
Results and Impact

The following overall results are supported by the data collected over the tenure of the project.

\begin{tabular}{|c|c|c|c|}
\hline \multicolumn{3}{|c|}{ Identified Gaps at Target University } & \multirow{2}{*}{$\begin{array}{c}\text { Goals } \\
5 \text { and } 6 \text { year } \\
\text { Metrics (\%) } \\
\text { 2017/18 Data }\end{array}$} \\
\hline & $\begin{array}{l}\text { All STEM } \\
\text { Students } \\
2012 \text { Data }\end{array}$ & $\begin{array}{c}\text { 5-year Goal (\%) } \\
\text { Target Goal }\end{array}$ & \\
\hline $\begin{array}{l}\text { Gap 1: Hispan- } \\
\text { ic and African } \\
\text { American } \\
\text { students not } \\
\text { proportionate- } \\
\text { ly represented } \\
\text { in STEM majors }\end{array}$ & $\begin{array}{l}\mathbf{3 1 . 9 \%} \text { of STEM } \\
\text { majors are His- } \\
\text { panic or African } \\
\text { American. }\end{array}$ & $\begin{array}{l}\text { Increase the } \\
\text { percentage of } \\
\text { Hispanic and } \\
\text { African Amer- } \\
\text { ican students } \\
\text { choosing STEM } \\
\text { majors to reach } \\
\text { a target of } \mathbf{3 4 \%} \\
\text { representation. }\end{array}$ & $\begin{array}{l}\text { 2017: 44.3\% of } \\
\text { STEM majors are } \\
\text { Hispanic or Afri- } \\
\text { can American. } \\
\text { 2018: } 46 \% \text { of } \\
\text { STEM majors are } \\
\text { Hispanic or Afri- } \\
\text { can American. }\end{array}$ \\
\hline $\begin{array}{l}\text { Gap 2: STEM } \\
\text { majors not } \\
\text { proportionate- } \\
\text { ly retained in } \\
\text { their chosen } \\
\text { field of study }\end{array}$ & $\begin{array}{l}\text { 2012-2014: } \\
62.7 \% \text { of 2nd- } \\
\text { year STEM } \\
\text { majors are } \\
\text { retained in their } \\
\text { chosen field of } \\
\text { study. }\end{array}$ & $\begin{array}{l}\text { Increase the } \\
2 \text { nd-year } \\
\text { retention rate } \\
\text { of STEM majors } \\
\text { to reach a } \\
\text { target of } 67 \% \\
\text { retention. }\end{array}$ & $\begin{array}{l}\text { 2015-2017: } \\
66.3 \% \text { of } 2 \text { nd- } \\
\text { year STEM ma- } \\
\text { jors are retained } \\
\text { in their chosen } \\
\text { field of study. }\end{array}$ \\
\hline $\begin{array}{l}\text { Gap 3: Hispan- } \\
\text { ic and African } \\
\text { American stu- } \\
\text { dents do not } \\
\text { graduate at the } \\
\text { same levels } \\
\text { as majority } \\
\text { students in } \\
\text { STEM }\end{array}$ & $\begin{array}{l}\mathbf{2 7 . 7 \%} \text { of STEM } \\
\text { bachelor degree } \\
\text { graduates are } \\
\text { Hispanic or Afri- } \\
\text { can American. }\end{array}$ & $\begin{array}{l}\text { Increase the \% } \\
\text { of Hispanic and } \\
\text { African Ameri- } \\
\text { can graduates } \\
\text { in STEM to } \\
\mathbf{3 4 \% .}\end{array}$ & $\begin{array}{l}\text { 2017: } 35 \% \text { of } \\
\text { STEM majors are } \\
\text { Hispanic or Afri- } \\
\text { can American. } \\
\text { 2018: } \mathbf{3 7 . 6 \%} \text { of } \\
\text { STEM majors are } \\
\text { Hispanic or Afri- } \\
\text { can American. }\end{array}$ \\
\hline $\begin{array}{l}\text { Gap 4: Female } \\
\text { students not } \\
\text { proportionate- } \\
\text { ly represented } \\
\text { in STEM majors }\end{array}$ & $\begin{array}{l}\mathbf{2 2 . 6 \%} \text { of STEM } \\
\text { majors are } \\
\text { female. }\end{array}$ & $\begin{array}{l}\text { Increase the } \\
\text { percentage } \\
\text { of female } \\
\text { students } \\
\text { graduating in } \\
\text { STEM to reach } \\
\text { a target of } \mathbf{2 5 \%} \\
\text { representation. }\end{array}$ & $\begin{array}{l}\text { 2017: } \mathbf{2 6 \%} \text { of } \\
\text { STEM majors are } \\
\text { female. } \\
\text { 2018: } \mathbf{2 5 . 2 \%} \text { of } \\
\text { STEM majors are } \\
\text { female. }\end{array}$ \\
\hline
\end{tabular}

Figure 2. Identified STEM majors' goals compared to 2018 student data. This figure illustrates the identified reductions in gaps based student representation, success, or retention data at the target university.

\section{Discussion}

\section{Impact of Strategy 1: Redesigning Courses and} Improving Instruction

The second-year retention rates for students in computer science courses exhibited a slight improvement as shown in Table 1 below.

Table 1

2nd-year retention rates of STEM students in CS

\begin{tabular}{lccc}
\hline & $\begin{array}{c}\text { Started Fall } \\
2012\end{array}$ & $\begin{array}{c}\text { Started Fall } \\
2015\end{array}$ & $\begin{array}{c}\% \text { change } \\
\text { 2012 vs 2015 }\end{array}$ \\
\hline $\begin{array}{l}\text { Hispanic and African } \\
\text { American }\end{array}$ & $64.30 \%$ & $67.70 \%$ & $3.40 \%$ \\
\hline All ethnicities & $65.50 \%$ & $69.50 \%$ & $4.00 \%$ \\
\hline
\end{tabular}

The retention rates increased by $3.4 \%$ for Hispanic and African American students and by $4 \%$ for students of all ethnicities. Thus, it is not clear if the introductory course modules that illustrate how computer science is relevant to their lives had any specific impact.
Impact of Strategy 2: Motivating Career Exploration and Visual Spatial Skill Development

Pre- and post-surveys were administered using the Revised Purdue Spatial Visualization Test (Guay, 1976). The survey evaluated the students' changes in self-efficacy by examining confidence, motivation, anticipation of success, and anxiety. The pre-surveys were administered as part of the semester's design project and the post-surveys were administered on the last class day. All of the increases in the post survey ratings were statistically significant. The positive results from the survey included: an increase of 20 (out of 100 points) both in average student confidence in engineering design abilities and in average student anticipation of success in conducting engineering design; gains in average student motivation to conduct engineering design; and lower post-test average of student anxiety in conducting engineering design. Despite the effectiveness of the infusion of engineering elements into the US 1100 course, the seminar format posed a number of constraints, including the number of students that could be served by the course (20 per section). During the year, we worked with the College of Science and Engineering to help establish a new Introduction to Engineering course that incorporates the core elements from the content and activities developed for the US 1100 course as well as additional elements to further enhance the course. The Introduction to Engineering course was offered and funded by the College of Science and Engineering and highlights a successful institutional implementation of this initiative.

\section{Impact of Strategy 3: Meaningful Student Engagement Experiences}

Strategy 3 included various social activities designed to bring students together to network, learn about resources, and have fun. Pre and post surveys were administered to evaluate students' changes in self-efficacy by examining confidence, motivation, anxiety and anticipation of success. The pre-surveys were administered as part of the semester's design project and the post-surveys were administered on the last class day. All of the increases in the post survey ratings were statistically significant. The positive results from the survey included: an increase of 20 (out of 100 points) both in average student confidence in engineering design abilities and in average student anticipation of success in conducting engineering design; gains in average student motivation to conduct engineering design; and lower post-test average of student anxiety in conducting engineering design. Despite the effectiveness of the infusion of engineering elements into US 1100 course, the seminar format posed a number of constraints, including the number of students who could be served by the course ( 20 per section). 
The revised summer internship required students to dedicate approximately 400 hours of effort during the 10-week internship period. This intensity provided an in-depth experience for the participating students. During the first week, the supervisor made a preliminary evaluation, followed by a midterm evaluation at five weeks, and the final evaluations at 10 weeks. The industry supervisor rated the students on each of the following attributes: critical thinking and problem solving, ability to learn, taking initiative and ability to engage in selfdirected professional development, interpersonal skills, team working skills, ability to work well in a diverse environment (culture, gender, age, etc.), oral and written communication, professional skills, good work habits, sound ethics and integrity, timeliness, time management, knowledge of contemporary issues, and understanding of the societal impacts of technical solutions. The evaluations were also used to offer recommendations for improvements to the program.

During the previous year, an analysis of the data from the industry supervisors' evaluations indicated that the new internship program was perceived to be working well and did not identify any major issues requiring corrective action. The evaluation form used a Likert scale in which a rating of 4 indicates "Sometimes exceeds expectations, "and a rating of 5 indicates, "Exceeds expectations." In order to encourage a deeper critical analysis of student performance by the supervisors, the evaluation forms underwent a major revision. The review of the comments made by supervisors continue to indicate a positive view of the new internships' program provide more specific information to improve interns' performance during their academic program.

\section{Impact of Strategy 4: Enact Instructional Approaches}

The Physics Learning Assistant Program has grown to include between 30 and 40 participating student LAs. Between $25 \%$ and $39 \%$ of LA participants have been women; between $24 \%$ and $32 \%$ have been Hispanic; and between $5 \%$ and $12 \%$ have been African American. Instructors met with LA members and indicated the challenges of coordinating the course schedule with the LAs personal schedule of classes and suggested that it would be helpful for the LAs and instructors to meet before the semester to coordinate the schedules and to also enable instructors new to the LA program to plan more effectively how to integrate the LAs into their class sessions. The present program provides for meetings during the semester between the LAs and all the faculty who teach the courses in that department to discuss problems and to identify ways that the department can more effectively use the LAs to address those problems. The LAs interviewed suggested that it might also be helpful to increase the frequency of meetings between LAs to more quickly respond to observed student learning challenges. In addition, a study led by one of the collaborative lead investigators examined the process of transformation that occurs through participation in the LA program. The focus of the study was on understanding what happens during the LA experience that leads to the positive outcomes observed in other studies. The data for the study were gathered from multiple sources including video recorded interviews, teaching reflections and program applications. The following themes and elements emerged from the data:

Students negotiate their learning experiences and recognize personal gains.

- LA students find helping other students to be rewarding.

- LA students can shape other students' ways of learning and interacting.

- The act of helping students and the experience of participating in the LA program strengthens the LA's own understanding of physics concepts.

- Serving as an LA strengthens the LA's relationships with peers and faculty.

Students become members of new communities and gain confidence.

- LAs become more competent and confident in physics.

- LAs feel like part of a supportive and collaborative community.

- Being an LA increases teaching competence and reshapes LAs' concepts of good teaching.

- Participation in the LA program changes ways of learning and of being a student.

Consistent with previous years, the incorporation of the Supplementary Instruction and LA programs continues to provide evidence of the impact of these initiatives in reducing the number of students who withdraw from courses or receive a grade of D or $F$. Of particular note are the results from the 
calculus-based introductory physics sequence in which the LA program was integrated beginning the Spring 2012 into one section of introductory calculus-based mechanics course ("mechanics"). The program was subsequently expanded to serve all sections of mechanics in Fall 2012, and over the following three semesters expanded to serve all sections of all three courses in the calculus-based introductory sequence.

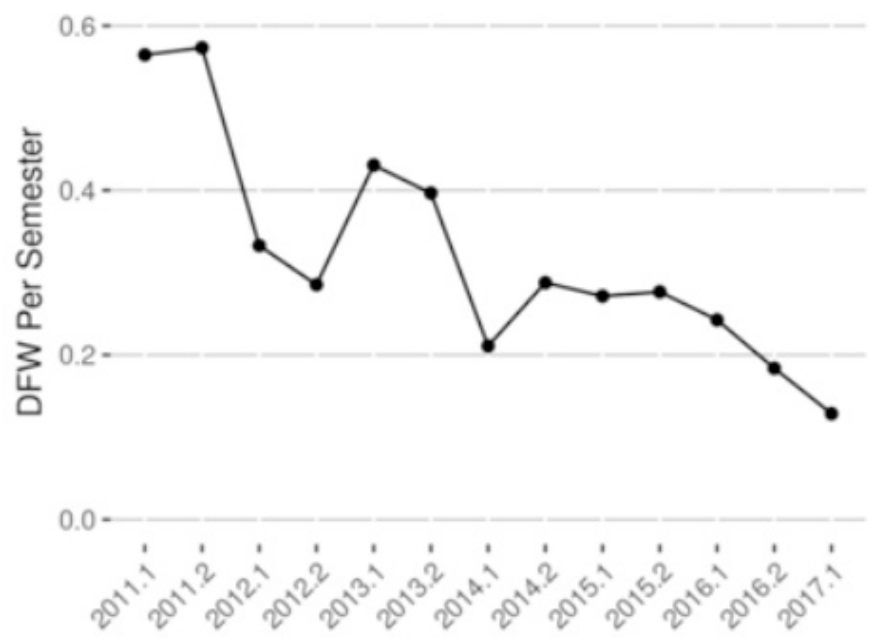

Figure 3. DFW rate (fraction of students who withdrew from course or receive grade of $D$ or $F$ ) by semester shows increased student success after course reforms implemented in Spring 2012 (labeled 2012.1).

As can be seen in Figure 3 (above), there is a clear improvement trend demonstrating a decrease in the fraction of students who withdrew from one of these courses or received a grade of $D$ or $F$, as compared over semesters after course reforms implemented in Spring 2012 (labeled 2012.1). It is clear that both the SI and LA components of the Rising Stars Collective Impact have had a major impact on the retention of students in chemistry, math and science introductory courses. It is also a positive finding that the $\mathrm{SI}$ program has been institutionalized by the university through financial support by the Office of the Provost. The study also points to the positive impact of the LA experience in the students' personal learning trajectory and for the potential to increase interest in science as well as sense of identity and membership in the science community.

\section{Limitations}

The manner in which this case study is structured, involving thousands of students over five years, leads to a great quantity of data that challenges easy analysis. Furthermore, since the groups of students who participate in various events change from year to year, there is limited data from the same students across the many interventions. This collective impact study focuses on the overall impacts of interventions over a long period of time (five years). This means that the naturally occurring demographic changes of the student body at the target university are also included, thereby masking or exaggerating the impacts of the interventions on their own. In future analyses, a smaller cohort can be specifically followed and documented closely to provide an even richer description of student motivation, an explanation of the effects of unique interventions, as well as, collective efforts.

\section{Conclusion and Future Study}

The data-driven results presented related to each of the above activities provide strong evidence of the positive trajectory of the collective impact project toward achieving its goals. To recap, the Rising Stars Collective Impact project components such as the SI and LA programs have positively impacted the retention of students in science and engineering courses. Specifically, the representation of Hispanics and African Americans has increased during the past five years. Since the inception of the Rising Stars Collective Impact project, the number of Hispanic students earning a bachelor's degree has more than doubled from 85 to 229. This is also true for African Americans students in which 16 completed their bachelor's degree in 2012 compared to 60 in 2018.

At present, $48 \%$ of STEM majors are Hispanic and African American. This represents an increase of $15 \%$ from the base numbers of the project of $33 \%$. Although there may be a number of factors contributing to this increase, the student survey and interview data support the view that the Rising Stars Collective Impact project initiatives for first year students, such as the New Student Orientations, STEM New Student Orientation Day, and the new introductory course for Engineering and Engineering Technology have contributed to the increases in enrollment. The number of female students completing undergraduate STEM degrees has increased from 23 in 2012 to 60 in 2018. This represents a greater than $250 \%$ increase. In 2018, $25.2 \%$ of STEM majors are females, representing an increase of $2.5 \%$ from the base numbers for this project of $22.6 \%$.

This project has operationalized a collective impact vision while employing a robust theory of change framework. To realize the large-scale, systemic change, the cultivation and nurturing of effective cross-sector partnerships has been critical to the success and well-being of the initiative. 


\section{References}

Committee on Equal Opportunities in Science and Engineering (CEOSE). (2014). Broadening participation in American's STEM workforce, 2013-2014 biennial report to Congress. Arlington, VA: National Science Foundation. Retrieved from https://www.nsf.gov/od/oia/activities/ ceose/documents/2013-2014\%20CEOSE\%20 Biennial\%20Report\%20to\%20Congress_ Final\%20Version_09-08-2015.pdf

Committee on Equal Opportunities in Science and Engineering (CEOSE). (2013). 2011-2012 biennial report to Congress: Broadening participation in America's STEM workforce. Arlington, VA. Retrieved from https://www.nsf.gov/od/oia/ activities/ceose/reports.Full_2011-2012 CEOSE_Report_to_Congress_Final_03-04-2014. pdf

Committee on STEM Education (COSTEM) of the National Science \& Technology Council. (2018). Charting a course for success: America's strategy for STEM education. Washington, D.C. Retrieved from https://www.whitehouse.gov/wp-content/ uploads/2018/12/STEM-Education-StrategicPlan-2018.pdf

Guajardo, M. A., Guajardo, F. J., Janson, C., \& Militello, M. (2015). Reframing community partnerships in education: Uniting the power of place and wisdom of people. New York, NY: Routledge.

Guay, R., Purdue Research Foundation, \& Educational Testing Service. (1976). Purdue spatial visualization test. West Layfette, IN: Purdue University.

Heldenfels IV, F., Hahn, H., Golden, D., Bridges, R., Agrawal, D., \& Jenkins, R., (2013). 2013 Texas public higher education almanac. Austin, TX: Texas Higher Education Coordinating Board.

Hodges, R., \& White, W. G. (2001). Encouraging high-risk student participation in tutoring and supplemental instruction. Journal of Developmental Education, 24(3), 2-4,6,8,10,43.

Jackson, J., \& Kurlaender, M. (2014). College readiness and college completion at broad access four-year institutions. American Behavioral Scientist, 58(8), 947-971.

Kania, J., \& Kramer, M. (2011). Collective impact, Stanford Social Innovation Review. (Winter, 2011. pp. 3641). Retrieved from http://www.ssireview.org/ articles/entry/collective impact

Kania, J., \& Kramer, M. (2013). Embracing emergence: how collective impact addresses complexity, Stanford Social Innovation Review. (Winter, 2013. pp. 1-14). Retrieved from: https://ssir. org/articles/entry/social_progress_through_ collective_impact\#
Malcom, S., \& Feder, M. (Eds.). (2016). Barriers and opportunities for 2-Year and 4-Year STEM degrees, systemic change to support students' diverse pathways. National Academies Press. Washington, DC. doi: 10:17226/21739

Meadows, D. H., \& Wright, D. (2008). Thinking in systems: A primer. White River Junction, VT: Chelsea Green.

National Academies of Sciences, Engineering, and Medicine. (2011). Expanding underrepresented minority participation: America's science and technology talent at the crossroads. National Academies Press. Washington, DC.

National Science Foundation \& National Center for Science and Engineering Statistics. (2013). Women, minorities, and persons with disabilities in science and engineering, Arlington, VA.

Ortiz, A. M., \& Sriraman, V. (2015). Exploring faculty insights into why undergraduate college students leave STEM fields of study: A three-part organizational self-study. American Journal of Engineering Education, 6(1), 43-60.

Page, S. E. (2007). The difference: How the power of diversity creates better groups, firms, schools and societies. Princeton, NJ: Princeton University Press.

Rodríguez Amaya, L., Guirguis, M., \& Marquez, J. (2019). Computer science is more than just programming: An early intervention to combat undergraduate student misconceptions. Computer Science Education. In W. Swail, K. Redd, \& L. Perna, (2003). Retaining minority students in higher education. An ASHEERIC reader. San Francisco, CA: Jossey-Bass.

Swail, S. W., Redd, E. K., \& Perna, W. L. (Eds.). (2003). Retaining minority students in higher education (ASHE-ERIC Higher Education Report). San Francisco, CA: Wiley Publishers.

Texas State University (2013). University strategic goals. Retrieved from https://lbj-stem.education. txstate.edu/About-Us/Goals.html

Tinto, V. (1993). Leaving college: Rethinking the causes and cures of student attrition (2nd Ed.). Chicago, IL: University of Chicago Press.

Turner, S., Merchant, K., Kania, J., \& Martin, E. (2012). Understanding the value of backbone organizations in collective impact. Part 1. Stanford Social Innovation Review, 25-32. Retrieved from http://www.leveragingourstrengths.ca/reading/ Health_BackboneOrgsCollectivelmpact.pdf

Waitzer, J. M., \& Paul, R. (2011). Scaling social impact: When everybody contributes, everybody wins. Innovations 6(2), 143-155. Retrieved from http:// www.ashokaglobalizer.org/files/INNOVATIONS Mcphedran-waitzer-Paul.pdf

Yin, R. K. (2012). Applications of case study research (3rd ed.). Thousand Oaks, CA., Sage. 


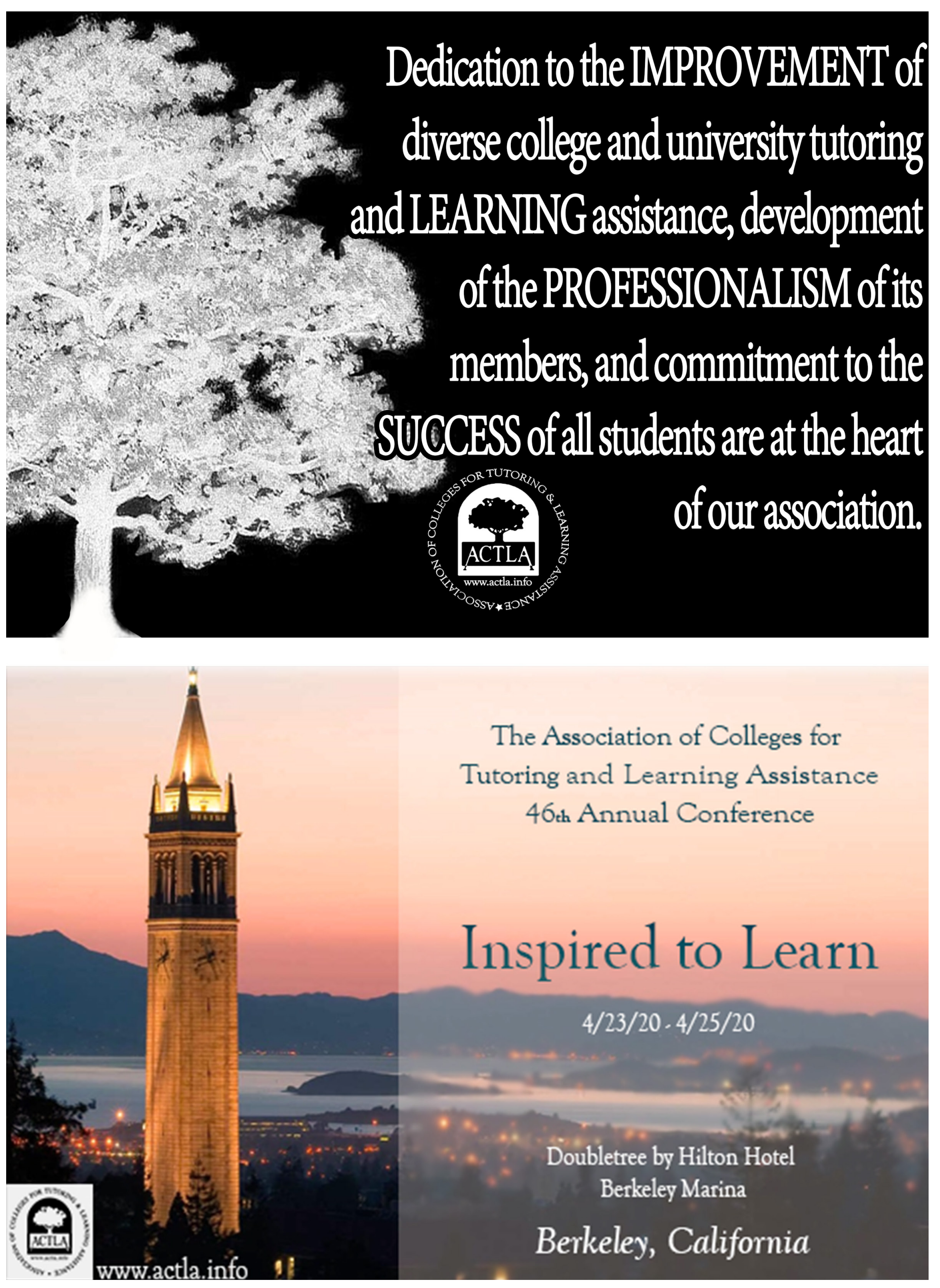




\title{
Recipe for Successful Collaborative
}

\section{Corequisites}

\author{
Mary Orlando, San Jacinto College \\ Karen Hattaway, San Jacinto College
}

\section{ABSTRACT}

This paper describes a corequisite pairing of Integrated Reading and Writing (INRW) and Humanities (HUMA) 1301 taught at San Jacinto College North in Houston, Texas. The authors describe their planning process, which combined course learning outcomes with cognitive theory and best-practice resources for effective teaching. These complementary courses provided students with contextualized learning activities designed to develop critical thinking and communication skills as students focused on cultural history to understand how human communities create monster stories to identify their fears and characterize the heroic figures who come to their rescue. The article includes sample content units and student activities and provides strategic insight into a process of integrating best practices and cognitive psychology with class planning focused on required learning outcomes.

evelopmental education courses in Texas community colleges changed from providing layered developmental education requiring students to complete as many as six courses in reading and writing to a streamlined structure of limited stand-alone courses and a growing number of corequisite courses. In 2015, fewer than $50 \%$ of college-preparatory students completed a transfercredit course within 2 years of their initial enrollment in developmental programs and by 2019 the record was not better because The Texas Higher Education Coordinating Board (THECB, 2019) reported that "only $44 \%$ to $64 \%$ meet readiness standards within two years, and about $28 \%$ to $41 \%$ go on to complete a college-level course" (p. 16). In response to those results, the Texas Legislature passed House Bill 2223 in 2017. This legislation significantly reshaped Texas college-preparatory education by setting required timelines for changes in course design.

Rather than thinking of college-preparatory courses as stand-alone components of an instructional program separate from degree-bearing programs, Texas educators re-imagined developmental courses as corequisites to transfer-credit classes. First, HB 2223 reduced stand-alone developmental education sources offered. The plan required that $25 \%$ of developmental students be enrolled in a corequisite model in Spring 2018, in Fall 2019 50\% would be enrolled in the new course organization, and $75 \%$ in Fall 2020 (THECB, 2018). Texas community-college leaders and faculty developed several options to increase student enrollment in credit-bearing courses. One option combines a shortened version of a developmental course added to a credit bearing course. This NonCourse Based Option (NCBO) generally provides justin-time instruction to fill in gaps of knowledge and skills that limit student progress in the credit-bearing course. Adding 1 or 2 hours of instruction to each week's class schedule, NCBOs extend a traditional course like English Composition I to include tutorial experiences designed to address weaknesses in student writing and reading skills.

Current research supports pairing integrated reading and writing (INRW) with English to enhance students' progress. Kuehner and Hurley (2019) conducted a 2-year study in which they measured developmental education students' success in their accelerated IRW and English courses during the Fall and Spring semesters of 2014 and 2015. Kuehner and Hurley determined that more students completed English Composition I in the accelerated program than students in traditional developmental courses and earned higher GPAs. However, INRW can be successful if paired with other college-level courses. The purpose of this paper is to discuss an alternative option in which college preparatory students simultaneously enroll in an INRW course and a credit Humanities (HUMA) course as an alternative to the traditional English composition (COMP) credit bearing course. This academic strategy provides students legitimate instruction in basic skills of reading, writing, and critical thinking and expedites student progress through the credit curriculum. The paper focuses on our initial planning, course delivery, and results in our INRW/HUMA course pairings. 


\section{Initial Planning}

We began by making assumptions about developmental courses and students who are assigned to developmental reading and writing based on our prior teaching experiences, our knowledge of course design and successful instructional practices grounded in research.

\section{Assumptions About Developmental Courses and Students}

The central innovation of our plan was to value the contributions the original design of INRW. We agreed that, while state legislation addressed a serious issue in the progress of students through a complex developmental curriculum, the legislators missed the intrinsic value of developmental education and the importance of this component of Texas higher education to establishing broad-based, easily expanded, and effective programs ensuring that students who are disadvantaged have genuine access and equity to higher education. We agreed that, on the one hand simplifying the process of developmental education was important so that the curriculum itself facilitated rather than blocked student progress toward graduation. At the same time, we also recognized that some developmental students come to college with significant gaps in their cultural background that often limit their academic success. Without some contextual information connecting history and culture, students have no schema to help them organize information from core courses.

\section{Assumptions About Course Design}

Rather than considering the INRW course as a tutorial for the HUMA students, our design focused on realizing the objectives of both courses. We based our assumption on Stanny's (2016) understanding of the purpose of learning outcomes: "The most explicit goal [of student learning objectives (SLOs)] is to describe the unique knowledge, skills, and abilities students acquire as they complete courses and degree programs. Two less explicit goals are to support the design of curriculum and align learning goals with learning activities and assessments" (p. 1). We organized our planning into two phases: analyzing learning outcomes and emphasizing structured learning.

Managing learning outcomes. The first phase of our planning was to analyze state mandated SLO's for both course in order to establish a common ground on which to begin developing both courses. The INRW 0301 and 0302 courses address the same ten SLOs, and the HUMA 1301 course addresses five
SLOs as well as four general education outcomes that emphasize critical thinking and communication skills in order to support the habits of mind that enable students to become life-long learners who contribute to society. We developed a plan emphasizing SLO's and integrated the general education outcomes in learning events and assignments that encouraged students to behave as developing learners. We organized the SLOs for both courses so that the complementary connection between the courses was clear so that students could understand how one course supported the other. Figure 1 shows the SLOs for both courses and the complementary connections we developed to link them.

\section{Emphasizing learning taxonomies.}

Recognizing the importance of providing developmental students with opportunities to understand their own learning processes, we agreed to emphasize more than one learning taxonomy. Thus, our combined courses would provide students with many strategies by which they could become self-sufficient learners. We recognized that developing the learning outcomes required also that we consider the learning processes required for success in each course. While course SLOs provide goals for instruction, they do not describe the learning processes required to achieve the goals. When considered as one learning experience, the two courses emphasized both Bloom's (1956) and Marzano and Kendall's (2008) taxonomies of learning.

We recognized that many of the INRW SLOs reflected the Bloom's (1956) taxonomy of levels of understanding in the verbs that were components of the course objectives: understanding, comprehending, analyzing, evaluating, and creating (as cited in Stanny, 2016). On the other hand, the HUMA 1301 SLOs centered on students' gaining an in-depth understanding of a variety of texts and learning how these texts reflected their times. Thus, learning in the HUMA course emphasized Marzano and Kendall's (2008) thinking that students become self-aware learners by retrieving information, identifying patterns in this information, and then using this knowledge to create new ideas. Our understanding was influenced by Stanny's observation that "Introductory courses might include SLOs that describe higher-order thinking skills because these courses create opportunities for students to develop and practice skills expected at more advanced levels" (p. 9). The INRW and HUMA SLOs illustrate this connection (see Figure 1). 


\begin{tabular}{|c|c|c|}
\hline INRW SLO's & HUMA 1301 SLO’s & $\begin{array}{l}\text { Complementary Connection in "Monster" } \\
\text { Course }\end{array}$ \\
\hline $\begin{array}{l}\text { - Locate explicit textual information, draw complex } \\
\text { inferences, and describe, analyze, and evaluate } \\
\text { the information within and across multiple texts of } \\
\text { varying lengths. } \\
\text { - Comprehend and use vocabulary effectively in oral } \\
\text { communication, reading, and writing. } \\
\text { - Identify and analyze the audience, purpose, and } \\
\text { message across a variety of texts. } \\
\text { - Describe and apply insights gained from reading and } \\
\text { writing a variety of texts. } \\
\text { - Compose a variety of texts that demonstrate reading } \\
\text { comprehension, clear focus, logical development } \\
\text { of ideas, and use of appropriate language that } \\
\text { advance the writer's purpose. } \\
\text { - Determine and use effective approaches and } \\
\text { rhetorical strategies for given reading and } \\
\text { writing situations. } \\
\text { - Generate ideas and gather information relevant } \\
\text { to the topic and purpose, incorporating the } \\
\text { ideas and words of other writers in student } \\
\text { writing using established strategies. } \\
\text { - Evaluate relevance and quality of ideas and } \\
\text { information in recognizing, formulating, and } \\
\text { developing a claim. } \\
\text { - Develop and use effective reading and revision } \\
\text { strategies to strengthen the writer's ability to } \\
\text { compose college-level writing assignments. } \\
\text { English in reading and writing. }\end{array}$ & $\begin{array}{l}\text { - Demonstrate awareness of the scope and variety of } \\
\text { works in the arts and humanities. } \\
\text { - Articulate how these works express the values of the } \\
\text { individual and society within an historical and social } \\
\text { context. } \\
\text { - Articulate an informed personal response and critically } \\
\text { analyze works in the arts and humanities. } \\
\text { - Demonstrate knowledge and understanding of the } \\
\text { influence of literature, philosophy, and the arts on } \\
\text { cultural experiences. } \\
\text { - Articulate an informed personal response } \\
\text { and critically analyze works in the arts and } \\
\text { humanities. } \\
\text { - Demonstrate an awareness of the creative } \\
\text { process and why humans create. }\end{array}$ & 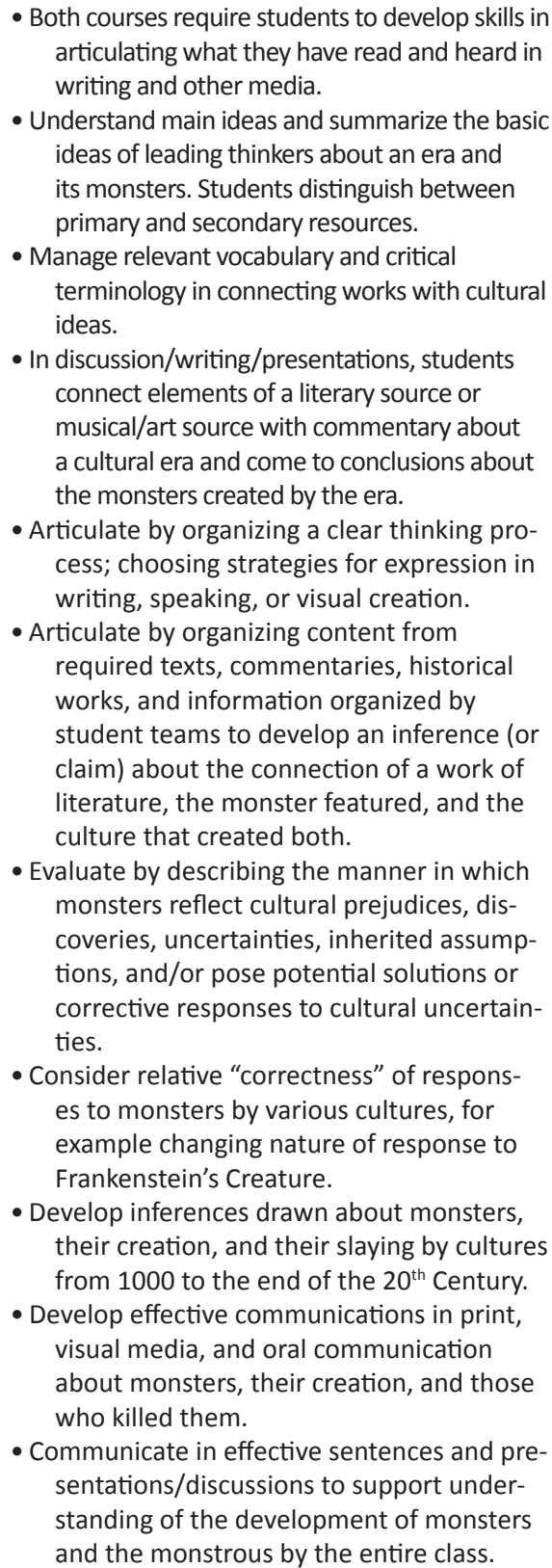 \\
\hline
\end{tabular}

Figure 1. Developing Composite Learning Outcomes

Course content design. We developed consistent commonalities and themes that allowed students to make deep connections between their INRW/ HUMA courses. Cho and Trent (2005) recommended that instructors "lend themselves to inquiring into the ways understanding is thoroughly unearthed in each subject area" (p. 111). We created complementary course units to teach similar concepts using different course material; Figure 2 provides information about sample course content units and illustrates the complementary nature of the two learning experiences for our students. While the overarching course units were the same, the skills addressed in each unit differed in the INRW/HUMA courses. For example, in the HUMA course, students discussed and analyzed Shelley's Frankenstein novel that illustrates the cultural fears of the transition from Romantic to Victorian thinking. In the INRW course, students discussed and analyzed cultural values and Gothic literature elements in Walpole's Castle of Otranto. 


\begin{tabular}{|c|c|c|c|}
\hline Focus & HUMA 1301 & INRW 0301 & INRW 0302 \\
\hline $\begin{array}{l}\text { Overview of } \\
\text { discussion of } \\
\text { cultures }\end{array}$ & Texas Culture & American Culture & $\begin{array}{l}\text { American Cul- } \\
\text { ture }\end{array}$ \\
\hline Anglo-Saxon & $\begin{array}{l}\text { - Grendel \& } \\
\text { Beowulf } \\
\text { - The Thirteenth } \\
\text { Warrior (1990 } \\
\text { film) }\end{array}$ & $\begin{array}{l}\text { - The Wife's Lament } \\
\text { (two versions) }\end{array}$ & $\begin{array}{l}\text { - The Seafarer } \\
\text { - The Wanderer }\end{array}$ \\
\hline $\begin{array}{l}\text { The Hairy } \\
\text { Beasts }\end{array}$ & $\begin{array}{l}\text { - Little Red Rid- } \\
\text { ing Hood (The } \\
\text { Brothers Grimm } \\
\text { \& Perrault } \\
\text { versions) } \\
\text { - The Three } \\
\text { Little Pigs } \\
\text { - B'rer Rabbit \& } \\
\text { B'rer Fox } \\
\text { - The Tale of } \\
\text { Jemima Puddle } \\
\text { Duck (Potter) }\end{array}$ & $\begin{array}{l}\text { - Lon Po Po } \\
\text { (Young, trans.) } \\
\text { - The True Story } \\
\text { of the Three Little } \\
\text { Pigs (Scieszka) } \\
\text { - Cinderella (The } \\
\text { Brothers Grimm \& } \\
\text { Perrault versions) }\end{array}$ & $\begin{array}{l}\text { - Little Red Cap } \\
\text { (Duffy) } \\
\text { - Lon Po Po } \\
\text { (Young, trans.) } \\
\text { - The True Story } \\
\text { of the Three Little } \\
\text { Pigs (Sciesza) } \\
\text { - Cinderella (The } \\
\text { Brothers Grimm \& } \\
\text { Perrault versions) }\end{array}$ \\
\hline $\begin{array}{l}\text { Gothic } \\
\text { Literature }\end{array}$ & $\begin{array}{l}\text { The undead } \\
\text { - Frankenstein } \\
\text { (Shelley) } \\
\text { - Frankenstein } \\
\text { (1930 film) } \\
\text { - Dracula } \\
\text { (Stoker) }\end{array}$ & $\begin{array}{l}\text { - The Castle of } \\
\text { Otranto (Walpole) }\end{array}$ & $\begin{array}{l}\text { - The Castle of } \\
\text { Otranto (Walpole) }\end{array}$ \\
\hline
\end{tabular}

Figure 2. Course Units

Our parallel units provided an opportunity to explore broad common concepts. In the INRW course, students learned about universal themes and analyzed Anglo-Saxon poems for these themes. In the HUMA courses, the students studied Beowulf while analyzing how Anglo-Saxons understood threats to their survival embodied in Grendel. In both classes, students analyzed and discussed how these themes still apply to today's society, but in different shapes. Additionally, students in the HUMA course analyzed a 1990's reinterpretation of Beowulf in the film The Thirteenth Warrior. Thus, multiple lenses provided students with a rich understanding of each theme and allowed us the flexibility to 'unearth' any content that naturally developed during their courses as we developed each unit. The two courses extended content to provide students with additional learning experiences to push beyond their existing knowledge to gain practice (and thus confidence) in creating new perspectives about their learning.

\section{Teaching Practice}

As we developed course content units and learning activities, we considered Perkins's (2009) idea that learning is the development of complex skills by practicing foundational skills. Perkins argued that understanding the "small games" or component skills within the "big game" of the course and its general outcomes enables instructors to create scaffolded learning experiences that emphasize basic skills in the development of broader critical-thinking capacities. In Making Learning Whole: How Seven Principles of
Teaching Can Transform Education (2009), Perkins argued that scaffolded experiences support student motivation to continue with the "big game" of the entire course. Instructors enable students to go beyond the "disorientation" of a new learning experience when they provide students with "some version of the whole game close to the beginning" (p. 9). This strategy supports Marzano and Kendall's idea that students' self-efficacy and motivation grow when they recognize that they can master a task and that the task is worth doing (p. 148-149). The recursive nature of the HUMA/ INRW courses provides an ideal setting for student mastery. Our courses began with the "small game" or component skills for understanding culture, focusing on local monsters in HUMA and on American culture in INRW, and developing to consider broader themes.

Part of our planning also included a review of best practices in teaching and a review of cognitive theory resources. Piaget (1952) argued that effective learning involves creating patterns. As students connect new experiences and bits of information to these frameworks, they create new knowledge associated with higher expectations for success. As Hepner (1996) suggested students need to see a connection between the course content and their world in order to expand that learning and apply it to a broader perspective. We were also influenced by Rosenblatt's research on the relationship of reading and knowing, particularly her emphasis on Bartlett's (1932) concept of the "'constructive character of remembering" (cited in Rosenblatt, 2005, p. 9). The INRW and HUMA courses construct informational and cultural schema that students do not bring to a college campus. We immersed students in cultural history and interpretation of human experiences. We created learning activities that provided the vocabulary and background necessary for students to talk and write about new information.

\section{Course Delivery}

We taught two sections of the HUMA/INRW corequisite at San Jacinto College North in the Spring 2019 semester. We paid attention to our student audience, both in terms of their academic backgrounds and in terms of the attitudes and experiences they brought into our classes. Our goals were to make connections between their experience and the early monsters we could study so they could establish a frame of reference for the entire term. At the same time, we recognized that students in developmental classes are very aware of the labels attached to them, that they are more ready to stop participating in their courses than students admitted via traditional standards.

\section{Academic Background}

The communities of students in our classes reflected TSI scores established by San Jacinto College 
and the demographics of our college service area. One section connected HUMA 1301 with INRW 0301, and the other connected HUMA 1301 with INRW 0302. Students in the INRW 0301 course scored lower on the TSI than the students in the INRW 0302. Table 1 illustrates the TSI placement cut scores for the Spring 2019 semester at San Jacinto College.

Table 1

TSI Cut Scores Spring 2019

\begin{tabular}{|c|c|c|c|c|}
\hline & $\begin{array}{l}\text { Reading } \\
\text { Score }\end{array}$ & $\begin{array}{c}\text { Reading } \\
\text { Skill }\end{array}$ & Writing Score & Writing Skill \\
\hline $\begin{array}{l}\text { INRW } \\
0301\end{array}$ & $342-346$ & Level 4 & 350-356 (no essay) & Level 4 \\
\hline $\begin{array}{l}\text { INRW } \\
0302\end{array}$ & $347-350$ & Level 6 & 357-362 (no essay) & Level 6 \\
\hline $\begin{array}{l}\text { College } \\
\text { Level }\end{array}$ & $\begin{array}{l}351 \text { or } \\
\text { higher }\end{array}$ & Level 7 & $\begin{array}{c}5 \text { on the essay OR } 4 \\
\text { on the essay \& } 340 \\
\text { or higher on the } \\
\text { multiple choice. }\end{array}$ & $\begin{array}{l}\text { Level } 7 \text { and } \\
\text { college ready in } \\
\text { reading }\end{array}$ \\
\hline
\end{tabular}

Students enrolled in the INRW/HUMA corequisite sections reflected the demographics of the North Campus: $56.3 \%$ female (Campus 58.5\%); 75\% Hispanic (Campus 67\%); and 93.8\% 18-24 years old (Campus 43.9\%). The 24 students were divided evenly into INRW 0301/HUMA and INRW 0302/ HUMA. Four of the students were developmental education students who had failed their INRW course previously. Three of the repeaters failed their previous INRW course because of low attendance and participation, the reason the fourth student failed previously is unknown. Two students enrolled in the course pairings were older than the traditional 18-25 year-old college freshmen.

\section{Student Attitudes and Experience}

Instructors in both courses emphasized deliberate personal development of students. We drew our information from both Marzano and Kendall (2008) and from Perry (1970/1999). Perry's theory of learning identified many beginning college students as novice learners. These students have dualistic beliefs that learning focuses on right or wrong and the challenge to them is to discover what is "right" and then never think beyond what the lecture and content materials offer.

Often, students in developmental classes enter college with a feeling that they are imposters and do not deserve to be there. There are several internal factors that influence students' imposter syndrome. Students fear that their instructors would find out about their inabilities and embarrass them for it; they do not believe in their skills, despite evidence that may illustrate their proficiency; and they doubt their abilities prior to even beginning the assignment or course. External factors such as comparison of their capabilities to others and performance feedback from instructors could further perpetuate or alleviate the imposter feeling (Lane, 2015). Experience helps diminish the students' imposter feelings; the more experience the students received, the more confident they became in their abilities (Lane, 2015). INRW students feel apprehensive about college and truly believe they are imposters since the TSI score has clearly indicated they are not college ready. INRW repeaters have their prior failures as another external factor negatively influencing their self-perception.

With this knowledge, we determined the beginning point for our courses We decided that both INRW/HUMA students should begin by discussing current culture. We could demonstrate the relevance of the course focus to contemporary life and showcase the conversational skills students brought to class with them. This built our students' confidence as they are knowledgeable about current culture and can use this knowledge to build upon throughout the semester. Our first focus was on zombies, emphasizing films and parts of novels and considering the various use of the term "zombie" to identify those whom a overpowering and manipulative culture made into unthinking consumers.

\section{Persistence and Retrieval}

Both instructors encouraged the students to acknowledge their experiences by identifying various elements of culture familiar to them and using these elements of personal schema to expand their thinking. Initial class discussion in the HUMA class, for example, considered the "distracted driver" as someone unable to maintain interest in physically present day-to-day life, choosing rather to "live" in the pixelated world of the Internet. Students in both sections began to construct new frameworks by building on their existing knowledge; in the INRW course, students discussed and analyzed their firsthand experiences in American cultural norms and fears. We discussed the rationale behind these fears, and then we extended the discussion to monsters and the cultural fears these monsters reflect. The students worked towards abstract thinking by connecting their external knowledge and experience to in-class topics and examples. This experience reflects Marzano and Kendall's Designing \& Assessing Educational Objections: Applying the New Taxonomy (2008) as students specified, from their retrieval of information, and then classified the information they gathered to discover generalizations about the monster tales and the people who sustained them. These foundational activities helped establish fundamental groundwork in the courses, as we would circle back to norms, breaking norms, fears, reasons for these fears, and monsters for each unit.

Our plan supports student persistence through active engagement (Pruett \& Absher, 2015). 
To increase active engagement and improve our students' speaking and listening skills, both courses provided students with class discussions, projects, and presentations. In the HUMA class, students practiced whole class discussions with question stems, which allowed students to engage in structured academic conversations and enhance their understanding of the culture depicted in the texts. As Seidlitz and Perryman (2011) explained, "structured conversations ensure that students get an exposure to academic vocabulary and a chance to use new terms in an authentic context" ( $p$. 45). Often, students in developmental education do not know how to articulate their thinking or develop questions to increase their learning. This inability can hinder developmental students in their college pursuit.

Inspired by Marzano and Kendall's (2008), the instructors encouraged the students in both INRW and HUMA courses to be self-aware in their development as thinkers and writers. Students immediately began to use vocabulary appropriate to a study of human culture: values, social systems, class conflicts, as well as the "learning vocabulary" central to the MarzanoKendall Taxonomy, which provide action terms for the processes of learning. The students skills expanded from retrieving information when they "recalled, recognized ideas, and executed" in various activities as they adapted what they remembered about historical events, cultural assumptions, literary genres, and writing and discussion strategies (Marzano \& Kendall, 2008, p. 4). Students "integrated and symbolized" their knowledge through visual representations, reflective writings, inclass presentations.

When studentsin developmental education classes receive difficult texts, they tend to shut down. They begin to focus on gathering a basic understanding of each sentence instead of looking at the text as a whole. "If 'remedial' students are to survive in the world of academy, they cannot do so through lower level drill and practice. They must learn to read analytically..." (Lesley, 2003, p. 84). Humanities is a reading intensive course that requires students to move beyond basic reading comprehension, which can be a challenge for students placed in developmental education. To circumvent this feeling of inadequacy, the INRW instructor taught the students to use their texts to prove their interpretations. Students learned realistic and substantial support in the INRW course, a process that could not occur if the INRW section were seen as providing tutorial experiences only. As Bartholomae and Petrosky (1986) stated, "A 'proof' is what a text offers; it is something a reader finds there. It is also, however, that which a reader brings to the text..." (p. 27). For example, the INRW instructor provided various interpretations of Anglo-Saxon texts to illustrate the importance of proof to support interpretations. The students developed their own understanding and perspective without the fear of having "the right answer and transferred this skill into the HUMA discussion of Beowulf and the Buliwyf character in The Thirteenth Warrior.

\section{Results}

Our assessments led us to develop many points of view. We could observe our students' skills through our college's assessment of core-curriculum outcomes. As is always the case with preliminary research focused on emerging approaches, our analysis of success had limitations, but we developed new ideas about how to strength the next iteration of the course combination in Fall 2019.

\section{Core Curriculum Outcomes}

As a core-curriculum course, San Jacinto College requires curriculum assessment in HUMA1301 in the form of a Signature Assignment that illustrates the students' mastery of content and corecurriculum learning outcomes. HUMA 1301 students are required to develop an artifact that illustrates their individual and creative responses to the content emphasis of the course. For this HUMA 1301, the artifact was the development of The Book of the Monster. This very intensive writing assignment required the students to develop their characters, settings, establish their monsters within a realistic realm of fiction and reflect on their creations.

This assignment extended across both courses to as students could find inspiration from any of the assigned readings or class notes in both their INRW and HUMA courses. The students could find inspiration from real-life "monsters" such as serial killers, or they could create a monster inspired from course readings. The requirement had potential to be a daunting task as INRW students are often not confident in their writing capabilities. Camfield's (2016) research revealed that instructors must develop a relationship with their students as this "positions the instructor as a mediator between what it is the writers want to say and the academic audience with which they communicate" (p. 10) To circumvent students' fears of writing as a 
daunting task, the INRW instructor mediated between the students and their academic audience through scaffold low-stakes writing assignments that build into larger high-stakes writing assignments. In the INRW courses, students brainstormed prior to writing their monster books, created a rough outline of their book, and began to develop their book one chapter at a time. Students peer reviewed their work and revised their chapters prior to compiling their final products. Students also analyzed how their Book of the Monster illustrated a cultural fear of its time. To ensure clear expectations and grading consistency, both instructors collaborated on the various chapter requirements and rubrics. Students finalized their Book of the Monster chapters and combined them together for submission in the HUMA course.

\section{Limitations}

This research centers on only the INRW/HUMA course pairings, which does not allow for generalization across disciplines. We did not begin our corequisite courses with a study of its success in mind, as such; we did not collect essential student data needed to measure overall success of our corequisite courses. The college no longer offers INRW 0301/HUMA 1301 course pairings, so we are only teaching INRW 0302/HUMA 1301 corequisite course in Fall 2019. Student enrollment for Spring 2019 courses was considerably smaller, making the applicability of our results extremely limited. More research is needed in assessing corequisite courses and overall student success. This research is merely a snapshot on a collaborative idea two instructors had. It could benefit from longitudinal analysis of student success in the INRW/HUMA corequisite courses.

\section{Reflection}

The simplest solution to address HB 2223's mandate is to establish many INRW and English corequisite courses but limiting corequisites to English classes pairings is not necessary. Saxon, Martirosyan, and Vick (2016) explained the various struggles corequisite instructors encounter, such as establishing a balance of reading and writing assignments, managing their time for course content, preparing to teach a corequisite course, locating appropriate course materials, and reducing redundancy. While Saxon et. al also noted that paired courses possess unique challenges, such as course sequencing and grading consistency, the benefit of a paired course is that it allows both instructors to collaborate and develop courses that offer an alternative to their traditional course models. Additionally, Hepner's (1996) research in interdisciplinary classes determined that faculty partners worked harder on their paired courses than their traditional courses and their collaboration energized the instructors.

We determined that pairing INRW and HUMA 1301 contextualizes basic-skill development and allows students to expand their cultural awareness through intensive reading, oral discussion, and writing activities.
HUMA courses taught at San Jacinto College address a variety of themes for the specific content of each course section, but all address the SLOs in the course syllabus. The central idea of the HUMA component of our corequisite was that cultures create monster stories to identify threats to the safety of the community. Students in INRW 0301 section showed remarkably stronger persistence and academic success than did those in the INRW 0302 section. The INRW 0301 students exhibited more academic growth (measured by complexity of thinking) than the higher-level INRW 0302 students. There could be various reasons for this, such as more overall attendance, the reward of college credit easier to attain, or the arbitrary TSI cut score for placement in INRW 0301 and 0302. Students in the HUMA/INRW 0301 could articulate abstract connections and developed astute critical thinking skills, while the HUMA/INRW 0302 group struggled in developing abstract connections among cultures and understanding the relationship of monster-slayers to the cultures that produced them. 
References

Bartholomae, D., \& Petrosky, A. (1986). Facts, artifacts, and counterfacts: Theory and method for a reading and writing course. Portsmouth, $\mathrm{NH}$ : Boynton/Cook.

Bloom, B. S. (1956). Taxonomy of educational objections: The classification of educational goals. New York, NY: Longmans, Green.

Camfield, E. K. (2016). Mediated-efficacy: Hope for "helpless" writers. Journal of Developmental Education, 39(3), 2-6.

Cho, J., \& Trent, A. (2005). "Backward" curriculum design and assessment: What goes around comes around, or haven't we seen this before? Taboo: The Journal of Culture and Education, 9(2), 105-122. Retrieved from https://files.eric.ed.gov/fulltext/EJ795704.pdf

Hepner, F. (1996). Interdisciplinary classes. Retrieved from https://files.eric.ed.gov/ fulltext/ED397872.pdf

Lane, J. A. (2015). The imposter phenomenon among emerging adults transitioning into professional life: Developing a grounded theory. Adultspan Journal, 14(2), 114-128. https://doi.org/10.1002/adsp.12009

Lesley, M. (2003). Exploring the links between critical literacy and developmental reading. In N. A. Stahl \& H. Boylan (Eds.), Teaching developmental reading: Historical, theoretical, and practical background readings (pp. 7286). Boston, MA: Bedford/St. Martin's.

Marzano, R. J., \& Kendall, J. (2008). Designing \& assessing educational objectives: Applying the new taxonomy Thousand Oaks, CA: Corwin Press.

Perkins, D. (2009). Making learning whole: How seven principles of teaching can transform education. San Francisco, CA: Jossey-Bass.

Perry, W. G. (1999). Forms of ethical and intellectual development in the college years: $A$ scheme. San Francisco, CA: Jossey Bass.

Pruett, P. S., \& Absher, B. (2015). Factors influencing retention of developmental education students in community colleges. Delta Kappa Gamma Bulletin, 81(4), 32-40.

Rosenblatt, L. (2005). Making meaning with texts. Portsmouth, NH: Heinemann.

Saxon, D. P., Martirosyan, N. M., \& Vick, N. T. (2016). NADE members respond: Best practices and challenges in integrated reading and writing, Part 1. Journal of Developmental Education, 39(2), 32-34.

Seidlitz, J., \& Perryman, B. (2011). Seven steps to a language-rich interactive classroom: Researched based strategies for engaging all students. San Clemente, CA: Canter.
Stanny, C. J. (2016). Reevaluating bloom's taxonomy: What measurable verbs can and cannot say about student learning. Education Sciences, 6(4), 37. https://doi.org/10.3390/ educsci6040037

Texas Higher Education Coordinating Board (2018). Developmental education update and 2018-2023 statewide plan for supporting underpreparedstudents. Retrievedfromhttp:// www.thecb.state.tx.us/reports/PDF/12271. PDF?CFID $=95582277 \&$ CFTOKEN $=84379529$

Texas Higher Education Coordinating Board (2019). Texas public higher education almanac. Retrieved online from http://www.thecb. state.tx.us/almanac 


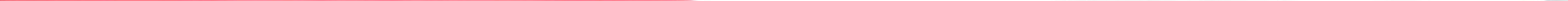




\section{Student-to-Student Support in Developmental Mathematics Courses}

\author{
Randy L. Collins \\ Rosemary M. Karr
}

\section{ABOUT THE AUTHORS}

Randy L. Collins graduated with a M.S. in Applied Mathematics in 2000 from the University of Tennessee Knoxville, and a Ph.D. from the University of Tennessee Knoxville in 2008 with a degree in Teaching and Learning-Mathematics Education. He joined Collin College in 2011, where he soon became the Department Chair of Developmental Mathematics. Currently, he is teaching for the Mathematics Department at Collin College.

Rosemary M. Karr graduated with a B.S. in Mathematics, a Master's from EKU, and a Ph.D. from UNT in 1996. After two years teaching high school mathematics, she joined the faculty at Eastern Kentucky University, earning tenure as Assistant Professor of Mathematics. At Collin College since 1990, she has written solutions manuals and textbooks, presented numerous papers, served on the Board of Editors for the JDE, and served associations including Past President of NADE. Her honors include Outstanding Professor by Collin College and national and state recognitions as U.S. Professor of the Year, Minnie Stevens Piper Professor, Lifetime Achievement Award, and Council of Learning Assistance and Developmental Education Associations Fellow. for a grant. A committee would review each grant request and make recommendations as to whether to approve the funding.

For developmental mathematics (DM), a group of three faculty members got together to brainstorm ways these innovation funds could be used to assist students enrolled in DM courses. The meeting focus was directed to students taking weekend DM courses as part of the Weekend College Program. The colleges' Weekend College Program offers alternative scheduling for those unable to attend college during a traditional time frame, desiring to augment a traditional class schedule, or add classes to their day, evening or online schedules.

During weekdays (Monday to Friday) students have support resources such as the Math Lab available to them. The Math Labs are centers located on all three campuses staffed with faculty, lab instructors, and student tutors to assist students enrolled in developmental and college-level mathematics courses. While the Math Labs are open on Saturdays, those hours are often limited for weekend students. Since the Weekend College is a major emphasis for the college, the grant would help satisfy both an Innovation Grant Challenge and provide a way to promote student success for weekend college students.

In order to help these students, a proposed program coordinator would hire formerly successful students in specific DM courses to serve as in-class tutors. Having tutors that had previously completed the DM course was essential, since the tutor would understand the struggles students have in a DM course. At times in the Math Lab, there has been a disconnect between the tutor and the DM student, where the student felt intimidated or uncertain how to communicate questions. A pilot was developed for weekend Beginning Algebra (MATH 0305) sections. The goal of the grant was to use best practices from SI programs to increase student learning, success, and retention rates in DM courses. The proposal was approved in March 2016.

\section{... a group of three

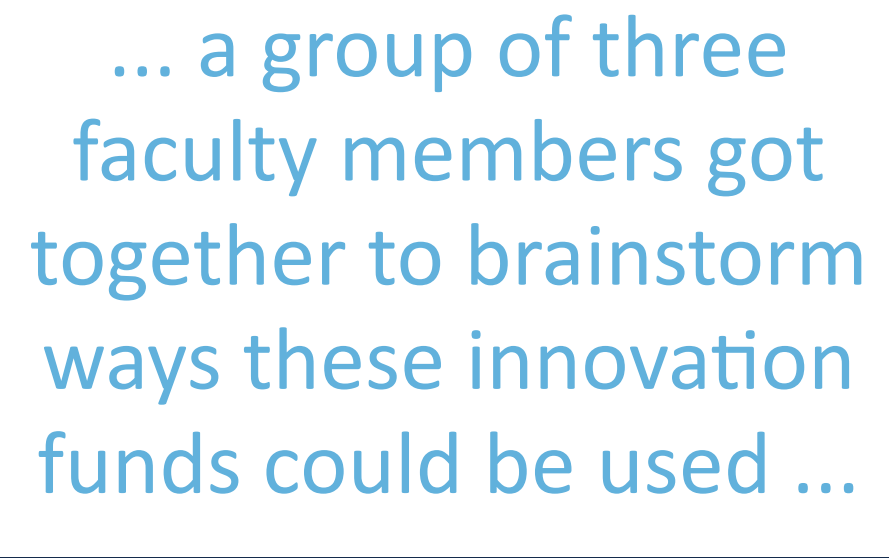
community college district with an enrollment of 55,000 in the Southwest United States were encouraged to apply for Innovation Challenge Grants. The goal of these grants was to allow faculty and staff an opportunity to create, innovate, and share ideas, so that the college could strive to be one of the best organizations by developing an environment for students to learn and grow. The funding of this grant came from the district president allowing $5 \%$ of the budget from each division to be funneled into a pool of money, from which faculty and staff could apply 


\section{Rational}

Supplemental Instruction (SI) was developed at the University of Missouri-Kansas City in 1973 (University of Missouri-Kansas City, n.d.).

Supplemental Instruction (SI) is an academic support model that utilizes peer-assisted study sessions. The SI program provides regularly scheduled review sessions on course materials outside the classroom. SI study sessions are informal seminars in which students compare notes, discuss readings, predict test items and develop tools for effective organization. The SI program targets traditionally difficult courses at the undergraduate, graduate and professional school levels (para. 2).

Based on the reported success of this support, it was proposed to tailor some of the key practices of this model for use with the Innovation Challenge Grant. SI is normally administered with either teaching assistants or upperclassmen at most colleges outside the classroom, but the innovation proposed in this idea was to use a similar concept inside the classroom with formerly successful students at this institution, although the tutors were available to tutor before/after class as well.

\section{Project Dynamics}

The tutoring program would allow tutors to help students in multifaceted ways. Those various aspects are the following:

- The tutor will encourage positive student study skills in conjunction with the classroom instructor.

- The tutor will engage with students before and after class to assist with mathematical understanding.

- The tutor will also, upon request, demonstrate study skills and mathematical concepts in front of the class.

- During classroom instruction, the tutor will quietly circulate among students to assist in the use of effective note-taking skills and to provide quick mathematical tips to allow a stuck student to quickly move on, if possible. More detailed follow-up with that student can occur at break or during subsequent group work.

- During classroom group work, the tutor will circulate among the groups to assist and help ensure deep understanding of the mathematical concepts.

- Students who fail the first exam will be required to meet with the instructor individually and a customized intervention plan, most likely involving the class tutor, will be developed to help ensure each student quickly gets back on track and improves the likelihood of success in the class. Having set out these parameters, it helped guide the type of tutor needed.

\section{Personnel and Responsibilities}

In order to facilitate the program, a tutor coordinator position was needed. The tutor coordinator needed to:

- Develop classroom tutoring requirements.

- Engage actively with all faculty who are assigned tutors (before the semester and periodically during the semester to assess progress and issues).

- Develop tutor training materials, including tutor time management and appropriate student assistance (e.g., tutors should not work the exercise for the student.)

- Recruit, interview and hire tutors.

- Train the tutors.

- Schedule the tutors.

- Supervise the tutors, including time clock approval, absences, etc.

- Develop and collect program metrics, and submit a formal report to the Dean to evaluate program success and identify expansion plans (i.e., scaling up), if appropriate.

It was important to select student tutors who were students in good standing with the college. Student tutors must have earned an A or $B$ in the course they would be tutoring and be nominated by a mathematics faculty member. Other qualities included: being familiar with the graphing calculator, if it is required in the course; being familiar with mathematical vocabulary; and being familiar with effective study skills. The student tutor would have various responsibilities including:

- Attend tutor training sessions.

- Be present for all class sessions.

- Be available before and after class to assist students as required.

- Meet with the instructor, when requested, to coordinate classroom activities, including study skills strategies to be implemented in the classroom.

- Meet with the tutor coordinator when requested.

\section{Development}

The project team leaders-two faculty members who wrote the proposal-planned and developed documents needed to implement the student tutor position. An announcement was created to find potential tutors. All full and part-time DM faculty members received the announcement. Faculty were to nominate students they felt would be great matches for the needs of the program. Once the tutor coordinator obtained the students' names, an interest email was sent to potential tutors. Interested students were encouraged to fill out an application on the college's Human 
Resources (HR) website. Once applications were submitted, the tutor coordinator set up interviews. The project team leaders developed interview questions based on the parameters set forth on the type of student tutor needed for the program.

To train tutors, a tutor handbook needed to be prepared. Fortunately, the office of disability services (ACCESS) already had a tutoring handbook. Permission was granted to make modifications to this handbook for this innovation grant. To assess the effectiveness of this project, the project leaders met with the Institutional Research Office (IRO) to determine what data should be collected. It was important to track those students who attended any tutoring sessions offered before and/or after class. To track those students a sign-in sheet was developed.

In addition to these documents, the Project Team worked with HR to develop the job posting for the HR online application. There were limitations based on policies as to the official title of the tutors and their pay. The college had already established a definition for the role of a student tutor. It required students to be in a credit course. Since DM tutors would more than likely be developmental education students, HR suggested a title change to student assistant. Although the official title was Assistant, the term tutor continued to be used because it was a clear definition of what the position entailed. Also, the pay was pre-established for the positions. Once the details were worked out, the position was posted in the HR system.

The payroll office had to be involved because student assistants would be filling out time sheets requiring tutor coordinator approval. This required the tutor coordinator to include, as part of the tutor training, important topics of how tutors would fill out paper time sheets, due dates for the time sheets submission, and how to use the online program to document.

\section{Implementation and Findings}

To find potential tutors, the tutor coordinator sent an announcement to all full-time and parttime DM faculty members during the Spring 2016 semester asking that the faculty encourage their students to participate as tutors. Students who were interested were encouraged to fill out an online application through the HR system. Disappointingly, few names were submitted. Additionally, reducing the applicant pool, the tutor coordinator was in contact with students that seemed interested; however, when students were told to fill out the HR application most students did not complete this step. For the Fall 2016 pilot, four students were interviewed for the position. Unfortunately, one student, who had previously worked for the college, did not submit a 2-week notice when resigning from the former job, so HR said the student was not eligible for employment. Another student lacked good communication skills. Only two students were hired for the Fall 2016 semester. Since the hiring process took time, the students were hired a week prior to the fall classes starting. Both tutors were hired to work with the same DM course.

On August 26, 2016, a 2-hour orientation was held with the tutors, the professor of record, and the tutor coordinator. At the meeting, tutors were given a copy of the tutor manual. They also received copies of the paper timesheets, and a personalized lanyard, which they were to wear when tutoring. During the orientation, program goals and the tutor manual were discussed with tutors and questions were answered. Time was spent on how to complete the paper copy of the timesheet. It would take a couple of weeks before they would be able to do the electronic timesheet.

The program started on August 27, 2016 and ran each Saturday that the MATH 0305 class was in session until the last day of class, December 3 , 2016. During each session, tutors arrived at 8:00 a.m. They helped any students requesting help before the class that started at 9:00 a.m. Tutors were also available for tutoring after class. During class time, tutors floated around the classroom to help students during individual and group work. One of the tutors had a more engaging personality and students tended to prefer that tutor over the other one. For the report, this tutor will be called Tutor A. Tutor A often spoke with the professor of record to make sure concepts were being explained correctly to the students. The other tutor, Tutor B, was helpful, but at times the professor of record indicated that the tutor, while explaining the work correctly, was doing so in a confusing way. Tutor $B$ was more reserved. It should be noted that Tutor A was a previous student of the instructor of record. Thus, it is reasonable that Tutor $A$ and the professor had a closer relationship. After the Fall 2016 semester, both tutors stated they could not tutor for the Spring 2017 semester. Tutor A was getting married and Tutor $B$ could not due to family obligations.

Table 1 contains the data from the sign-in sheets for the Fall 2016 tutoring sessions. For this course there were 17 students enrolled by census date. The census date is the 12th class day of a regular 16-week semester; it marks the official class enrollment for the college. Two students withdrew by the withdrawal date. Test dates were noted to see how many students took advantage of the tutors before the test. 
During the Spring 2017 semester it was again difficult to find students willing to serve as tutors. The program planned to hire four tutors so the project team leaders looked at changing the parameters to get potential tutors to apply. The expanded search included students in credit math courses that had taken DM at some point. Unfortunately, it was too late to find additional tutors.

Table 1

Fall 2016 Tutoring Data Before/After Class

\begin{tabular}{cccc}
\hline Date & Number of Students & Before/After Class & Tutor \\
\hline $08 / 27$ & 0 & NA & NA \\
$09 / 03$ & 0 & NA & NA \\
$09 / 10$ & 2 & Before & A \\
& 1 & After & B \\
$09 / 17^{*}$ & 1 & Before & A \\
$10 / 01$ & 0 & NA & NA \\
$10 / 08$ & 0 & NA & NA \\
$10 / 15^{*}$ & 1 & Before & A \\
$10 / 22$ & 0 & NA & NA \\
$10 / 29$ & 1 & Before & A \\
& 1 & After & B \\
$11 / 05$ & 0 & NA & NA \\
$11 / 12^{*}$ & 1 & Before & A \\
$11 / 19$ & 0 & NA & NA \\
$12 / 03^{*}$ & 1 & Before & A \\
$12 / 10^{*}$ & 1 & Before & A
\end{tabular}

Note. Class enrollment of 17 on Census Date with two withdraws by the Withdraw Date.

*Test Dates

Two students did fill out the application and were interviewed. Again, hiring the tutors took place a week before the Spring 2017 semester started. For the Spring 2017 semester there was only one tutor, Tutor C, for the entire semester. Tutor $C$ was hired to help with a DM course with the same professor of record from the Fall 2016 pilot. Since there was only one tutor, the professor of record indicated the flow during class was not as great as when two tutors were in the classroom. Tutor C often would spend too much time with one student and thus was not able to help many others during individual and group work. Tutor $\mathrm{C}$ was helpful but not as engaging as Tutor $A$ from the fall semester.

Table 2 contains the data from the sign-in sheets for the Spring 2017 tutoring sessions. For this course, there were 19 students enrolled by Census Date. Three students withdrew by the withdrawal date. Test dates were noted to see how many students took advantage of the tutors before the test.
Table 2

Spring 2017 Tutoring Data Before/After Class

\begin{tabular}{lccc}
\hline Date & Number of Students & Before/After Class & Tutor \\
\hline $01 / 21$ & 0 & $N A$ & $N A$ \\
$01 / 28$ & 1 & After & $C$ \\
$02 / 04$ & 1 & After & $\mathrm{C}$ \\
$02 / 11^{*}$ & 2 & Before & $\mathrm{C}$ \\
$02 / 18$ & 0 & $N A$ & $N A$ \\
$02 / 25$ & 0 & $N A$ & $N A$ \\
$03 / 04^{*}$ & 0 & $N A$ & $N A$ \\
$03 / 18$ & 0 & $N A$ & $N A$ \\
$03 / 25$ & 1 & $B e f o r e$ & $C$ \\
$04 / 01$ & 0 & $N A$ & $N A$ \\
$04 / 08^{*}$ & 0 & $N A$ & $N A$ \\
$04 / 22$ & 0 & $N A$ & $N A$ \\
$04 / 29$ & 1 & $B e f o r e$ & $C$ \\
$05 / 06^{*}$ & 0 & $N A$ & $N A$ \\
$05 / 13^{*}$ & 0 & $N A$ & $N A$
\end{tabular}

Note. Class enrollment of 19 on Census Date with three withdraws by the Withdraw Date.

*Test Dates

\section{Discussion}

With so few tutors as well as few students taking advantage of the opportunity for extra help, the outcome was not as significant as the developers had envisioned. The major obstacles for the program were the lack of students interested in becoming tutors and the lack of student attendance during tutoring sessions. This could be because of restrictions placed on tutors requiring them to have previously completed the DM course they were tutoring. This parameter was broadened, but it was done on short notice. Thus, no additional tutors were found.

The lack of interested students could be due to the times they were needed to work. At most, the position offered a tutor five hours per week which may deter students from applying. Most of the college's students work 20+ hours a week. Whereas some institutions require tutoring, the project team leaders and the instructor of record decided to make it available but not required. Future pilots could investigate mandatory tutoring options and programs.

For the sections that did have the tutors, students usually did not make use of the tutors before and/or after class. For Fall 2016, tutors were utilized for only $50 \%$ ( 7 class days out of a total of 14) of the class sessions. For Spring 2017, tutors were utilized for only $33.3 \%$ ( 5 class days out of a total of $15)$ of the class sessions. The majority of that time was one student attending the out-of-class tutoring sessions. One would think that many students would take advantage of the tutoring sessions on the day of the test but that was not the case. For Fall 
2016, there was one student attending the tutoring sessions before class during each test. For Spring 2017, there was only one test where two students attended the tutoring session before the test. It might be that students went to the professor of record during office hours to obtain help.

Tutor A had an interesting perspective on why students did not take advantage of the tutoring sessions. Tutor A said of her experience,

I think a lot of the help has to come from the students wanting to use it. You can have tutors in class willing to help but if the students do not partake in the assistance then it is a waste. My only thought would be having "undercover" tutors. This generation does not like asking for help; whereas, if it's from their fellow classmates it is easier to get guidance from. This is a personal opinion. I do not know how well it would work. As well as it would be limited to those only seated around the "undercover" tutor. I also felt like not sitting with the classmates made them feel intimated by us. Even if the tutors are not undercover they should sit with the other classmates and not off to the side, separated from them. Being a tutor was a positive experience for me. I greatly enjoy helping others especially with something that I love.

Part of the design of the grant by the original developers included a discussion of how the tutor may benefit as much as the students in the program. Teaching certainly reinforced subject content and had the potential to strengthen the tutors, a part of the same college community. Thus, although paid for the five hours per week, the reward could be more intangible.

Although few students took advantage of the tutoring sessions, there were positive comments from students. A student said of her experience,

During the Fall of 2016, I found it extremely helpful to have the student teaching assistants. Before attending college, math was a problematic subject. Thankfully, taking 0305 changed that for me. I took advantage of the hour before class prior to every test to study the material that most confused me. Having the student help allowed for extra time to get clarification, and gave way for more students (taking advantage of the opportunity) to succeed. This also instilled study habits that have carried me through my first year of college with a 4.0. I'm extremely grateful and hope the college continues to implement student teaching assistants in the classroom.

Another student said of her experience, "I went to him for help and he did great showed [sic] me different ways till I found one that made since [sic] to me. I think the tutor project is great."

This project was successful since some students did gain help and saw the value in the tutors. However, it did not have the impact expected. Due to a lack of student interest in tutoring resources, the grant was terminated.

A group of DM faculty and administrators did use the findings from this grant to develop a SI and tutoring program for the college's corequisite courses, which paired DM courses with credit courses. The corequisite courses are statemandated course pairings to accelerate underprepared students to collegelevel courses. In order to support the students, SI was a component of the corequisite courses. In April of 2018, a grant was awarded to the institution from the Texas Higher Education Coordinating Board. This grant allowed full and part-time faculty to be used as SI tutors. For the Fall of 2018, 25\% of DM students were to be enrolled in a corequisite course as mandated by the state. As expected, the attendance rate was low once again. Unless tutoring is mandatory, it seems to have low attendance regardless of structure.

For Spring 2019, tutors were hired for each of our three campuses and were scheduled to attend corequisite college algebra classes. They served as floaters during the class session. Tutoring for students in the corequisite courses was available both on campus and online. Analysis of the results of this tutoring program is in the process of being compiled. This data will be discussed as a part of the state grant report. Some preliminary data indicated that at one campus there were 350 visits to the SI/tutoring program. This represents 90 students. This means that $70 \%$ of the students in the corequisite courses at that campus attended at least one $\mathrm{SI}$ /tutoring session.

\section{Future Work}

There is overwhelming evidence that students who participate in tutoring opportunities have significant improvements in grades and increased pass rates. Overall, the results of this study demonstrated significant improvements in grade performance for students that took advantage of out-of-class SI 
sessions, as well as for students who only had inclass interaction with an SI Leader. For all semesters included in this study, students in SI-assisted sections performed better than students without an SI Leader. Furthermore, students who participated in out-of-class SI study sessions passed at a higher rate compared to non-attendees. (Altomare, p. 23)

However, during this pilot program, the difficulty was getting students to participate amid research evidence that shows it would help them succeed. Educators may need to help students develop the skills toward a more engaged classroom experience (Weinerman, 2016) by addressing the students' reasons for lack of involvement. Additional research is needed in developmental education in general where the focus is bringing students to action by accessing all the opportunities for college success support. Kosovich (2019) stated, "Fostering perceptions of value for students is helpful because it relates to positive attitudes toward the course material in the short term and long term" (p. 8). Philosophically encouraging the attitude "I cannot do math YET, compared to I have always had difficulty with math" may be necessary to increase engagement.

Another study (DeFeo, 2017), observed that students who need the most help often times do not ask for it. During the student observations by DeFeo (2017), the researchers found a lack of vocabulary skills and other metacognitive strategies. Understanding, by the students and the tutors, of procedural questions versus understanding of why math works as it does is essential to the learning process. The instructor, the tutor, and the student need to work together to create an environment where mathematical understanding is the focus rather than rote memorization of de-contextualized solution algorithms. DeFeo further noticed that students do not "regard one another as resources" and do not access that form of support (2017, p. 21). Future research could include ethnographic studies of why some students seek outside support, collaborate with classmates, or are simply passive learners. Additionally, measurable factors of motivation, metacognitive behavior, and support services could be studied.

\section{Conclusion}

$\mathrm{SI}$ in community colleges, especially in DM, is a fairly new concept. There have been mixed reviews on its use. A two-year research study involving $\mathrm{SI}$ in DM showed that SI did have a positive impact on DM students' academic performance; however, no impact was indicated on retention (Dias, Cunningham, \& Porte, 2016). As the movement for DM to be accelerated increases, programs such as SI may be a way to support those academic endeavors. More research needs to be conducted so that students can get the support that they need.
References

Altomare, T. K., \& Moreno-Gongora, A. N. (2018). The role and impact of supplemental instruction in accelerated developmental math courses. Journal of College Academic Support Programs, 1(1), 19-24.

DeFeo, D. J., Bonin, D., \& Ossiander-Gobeille, M. (2017). Waiting and help-seeking in math tutoring exchanges. Journal of Developmental Education, 40(3), 14-22.

Dias, O., Cunningham, A. W., \& Porte, L. (2016). Supplemental instruction for developmental mathematics: Two year summary. MathAMATYC Educator, 7(2), 4-9.

Kosovich, J. J., Hulleman, C., Phelps, J., \& Lee, M. (2019). Improving algebra success with a utility-value intervention. Journal of Developmental Education, 42(2), 2-9.

University of Missouri Kansas City. (n. d.) Academic support and mentoring. Retrieved from https://www.umkc.edu/asm/umkcsi/

Weinerman, J., \& Kenner, C. (2016). Boredom: That which shall not be named. Journal of Developmental Education, 40(1), 18-23. 


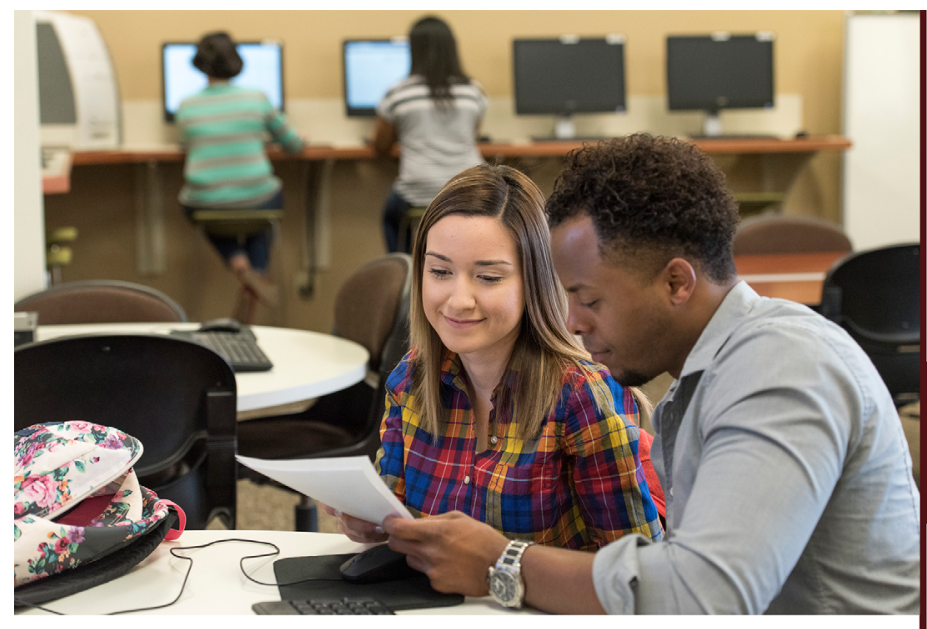

The Master of Arts degree in Developmental Education focuses on facilitating learning success in postsecondary programs. We prepare future educators, leaders, program developers, and administrators to enhance the learning and educational experiences of postsecondary students in a variety of contexts.

\section{PROGRAM HIGHLIGHTS}

次 Paid graduate assistantships available on campus

* Internship and independent study experiences

Opportunities to qualify for in-state tuition

次 Supportive and diverse students, faculty, and staff

* Easily matriculate to our Ph.D. and Ed.D. programs

\section{EARN YOUR DEVELOPMENTAL EDUCATION MASTER'S DEGREE ONLINE \\ through Texas State University} $\therefore$

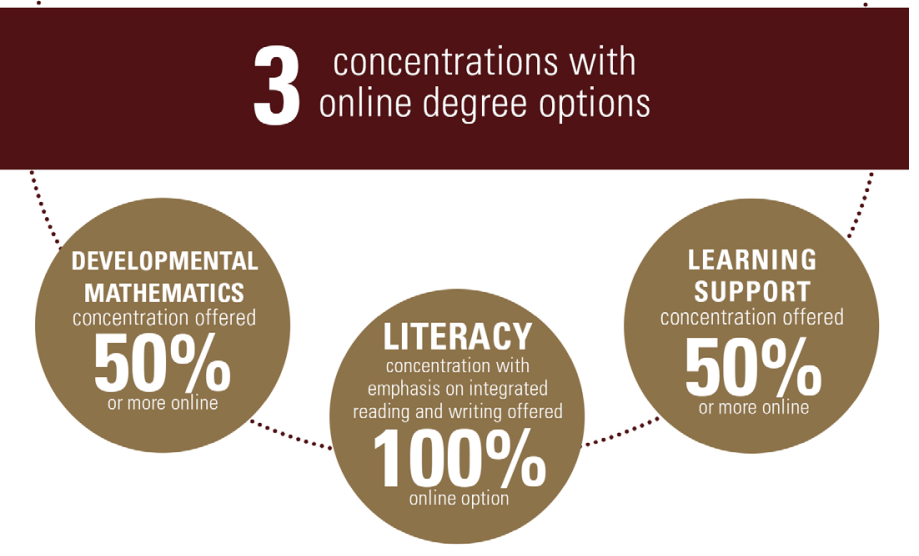

learn more:

www.education.txstate.edu/devedma

apply online:

www.gradcollege.txstate.edu/apply

\section{FOR MORE INFO:}

Dr. Taylor Acee

512.245 .7903

ta19@txstate.edu

\section{TEXAS STATE CURRICULUM AND INSTRUCTION}

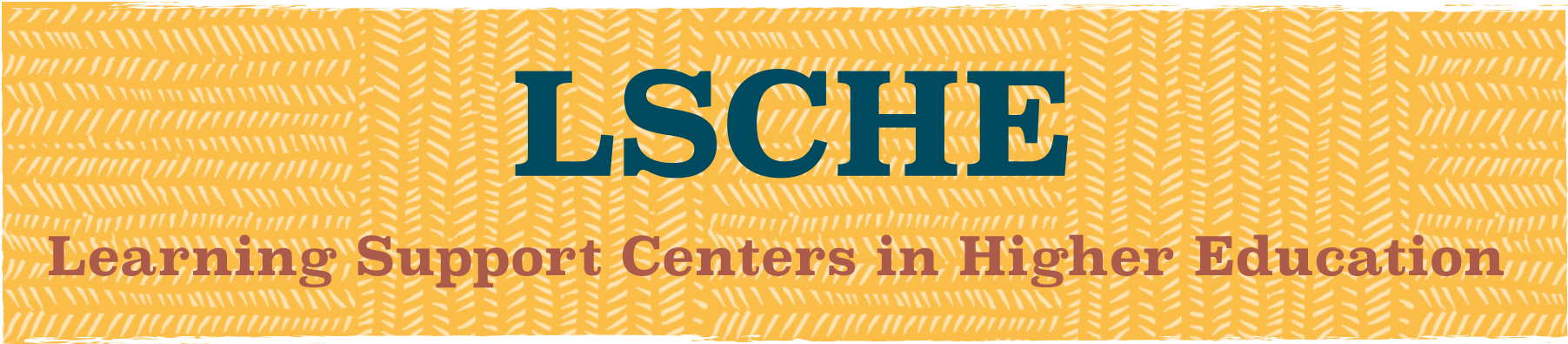

\section{About ISSCIHID}

The only Open Educational Resource (OER) web portal that provides a searchable resource for articles, presentations, archives, events of interest, history, research, and best practices for the Learning Support Centers (LSC) field.

LSCHE seeks to identify and provide a cornucopia of ideas, resources, and tools for learning support professionals in higher education to enable them to create the best possible learning support centers for the ultimate benefit of all our students. 


\section{Merging Personal and Academic Identities}

\section{Tamara Harper Shetron Kristie O’Donnell Lussier}

\section{ABOUT THE AUTHORS}

Tamara Harper Shetron is a doctoral candidate in developmental education at Texas State University with a concentration in literacy studies. Her research includes inclusive post-secondary education for students with intellectual and developmental disabilities and active and engaging teaching pedagogy. She is committed to supporting diverse and non-traditional students in higher education and life-long learning settings. Tamara is also an accomplished musician and fine arts consultant. She is actively engaged in the creative arts special interest group sponsored by the American Association of Intellectual and Developmental Disabilities (AAIDD) and she is a the past board president of the Austin based inclusive performing arts company, TILT.

Kristie O'Donnell Lussier is a professor of English and Integrated Reading and Writing at Collin College. She is a graduate of Texas State University where she earned a Ph.D. in Developmental Education- Literacy and an M.A. in Rhetoric and Composition. Kristie's professional interests lie in literacy education, academic literacies, postsecondary educational transitions, and the role of language in personal and educational development. Kristie has presented and published on college student literacy development, teacher education in international and multilingual settings, student identity development, humanizing pedagogy, and language and literacy development in international settings.

$\mathrm{n}$ this article, we describe rationales and processes of using a tableau theater model for student engagement in a developmental education literacy course. Tableau theater is an instructional technique in which students physically reenact moments in texts they read. Asher's (1969) total physical response (TPR), and constructivist and theories of embodied literacies (Cope \& Kalantzis, 2009; New London Group, 1996) informed the development of this technique. Repeated use of this instructional model in a variety of class contexts and with different texts and instructors demonstrated the value of using classroom time to allow students to engage physically with the text and create their own meaning, thus putting them in control of building their own academic identities.

As literacy instructors, we set out to engage students in a meaningful understanding of texts by creating an opportunity for students to actually step into the situation. According to Asher (1969), when students physically engage with material that they are learning, the combination of both physical and mental interaction with it engages both hemispheres of the brain. Asher's work demonstrates that physical response to language naturally occurs before a verbal response. Butterwick and Selman (2012) focused on the power that theater processes have due to the inclusivity of all our senses. More specifically, Dolan (2001) argued for the use of theater in the public sphere as a means for deep engagement with complex modern issues from multiple perspectives.

From our perspectives as teachers of developmental literacy courses, we understand that part of the developmental literacy process is meant to help students form scholarly identities and relate themselves to the academic world in meaningful and personal ways. The processing of stepping into the textual experience allows students to embody the literacies they are experiencing and to take personal control of their learning.

The process of academic community building is a process of merging identities between the existing home community and the new academic community (New London Group, 1996; Tapp, 2014). By embodying the situation physically and having the chance to talk through the situation and the text with their peers and instructor and to have time to reflect on their personal journey through the tableau exercise, students engage many aspects of their literacy learning. Indeed, students express that making meaning through tableau sheds new light on reading and writing transactions, personal expression, and agency. In our experiences, students make a far more engaged and dynamic response to their literature when they connect through tableau.

\section{The process of academic} community building is a process of merging identities between the existing home community and the new academic community. 
As scholars, we set out to answer the question, "how do students respond to and engage in tableau theater?" Our question is framed by social constructivism (Vygotsky, 1978) and builds on Sheehy's (2004) notion that "engagement is a chief concern of literacy research" (p. 93). In this case, students individually interact with a text to construct their own interpretations based upon their past experiences, the text, and their participation in the textual activity through tableau. By studying the student-produced work, we have been able to identify several themes that answer this question; we will highlight two of these. First, students achieve an active subjective engagement with texts. For example, in one tableau iteration, several students changed the outcomes of the role in which they were positioned and reasoned through their thought processes through writing. Second, students were better able to connect what they were learning to experiences in their own lives. For example, in their reflections, some students were able to compare and contrast analogous experiences from their lives. Furthermore, some students began this critical comparison with little direct prompting to do so.

With its inclusivity of all the senses (Butterwick \& Selman, 2012), tableau provides the opportunity for students to take on the roles of others, allowing for a deeper exploration of positionality as well as multiple and sometimes contradictory responses to the same text. This provides an antithesis to the banking method of education in which students are directed in their thoughts and interpretation of a text (Freire, 1993) by providing a rich classroom instructional pedagogy whereby students can develop their own academic identities bridging their own prior experiences and responses to classroom activities.

\section{References}

Asher, J. J. (1969). The total physical response to second language learning. The Modern Language Journal, 53(1), 3-17.

Butterwick, S., \& Selman, J. (2012). Embodied knowledge and decolonization: Walking with theater's powerful and risky pedagogy. New Directions for Adult and Continuing Education, 2012(134), 61-69.

Cope, B., \& Kalantzis, M. (2009). "Multiliteracies": New literacies, new learning. Pedagogies: An International Journal, 4(3), 164-195.

Dolan, J. (2001). Rehearsing democracy: Advocacy, public intellectuals, and civic engagement in theatre and performance studies. Theatre Topics, 11(1), 1-17.

Freire, P. (1993). Pedagogy of the oppressed. New York, NY: Bloomsbury.

New London Group. (1996). A pedagogy of multiliteracies: Designing social futures. Harvard Educational Review, 66, 60-92.

Sheehy, M. (2004). Between a thick and a thin place: Changing literacy practices. Spatializing Literacy Research and Practice, 15, 91-114.

Tapp, J. (2014). "I actually listened, I'm proud of myself," the effects of a participatory pedagogy on students' constructions of academic identities. Teaching in Higher Education, 19(4), 323-335.

Vygotsky, L. S. (1978). Mind in society: The development of higher psychological processes. Cambridge, MA: Harvard University. 


\section{StudentLingo}

More Skills. More Success.

\section{Sign up for your free trial today! www.studentlingo.com/freetrial}

\section{Online Student Success Videos}

\section{A la carte \& package pricing available}

\section{Academic \& Career Exploration}

Creating Your College Bucket List:

Explore, Experience, Succeed

Exploring Careers \& Choosing A Major

Mastering The Job Interview

Maximizing Your College Experience

What It Takes To Be A Successful Student

Writing Effective Resumes \& Cover Letters

\section{LEARNING To LEARN}

Academic Integrity: The Do's and Don'ts

10 Habits Of Mind For College Success

Classroom Expectations \& Behaviors

Developing Critical Thinking Skills

Exam Preparation Tips \& Test-Taking Strategies

Handling Failure In \& Out Of The Classroom

How To Reduce Test Anxiety

How To Succeed In Math

How To Overcome Math Anxiety

Information Literacy: How To Master College Research

Study Tips \& Note-Taking Strategies

The Difference Between High School \& College

Learning Strategies Every Student Should Know

Preparing For Final Exams

Understanding \& Avoiding Plagiarism

\section{OnLine LeARning}

10 Tips For Success In Your Online Course

Effectively Communicating Online

Online Courses: Staying Motivated \& Disciplined

Taking Tests Online: Strategies For Success

\section{Reading \& Writing Strategies}

- Developing A Strong Thesis Statement

Drafting Introductions, Body Paragraphs \& Conclusions

- Pre-Writing Techniques: Planning \& Idea Development

- Reading Comprehension Strategies

- The Revision Process: How To Proofread \& Edit Your Writing

\section{Personal Management}

- Emotional Intelligence: The Other Key To Academic Success

Financial Literacy: Smart Money Skills For College \& Beyond

- How To Achieve Well-Being, Balance \& Success

How To Develop Your Cross-Cultural Skills

- How Your Personality Style May Impact Your Academic Success

- Improving Student-Faculty Relationships

Mental Health \& Suicide: Helping Yourself \& Others

Navigating The Financial Aid Process

Overcoming Procrastination: Causes \& Cures

Stress Management Techniques

Setting \& Accomplishing Realistic Goals

Sexual Violence Awareness \& Prevention: A Title IX Training For Students

- Time Management: Strategies For Success

\section{Success Strategies}

- Discover Your Learning Style Preferences

Leading As A Student-Athlete In \& Out Of The Classroom

Student Veterans: How To Succeed In College

Success Strategies For First Generation Students

- Success Strategies For Students On Probation

\section{Did You Know?}
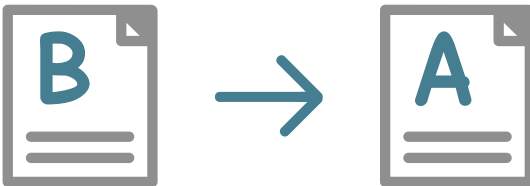

College of Southern Nevada integrated StudentLingo in courses with the lowest success rates and saw better grade achievement (on average one letter grade) in $92 \%$ of these courses.

\section{Benefits}

Unlimited Learners

Aggregate Reporting \& Learner Analytics

ADA Compliant - WCAG 2.AA

Tailored Actions Plans

SSO \& LTI Integration 
One Company.

Five Great Products.

Technology

Transforms

Learning
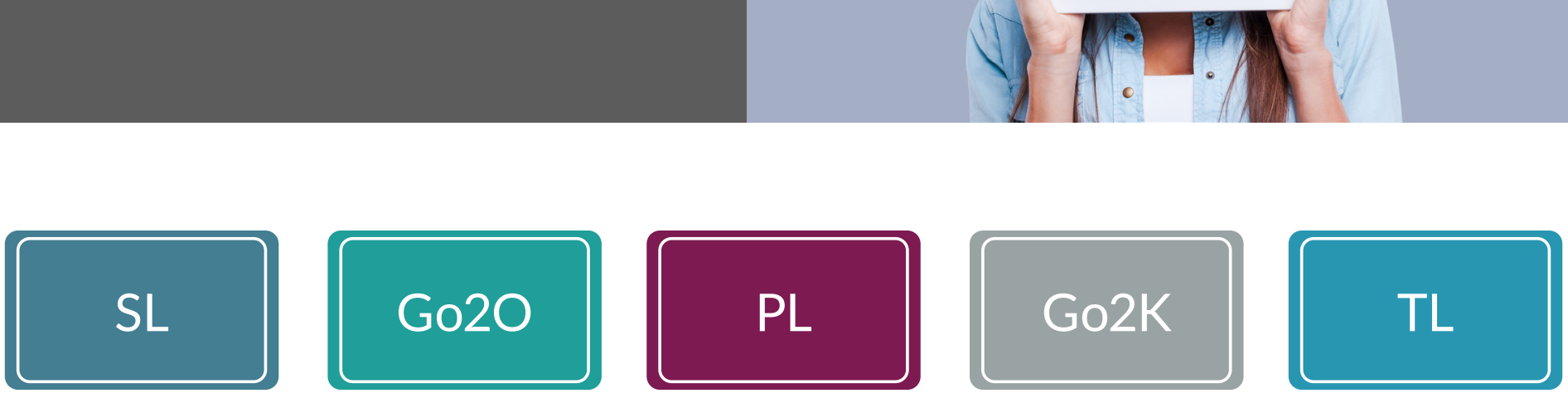
StudentLingo ${ }^{\oplus}$
More Skills.
More Success.
Go2Orientation ${ }^{\circledast}$
Your Story.
Their Success.

ParentLingo ${ }^{\otimes}$

Inform Parents.

Empower Students.
Go2Knowledge
Train Online.
Learn Anytime.

TutorLingo ${ }^{\oplus}$

Train Efficiently. Tutor Effectively.

\section{About Us}

Innovative Educators partners with institutions of higher education to provide online services for students, faculty \& staff.

Our experience in student success/affairs, academic affairs, and online learning gives us first-hand knowledge from a higher ed perspective and from a shared vision of helping students succeed, while fostering the goals \& mission of your institution.

\section{We Believe}

Learning Happens Everywhere Education Must Be Engaging \& Accessible

Technology Transforms Learning Your Challenges Are Our Challenges

Our Products Solve Problems

We Can Make Your Job Easier

\section{Pet Ambassadors}
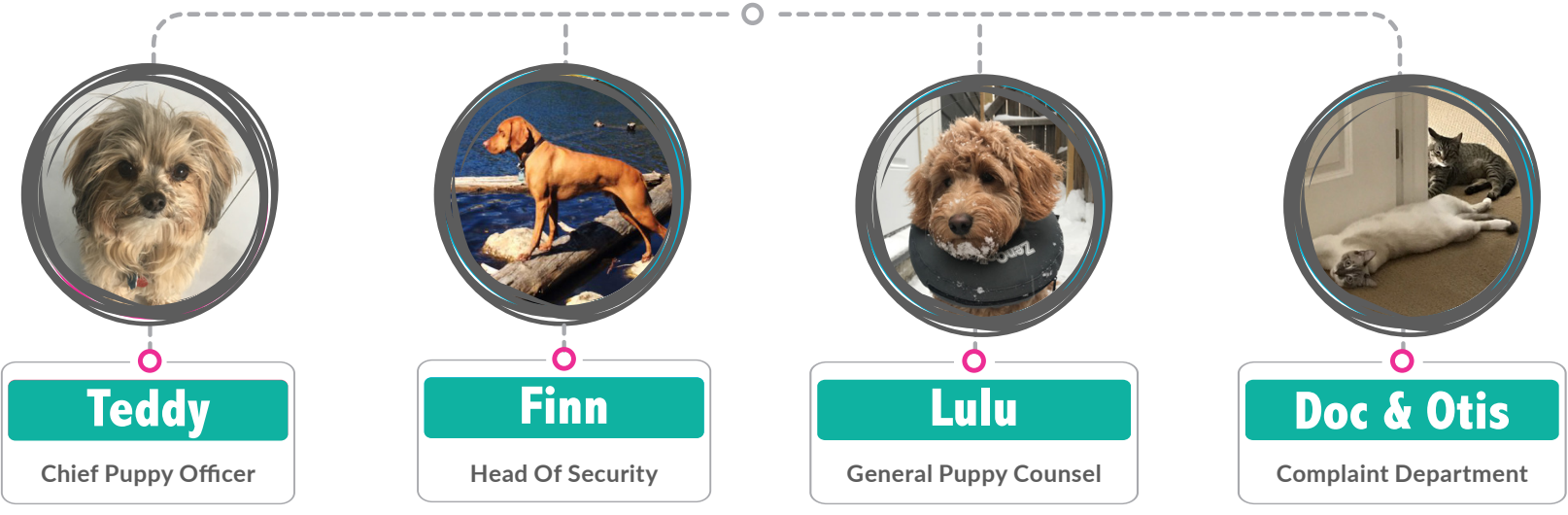

Meet all of our Pet Ambassardors at

www.innovativeeducators.org/pages/aboutus\#pets 
ASU moved towards a corequisite model several years before the implementation of House Bill 2223. Prior to our current corequisite model, ASU

The Evolution of the T-Section: Angelo State University's Approach to the Corequisite Model

\section{Codi Jaynes \\ Mario Barrientos \\ Wayne Humphrey}

\section{ABOUT THE AUTHORS}

Codi Jaynes received a B.S. degree in Mathematics from Angelo State University in 2015 and a M.A. in Curriculum and Instruction with a concentration in Mathematics from Angelo State in 2017. Codi has experience teaching remedial mathematics in high school and in higher education. She is currently working as an Instructor of Mathematics at Angelo State University.

Mario Barrientos received a B.S. degree in Mathematics from Sul Ross State University in 2006 and an M.S. degree in Applied Mathematics from The University of Texas at San Antonio in 2007. He began teaching remedial mathematics at Southwest Texas Junior College in Del Rio, Texas and is currently working as a Senior Instructor in the Department of Mathematics at Angelo State University in San Angelo, Texas.

Wayne Humphrey has been teaching Developmental Mathematics for the past 12 years. He spent 5 years at Cisco College as an instructor of Mathematics and the Developmental Mathematics Coordinator, 5-and-a-half years at Navarro College as a professor of Mathematics and Developmental Mathematics. Wayne is currently an instructor of Mathematics and Developmental Mathematics Coordinator at Angelo State University.

s the state of Texas transitions its developmental programs to the corequisite model, the faculty at Angelo State University (ASU) are adjusting their corequisite model, which was implemented 5 years ago. This article traces the origin and development of the current model of corequisite learning at ASU, as well as illustrate best practices that are found in our university. followed a traditional two-semester sequence for our remedial mathematics program. Students who did not meet TSI requirements would be placed into MATH 130A. Topics for this course included fundamental operations involving whole numbers and fractions, decimals, ratios and proportions, interpretations of graphs, metric and nonmetric geometry, counting, combinations and permutations, and an introduction to algebra. Upon successful completion, the students moved on to MATH 130B. This course consisted of topics including axioms and properties of the real number system, fundamental operations involving algebraic expressions, first degree equations and inequalities in one variable, products and factoring, algebraic fractions, exponents and radicals, quadratic equations, functions and graphs, systems of equations, and applications of these topics. To achieve successful completion for both of these courses meant the student had to achieve a grade of $\mathrm{C}$ or higher. Once a student completed this entire sequence with a grade of $C$ or higher, the student was considered TSI complete and could then register for their college-level freshman math course required by their degree.

This original two-semester sequence had a couple of advantages, which were primarily administrative. For example, both MATH $130 \mathrm{~A}$ and 130B were standard 3-hour credit courses. Being a 3-hour credit course meant that scheduling was both straightforward and flexible. These courses could follow the traditional Monday, Wednesday, and Friday or Tuesday and Thursday course layout. Another advantage for this two-semester format was that any student who was not TSI complete was required to take this remedial sequence their first semester at ASU. The sequence was not discipline specific, meaning any student regardless of major could take the same twocourse sequence. However, the topics and rigor of the sequence were designed to prepare the student for success in College Algebra (MATH 1314) whether students were on track for that course or not.

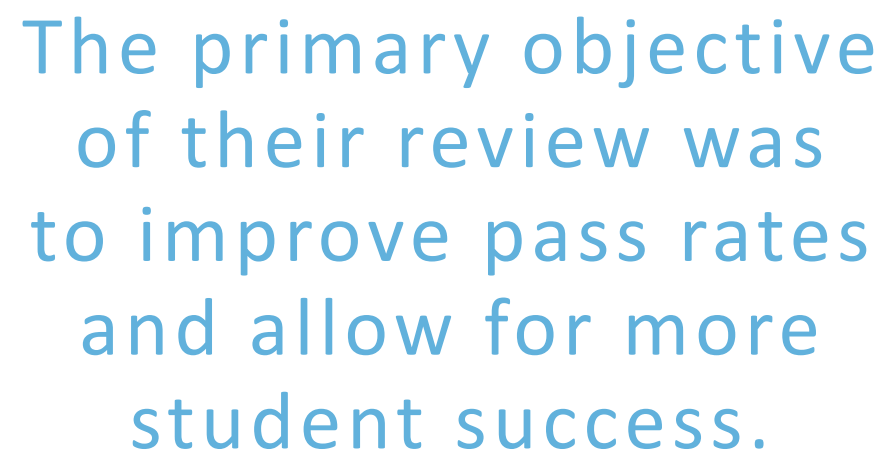


One consistent issue with this sequence was the low rate of success. In Fall 2011, 130A had a success rate of $35 \%$ and $130 \mathrm{~B}$ of $31 \%$. Fall 2012 had no improvement with $130 \mathrm{~A}$ passing $35.6 \%$ and $130 \mathrm{~B}$ passing $29 \%$. These pass rates were common for the $130 \mathrm{~A} / 130 \mathrm{~B}$ sequence. These pass rates had traditionally been regarded as acceptable by mathematic department faculty as well as the university administration. It was generally felt that no changes to the sequence were necessary, because if a student could not pass this sequence, they were probably not college-ready and needed to follow a different path.

This mindset began to change when the new dean of the College of Arts and Sciences, who was a previous chair of the mathematics department, and the provost initiated a review of the developmental program which specifically looked at the math side of the program. The primary objective of their review was to improve pass rates and allow for more student success. It came to their attention that most of the students who enrolled, being not TSI complete, were not STEM majors. This began to play a substantial role in the initial restructuring of the program. The main objective of their first reform was to improve retention in two primary ways: increase pass rates and streamline the sequence. Schudde and Keisler (1999) recent research also supports this mindset, they found that students in an accelerated developmental education program are more likely to pass college level mathematics. The challenge with implementing a new program was to achieve these two goals without sacrificing content or rigor, so students would still be prepared for future math coursework.

The initial change to the program was the development and implementation of a one-semester course called MATH 130C. Topics for this course included elementary and intermediate algebra and functions, geometry and measurement, data analysis, statistics, and probability. A major difference between this course and the previous two-course model was the means of content delivery. MATH $130 \mathrm{C}$ was an Assessment and Learning in Knowledge (ALEKS)-based course. ALEKS was selected because research indicated positive results with respect to decreasing student anxiety as well as increasing positive learning outcomes (Taylor, 2008). ALEKS is a web-based, interactive system which is presented in a computer lab. For MATH 130C, an instructor supervised and assisted students as necessary, along with conducting brief lectures on selected topics. The program was self-paced, which made it possible for students to complete the required course material before the end of the regular semester. To complete this course successfully, a student was required to work through all the assigned materials, as well as complete a standard final exam with an average of $C$ or higher. MATH $130 \mathrm{C}$ was structured as a traditional 3-hour course, but each class required the use of a computer lab. Given the nature of our labs, class sizes were limited to around 20 students, where previous classes could contain 35 to 45 students depending on the classroom used. This led to scheduling conflicts, as well as issues regarding seat availability. It was a concern that the small computer labs available would not be able to adequately support the full population of our developmental students. In its initial semester, MATH $130 \mathrm{C}$ showed an improvement over the previous sequence, with the pilot yielding a pass rate of $51.8 \%$. Although these results were well-regarded, the pass rates were not the results being sought after. The main benefit to this $130 \mathrm{C}$ course seemed to be the one-semester format.

Given that the results of MATH $130 \mathrm{C}$ were not as positive as expected, a new program was developed. In Fall 2013, a linked class, similar to paired courses already being implemented at other colleges, called the T-section was introduced at ASU. The " $T$ " denoted the course as a linked course for non TSI complete students, and also indicates that completion of this course satisfied the requirements for a student to become TSI complete. Research being done at this time supported the implementation of a more streamlined, paired course model. According to Hern (2012), accelerating the remedial math program leads to improved retention. Initially, one section of MATH 1342 (Elementary Statistics), named MATH $1342 \mathrm{~T}$ was started. This course became known as a T-section. It was run along a corequisite model, with a total of 6 contact hours in the classroom. The course consisted of review and exercises of the developmental math topics, along with the traditional college-level statistics material. After successful completion of the class with a grade of D or higher, the student became TSI complete. In addition, the student would earn three credit-hours of college level math for 1342 . Initially, this program was run as a single pilot section along with multiple sections of MATH 130C. The pilot T-section course had 14 students enrolled, all who passed with a grade of $D$ or higher.

In Fall 2014, T-sections were permanently implemented in 3 different freshman math courses: MATH 1332 (Introduction to Contemporary Math- a standard math for liberal arts), MATH 1314 (College Algebra), and MATH 1324 (Finite Math). All non-TSI complete students were either placed in a T-section that fit their degree plan, or in a non-course based (NCBO) option using the ALEKS computer system. Students were only placed in the NCBO course if all the seats in their appropriate T-section course were filled. For this initial implementation, MATH 1314T saw a success rate of $21.5 \%$, while MATH $1324 \mathrm{~T}$ was $35.8 \%$, and MATH $1332 \mathrm{~T}$ was $65.6 \%$. Through some minor revisions, the success rates climbed to $46.8 \%$, 
$59.3 \%$, and $85.4 \%$ respectively in Fall 2015 . Fall of 2016 and 2017 showed continued increase in success for both MATH 1324T and MATH 1332T. However, the success rates for MATH $1314 \mathrm{~T}$ stayed stagnant.

In Fall 2018, another major revision was implemented. An algebra review section was included in the MATH 1332T curriculum and the MATH 1314T course was eliminated. The objective of this change was to have a majority of developmental math students placed in MATH $1332 \mathrm{~T}$ since a large majority of non TSI complete students were not pursuing degrees that required college algebra. This coincides with research by Gayles and Ampaw (2014) that indicated about $20 \%$ of students planning to major in the sciences reported needing remedial math. The additional algebra review was implemented to ensure that students gained basic algebra skills after successful completion of MATH $1332 \mathrm{~T}$ as preparation for additional math courses if needed.

At ASU today, our corequisite T-sections can be found in three different formats. A majority of our classes meet for multiple successive class blocks: on Monday, Wednesday, and Friday for two 50-minute blocks, or on Tuesday and Thursday for two 75-minute blocks. However, a few of our sections meet every day: Monday, Wednesday, and Friday-for a standard 50-minute block and Tuesday and Thursday for a standard 75-minute block. This gives the students an estimated three hours of lecture and instruction, as well as three hours of lab and practice time. According to Atkins and Beggs (2017), the learnercentered support provided by the corequisite model has been shown to increase mastery of college-level mathematics. The way each individual class is broken up into lecture versus practice varies by topic and by instructor. Upon completion with a grade of $D$ or higher, students receive credit for their college-level math (typically 1332), as well as become TSI complete.

From the student perspective, a T-section course shows up as six hours on their schedule, as lab time is mixed within the lecture time. For example, if a student was registered for a class that met Monday, Wednesday, and Friday from 1:00 to 2:50 p.m., the computer would show that entire time as booked. This schedule prevents a student from registering for another class that conflicts with the scheduled T-section. However, from the transcript side, only three hours are recorded in the form of a letter grade the student receives for their specific math course.
Currently, there is no designation on a student's transcript that denotes a T-section as such.

From an administrative perspective, this T-section model can cause some problems regarding classroom allocation and scheduling. Class sizes are capped at 35 students to allow effective remediation to occur. In addition to the smaller class sizes, the unusual lengths of the courses can cause conflicts within the scheduling. Another administrative issue with the T-section model is funding. Students only pay for three hours of tuition, as that is what they receive on their transcripts. However, instructors teach for 6 hours a week. ASU's administration made the decision to compensate each T-section instructor for the full six hours they are in the classroom, despite the university only receiving payment for three hours from the students.

Our T-section courses are designed where one instructor is responsible for the entirety of the class meetings. The institution does not have separate labs that are staffed by graduate assistants or adjunct professors. To help the instructors answer questions and guide students, Angelo State has agreed to hire student assistants for each T-section course. These assistants are undergraduate students who fit into one of the following categories: mathematics majors or minors, education majors who have displayed a strength in math, or students who have previously excelled in the designated T-section. These assistants have the primary job of assisting with immediate remediation and answering questions during both the lecture and lab times. Students hired as assistants are held to a high standard and must be able to effectively explain their mathematical thinking and problem-solving skills. They must also be reliable enough to attend each class meeting in its entirety. These student assistants are paid by the Freshman College, as are other tutors in our additional tutoring center. These student assistants play an imperative role in the success of our courses. "Vygotsky (as cited in Finlayson, 2014) suggested that learners can be assisted by working with others who are 'more knowledgeable' A range of knowledge may be out of reach for the individual to learn alone but is accessible if the learner has the support of peers and more knowledgeable others" (p. 22).

Another key aspect of the T-section is the small-group collaboration and work. While we do not necessarily assign group projects or assignments, it is common to find students in groups of two or three, 
all working together during the lab portion of class. Hodara (2011) found that "...the act of explaining material to another student is one method of cognitive elaboration, which facilitates the retention of information" (p. 6). Additional research indicates that when students have the chance to work in groups, they are given an opportunity to discuss mathematics in an environment where they can share their thinking and work. Having peers with whom they can discuss and practice math was found extremely useful as opposed to working alone (Finlayson, 2014).

Finlayson (2014) also went on to discuss that working in groups allows the students to ask questions and get them immediately answered by peers, which helped reduce math anxiety. Within our T-sections, the instructors at ASU have noticed a trend of increased math anxiety in our students. These students have typically struggled with math throughout their entire educational career and have a mindset that they will never be successful in math. Using strategies such as a peer tutor and allowing group work can help to reduce this anxiety, allowing the students to experience success in math, possibly for the first time.

In conclusion, we believe that our corequisite practices of student aids, group work, and scheduling options at ASU are setting our students who arrive as not-TSI complete on a path towards success. Research supports our methods, and our department is committed to continually evaluating and adjusting our program to best meet the needs of our students.
References

Atkins, C., \& Beggs, C. T. (2017). Commuting the math sentence: Accelerating developmental mathematics using the co-requisite model. NADE Digest, 9(1), 20-24.

Finlayson, M. (2014). Addressing math anxiety in the classroom. Improving Schools, 17(1), 99-115. Retrieved from http://sagepub.com.easydb. angelo.edu

Gayles, J. G., \& Ampaw, F. (2014). The impact of college experiences on degree completion in STEM fields at four-year institutions: Does gender matter? The Ohio State University Press, 85(4), 439-468. doi: 10.1353/jhe.2014.0022

Hern, K. (2012). Acceleration across California: Shorter pathways in developmental English and math. Change: The Magazine of Higher Learning, 44(3), 60-68. Retrieved from https:// www-tandfonline-com.easydb.angelo.edu/ toc/vchn20/current

Hodara, M. (2011). Reforming mathematics classroom pedagogy: Evidence-based findings and recommendations for the developmental math classroom. Retrieved from http://www. tc.columbia.edu/ccrc

Schudde, L., \& Keisler, K. (2019). The relationship between accelerated dev-ed coursework and early college milestones: Examining college momentum in a reformed mathematics pathway. AERA Open, 5(1), 1-22. Retrieved from http://sagepub.com.easydb.angelo.edu

Taylor, J. M. (2008). The effects of a computerizedalgebra program on mathematics achievement of college and university freshmen enrolled in a developmental mathematics course. Journal of College Reading and Learning, 39(1), 35-53. 


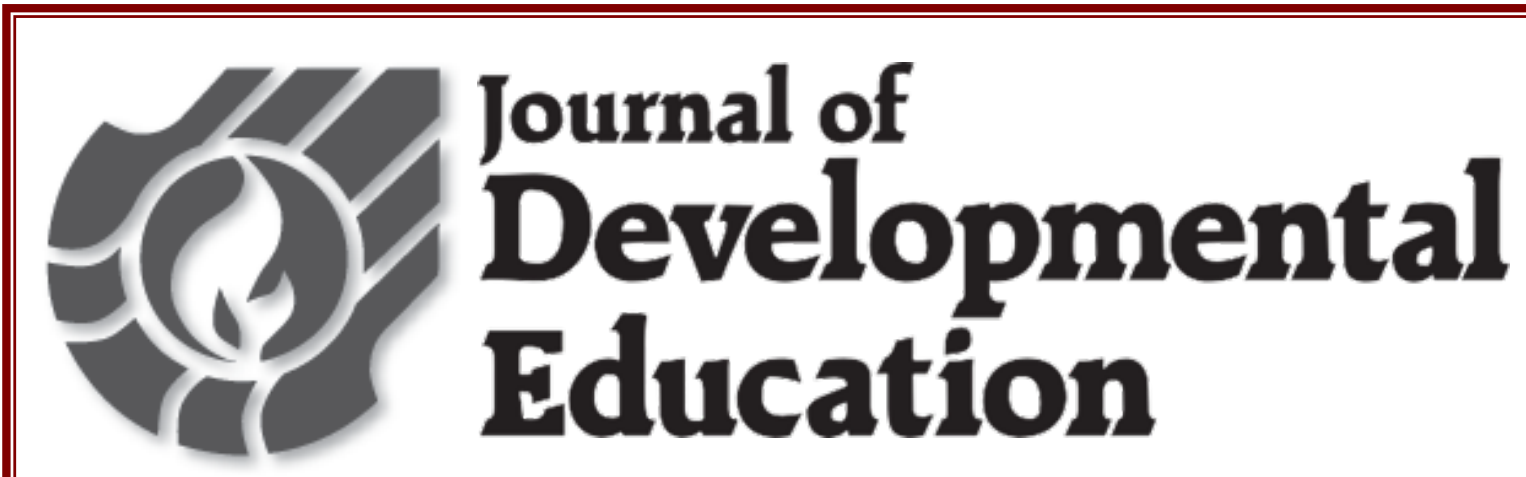

\section{Call for Manuscripts}

The Journal of Developmental Education, the official Journal of the National Association for Developmental Education, invites the submission of original manuscripts for publication consideration. Manuscripts are accepted year round and considered on an ongoing basis.

The Journal's content focuses on basic skills education, developmental education activities, learning assistance, and counseling as they relate to at-risk students at the postsecondary level. Editorial emphasis is placed on manuscripts that relate theory to practice (i.e., teaching, learning, and student development) and studies that include evaluative results of implementation. Sample hot topics include: technology, P-16 initiatives (seamless education), Integrated Reading and Writing (IRW), Redesign initiatives, and placement and assessment policy and instruments. The Journal also publishes manuscripts that expand current knowledge or have a clearly demonstrated impact on the field.

Author's Guidelines are available upon request from the Journal or may be found at the National Center's Web site (www.ncde.appstate.edu). Electronic file submissions should have author identity removed and be submitted as Word files and hard copy sent as typewritten, doublespaced documents, original and four copies. Manuscripts submitted for publication consideration should not exceed 25 pages in length and follow the APA Publication Manual (6th edition) editorial style. Publication decisions are made by the JDE's editorial board through a doubleblind peer-review process.

Send manuscripts to "Office Manager" (turrisiak@appstate.edu) and requests for additional information to: Editor; Journal of Developmental Education; National Center for Developmental Education; Appalachian State University; ASU Box 32098; Boone, NC 28608; 828-262-6101; calderwoodbj@appstate.edu

\section{Subscribe}

\begin{tabular}{|c|c|c|}
\hline & 1 year & 2 year \\
\hline Personal Subscriptions & $\$ 48.00$ & $\$ 85.00$ \\
\hline Institutional Subscriptions & $\$ 67.00$ & $\$ 117.00$ \\
\hline
\end{tabular}

NOTE: Canadian subscriptions add \$6/year \& other international subscribers add $\$ 12 /$ year for shipping.

Subscription starts when payment is received.

Access publications order form at

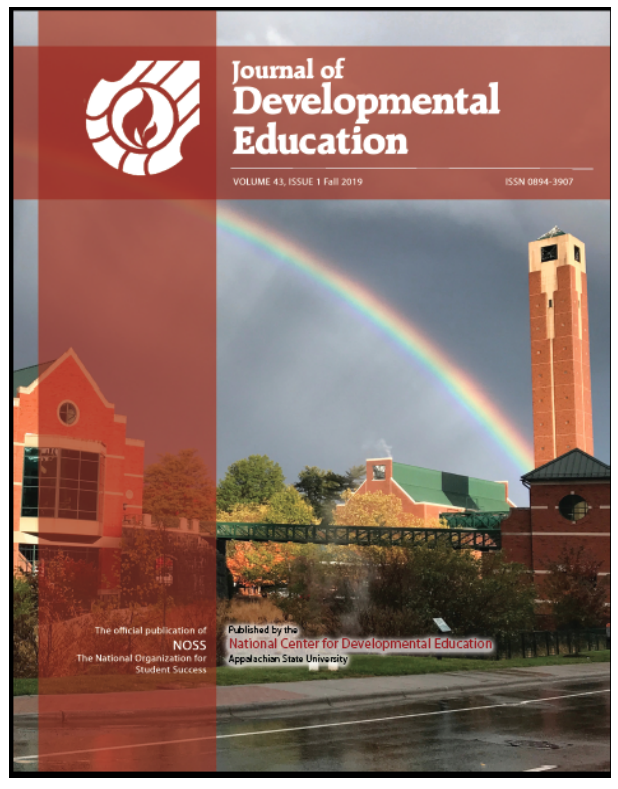

www.ncde.appstate.edu 


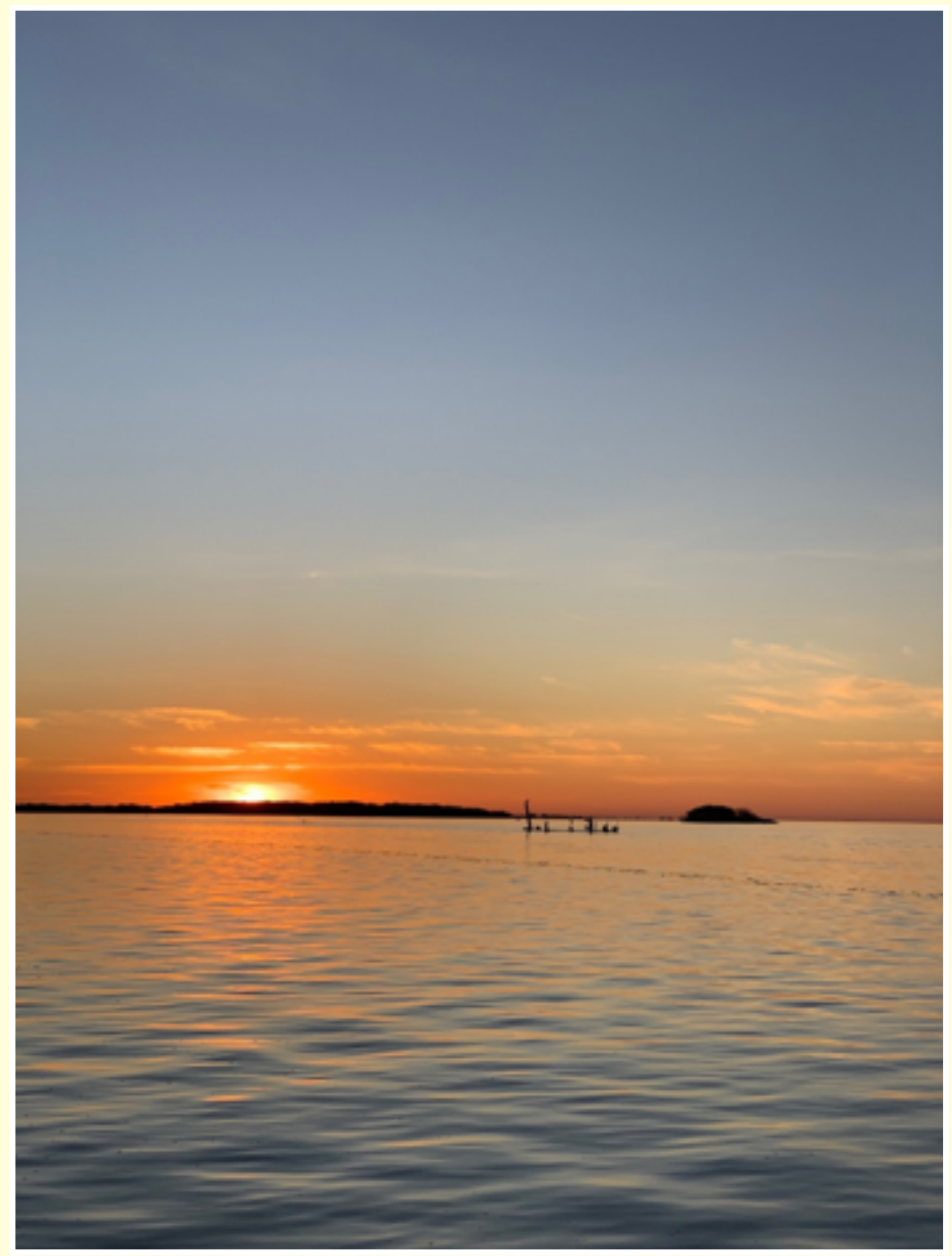




\title{
Discussing the Place of Corequisites in Juvenile Correctional Education and GED Success
}

\author{
Jonathan Lollar
}

Cesar Bernal

\section{ABOUT THE AUTHORS}

Jonathan Lollar is a doctoral student in the Developmental Education Program, at Texas State University. He currently teaches Learning Frameworks (EDP 1350) at Texas State University. He also has a Master's in Applied Philosophy and Ethics from the Texas State University Department of Philosophy, where he taught Ethics and Society for four years.

Cesar Bernal is a staff member in the Testing and Evaluation Measurement Center, at Texas State University, San Marcos. He currently coordinates the Academic Testing for Students with Disabilities, serving students registered with the Office of Disability Services, at Texas State University.

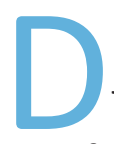

iscussions

surrounding juveniles, education programs, and recidivism are difficult to find. In fact, gathering data is incredibly difficult in juvenile facilities because of high turnover rates and difficulty of obtaining permission to conduct studies in juvenile facilities (Calderone, Bennett, Homan, Dedrick, \& Chatfield, 2009; Shippen, Morton, Flynt, Houchins, \& Smitherman, 2012). A study by David, Bozick, Steele, Saunders, and Miles found that participating in a GED or equivalent program reduced recidivism rates by $30 \%$ (2013). Assuming there is a relationship between juvenile recidivism rates and education programs, an important question remains. What types of education work best, and why? We believe a corequisite model paired with a philosophy course may be an important piece to this question.
A philosophy based corequisite approach has been developed for two primary reasons. The first being that pre-college philosophy classes have been shown to improve scores on the Cognitive Abilities Test 3-which tests verbal, non-verbal, and numerical reasoning (Topping \& Trickery, 2007). Philosophy majors also have the highest mean scores in verbal reasoning and analytic writing, as well as having the third highest mean score for quantitative reasoning (Education Testing Service, 2019). Some universities have even begun partnering with $\mathrm{K} 12$ schools in order to teach philosophy summer camps or instruct during normal school hours (Center for Philosophy for Children, 2019; Texas A\&M University, 2019). GED program completion is a major concern for juvenile detention centers, so it is important that critical thinking and reasoning skills are fostered. Philosophical discussion can certainly develop critical thinking and reasoning skills-with the bonus of increasing test taking skills.

The second primary reason for choosing a philosophy based corequisite approach is that research shows improving things like selfesteem, personal development, and a sense of empowerment, are all ways in which motivation to complete education programs amongst incarcerated adults is fostered (Baranger, Rousseau, Mastrorilli, \& Matesanz, 2018). Philosophy as a field is inundated with literature related to meaning making and values, selfrespect, classroom engagement, and identity (Locke, 1935; Boxill, 1976; hooks, 1994). After facilitating discussions on these topics and having students complete reflection assignments, students will learn the skills and foundations for cultivating and maintaining things like value, self-respect/self-esteem, and empowerment in their own lives (personally and academically). Students would be given the opportunity to speak, hear others, and experience validation through their own ideas.

The structure of the philosophy course will be simple. The course will focus on reading and writing skills through article readings, reflection papers, and narrative creation exercises (where students develop a case study to coincide with the discussion topic of the day). Dialogue is heavily utilized so that students can grapple with these concepts in a low stakes 
environment and build confidence, as well as watch their ideas and the ideas of others form.

We believe that a philosophy course that is taught alongside a GED class at a juvenile detention center will do much more than simply grant students an avenue for content centered application of their developing reading and writing skills. The content of the philosophy course will help students become more confident, as well as autonomous learners; this in turn will translate to higher GED completion and lower recidivism rates amongst juveniles.

\section{References}

Baranger, J., Rousseau, D., Mastrorilli, M., \& Matesanz, J. (2018). Doing time wisely: The social and personal benefits of higher education in prison. The Prison Journal, 98(4), 490-513. https://doi. org/10.1177/0032885518776380

Calderone, C., Bennett, S. V., Homan, S., Dedrick, R. F., \& Chatfield, A. (2009). Reaching the hard to reach: A comparison of two reading interventions with incarcerated youth. Middle Grades Research Journal, 4(3), 61-80. Retrieved from http:// libproxy.txstate.edu/login?url=http://search. ebscohost.com.libproxy.txstate.edu/login.aspx? direct=true $\& \mathrm{db}=$ eue $\& A N=45562612 \&$ site $=$ edslive \&scope=site

Center for Philosophy for Children (CPC). (2019). Empowering young people through philosophical inquiry. Retrieved from https://www.philosophyforchildren.org/

Davis, L. M., Bozick, R., Steele, J. L., Saunders, J., \& Miles, J. N. V. (2013). Evaluating the effectiveness of correctional education: A meta-analysis of programs that provide education to incarcerated adults. Santa Monica, CA: RAND Corporation.

Education Testing Service (ETS). (2019). GRE quide to the use of scores. Retrieved from https://www.ets. org/s/gre/pdf/gre guide.pdf

Fischer, B. (Ed.). (2017). College ethics: A reader on moral issues that affect you. Oxford, England: Oxford University Press.

hooks, b. (2003). Teaching to transgress: Education as the practice of freedom. New York, NY: Routledge.

Locke, A. (1935). Values and imperatives. In L. Harris (Ed.), The philosophy of Alain Locke: Harlem renaissance and beyond (pp.34-50). Philadelphia: Temple University Press.

Shippen, M. E., Morton, R. C., Flynt, S. W., Houchins, D. E., \& Smitherman, T. (2012). Efficacy of a computer-based program on acquisition of reading skills of incarcerated youth. Remedial and Special Education, 33, 14-22. https:// doi.org/10.1177/0741932510362512

Texas A\&M University (TAMU). (2019). P4C Texas philosophy for children at Texas A\&M. Retrieved from https://p4ctexas.sites.tamu.edu/

Topping, K. J., \& Trickey, S. (2007). Collaborative philosophical enquiry for school children: cognitive effects at 10-12 Years. British Journal of Educational Psychology, 77, 271-288. https://doi.org/10.1348/000709906X105328 


\section{CASP 2020 \\ October 18 - 20, 2020 Houston, Texas}

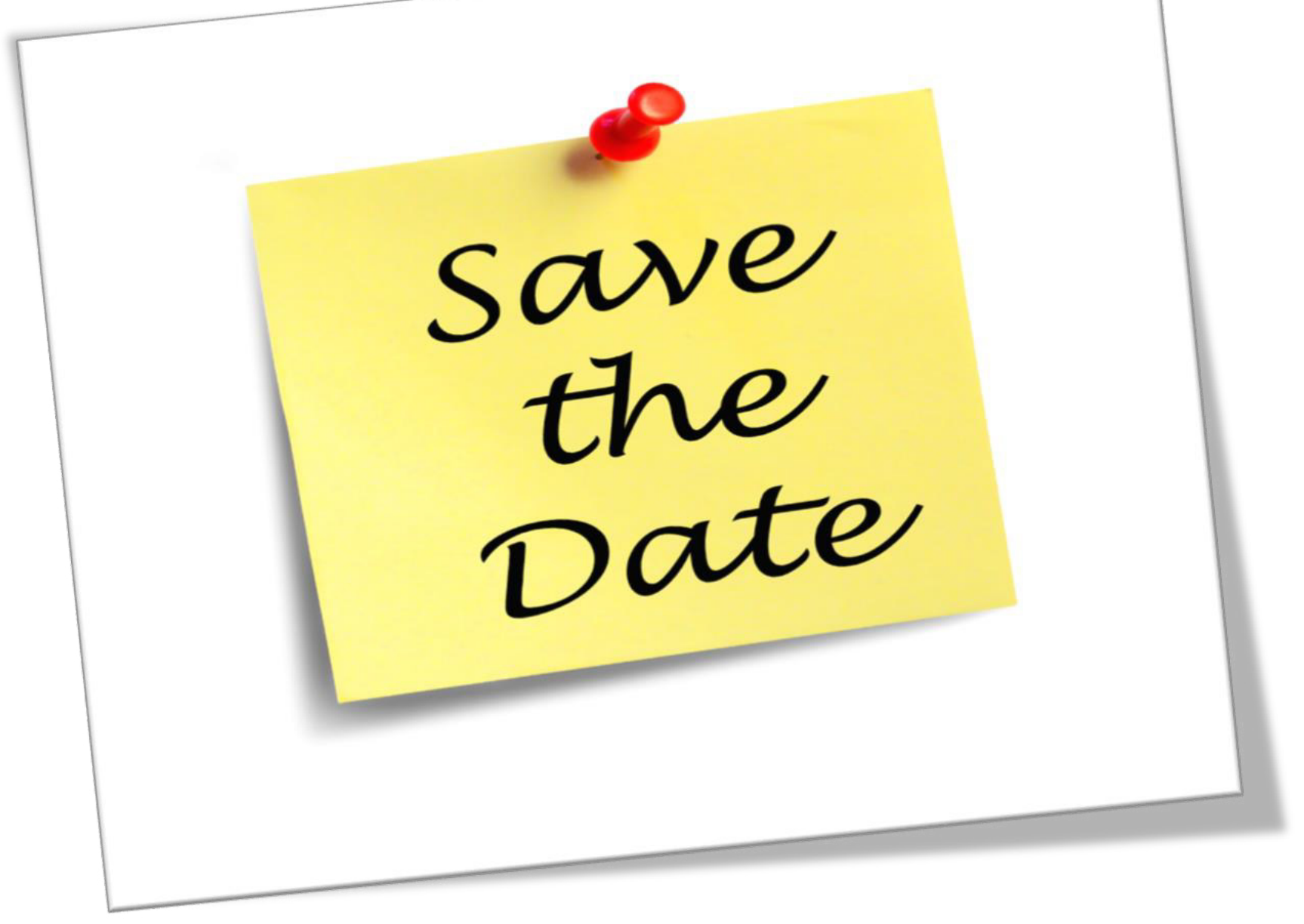

Mary Helen Martinez

President, TADE

Alamo College District

mmartinez2245@alamo.edu
Rachel Hunt

President, TxCRLA

Angelina College

rhunt@angelina.edu

\section{College Academic Support Programs}




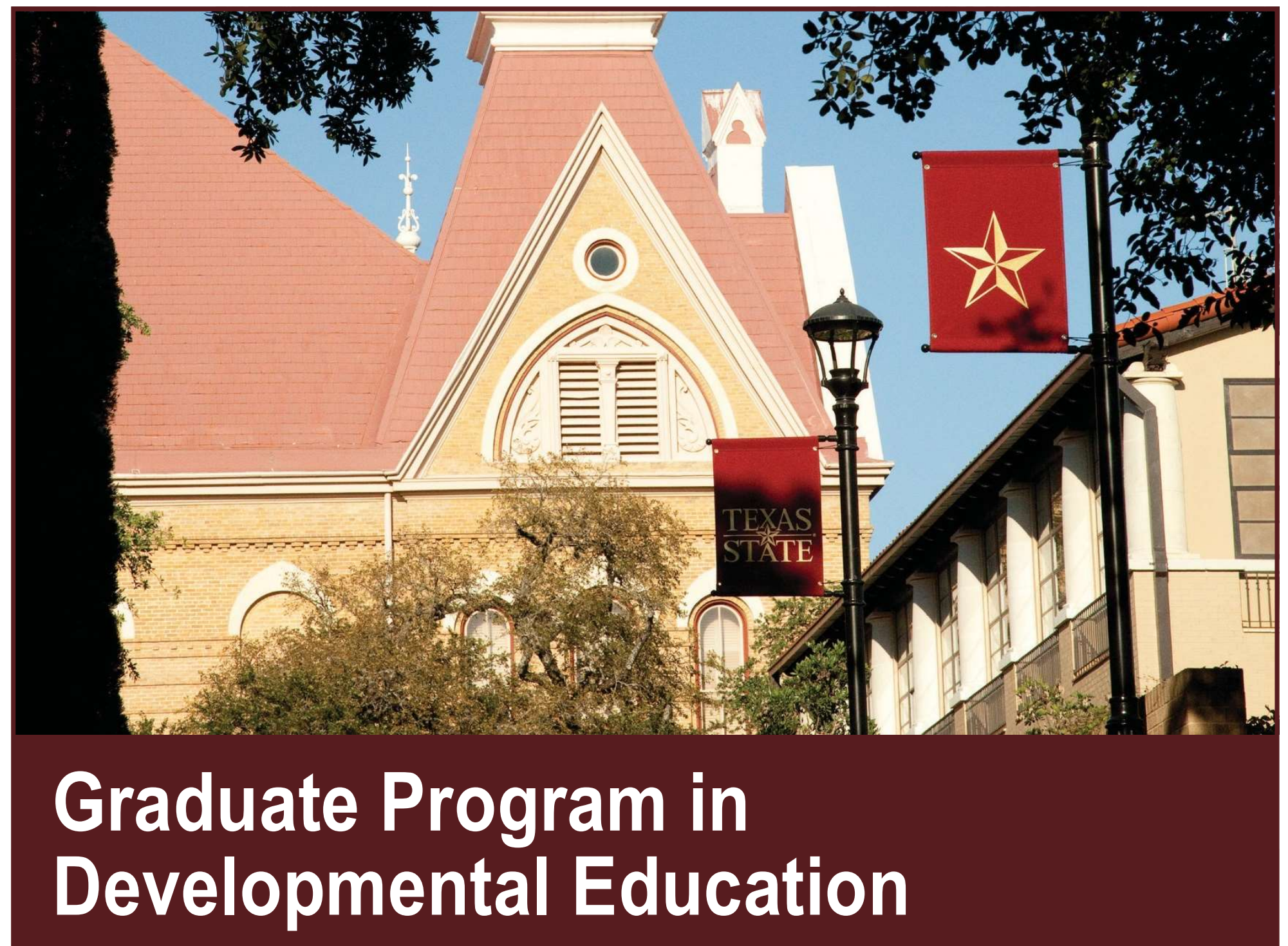

With degree concentrations in Learning Support, Developmental Mathematics, and Developmental Literacy

Ph.D. in Developmental Education

Ed.D. in Developmental Education

M.A. in Developmental Education

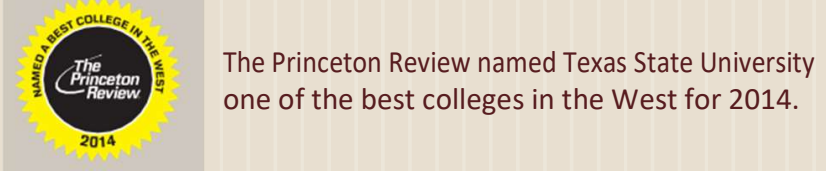

For more information, call 512.245.6839

facebook.com/DevEdTxSt @DevEdTxSt

Texas State University is an equal opportunity educational institution. education.txstate.edu/ci/dev-ed

\section{Faculty}

Taylor Acee, Ph.D.

Sonya L. Armstrong, Ed.D.

Carlton J. Fong, Ph.D.

Russ Hodges, Ed.D

Jodi Patrick Holschuh, Ph.D.

Rebecca Jackson, Ph.D.

Eric J. Paulson, Ph.D.

Emily Miller Payne, Ed.D.

Emily Suh, Ph.D.

Emily J. Summers, Ed.D.

Alexander White, Ph.D. 


\section{Developmental Education Administration}

Doctorate of Education

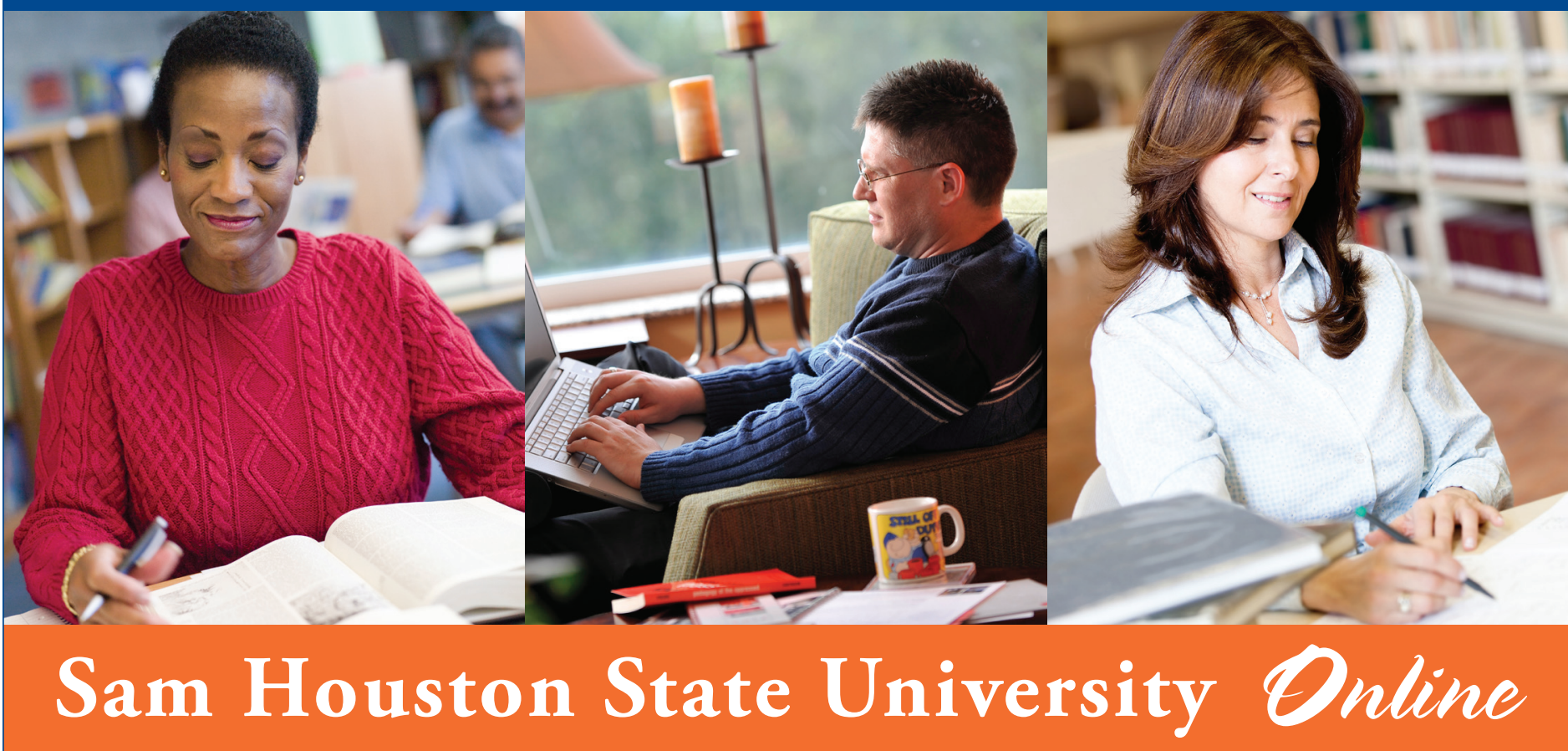

Preparing professionals to design and lead programs that help students succeed.

- $100 \%$ online program

- Flexible course scheduling

- Designed for working professionals

- Scholarships available

Priority Deadline March 15 New Cohorts Begin Each Summer Apply Today at ApplyTexas.org

For more information, please contact:

D. Patrick Saxon

patrick.saxon@shsu.edu 936.294 .1147

Or visit the program website at: shsu.edu/DevEd

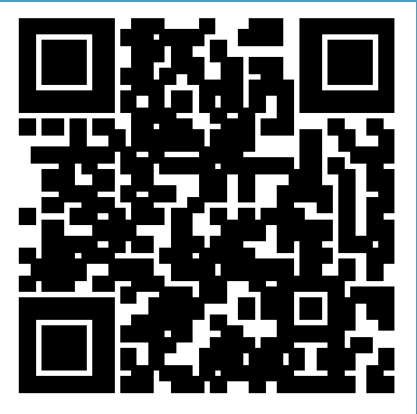




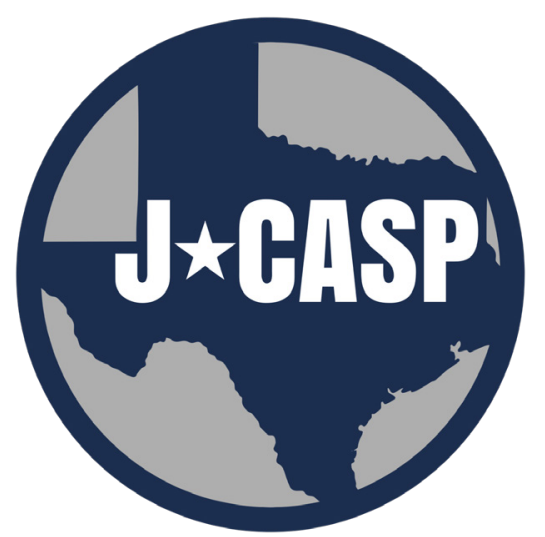

\section{Journal of College Academic Support Programs}

\section{Call for Submissions February 15, 2020}

Supported by the Texas Association for Developmental Education (TADE), the Texas Chapter of the College and Reading Learning Association (TxCRLA), and the Texas State University's Graduate Program in Developmental Education, the Journal of College Academic Support Programs (J-CASP)-a double-masked, peer-reviewed, biannual scholarly journal relevant to Texas developmental education and learning assistance professionals-seeks feature articles, promising practices, and exploratory pieces for the Spring 2020 issue.

For double-masked peer review, the J-CASP seeks scholarly research articles, research-to-practice articles, theory-to-practice articles, and reviews of literature that include recommendations and implications. Appropriate articles that are not write-ups of empirical research studies will be considered for double-masked peer review based on scholarly rigor. More reflective, practitionerbased articles and op-ed articles or opinion pieces will be considered for publication as non-peerreviewed promising practices.

The J-CASP is now accepting exploratory pieces. These short articles should be approximately 500 words with at least 2-3 references cited in the text. Exploratory pieces should introduce a conversation and generate implications for future research and practice. Whereas a promising practice can be considered a stepping stone toward further scholarly rigor, an exploratory piece can be considered as opening the door for further inquiry.

Appropriate manuscripts will undergo a peer-review process by members of the J-CASP editorial board. The review process will take approximately six weeks, including two weeks for authors to address reviewer comments. Submit your manuscript as a Microsoft Word (.doc, .docx, etc.) file, double-spaced with 12-point Times New Roman font. Your manuscript should be approximately 6,000 words and must adhere to the APA Publication Manual ( $6^{\text {th }}$ edition) guidelines for writing, citation, and documentation style. Please include an abstract not exceeding 250 words.

Promising practices articles should be approximately 1,000 words with at least 3-12 APA references cited in the essay. For questions, comments, concerns, or suggestions as well as to submit promising practices articles and exploratory pieces, please use the following email address:

JCASP_Editor@txstate.edu.

Please refer to the J-CASP website for full submission information and to view current and past issues at https://journals.tdl.org/jcasp 